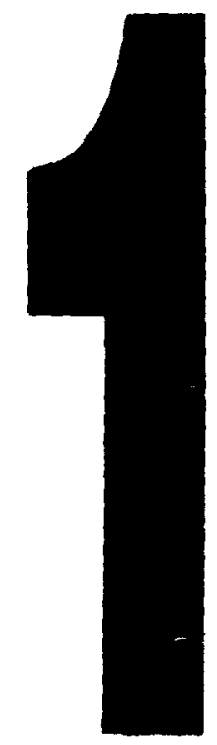

PM-1 3\%"x4" PHOTOGRAPHIC MICROCOPY TARGET NAS 1010a ANS1/1SO "2 EQUIVALENT

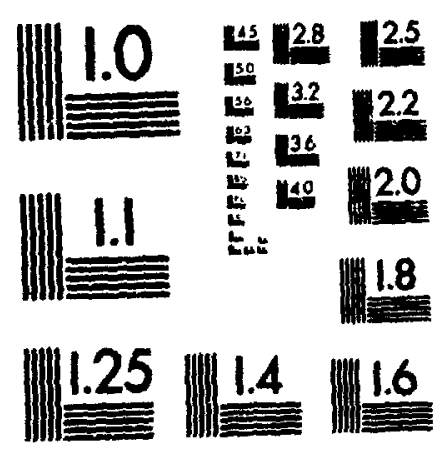

PRECISIONSM RESOLUTION TARGETS 
National Library

of Canada

Acquisitions and

Bibliographic Services Branch

395 Wellington Street

Ottawa, Ontario

KTA ON4
Bibliothèque nationale

du Canada

Direction des acquisitions et

des services bibliographiques

395, ne Wellington

Ottawa (Ontario)

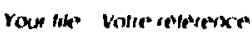

Our the Notrsterterente

NOTICE

AVIS

The quality of this microform is heavily dependent upon the quality of the original thesis submitted for microfilming. Every effort has been made to ensure the highest quality of reproduction possible.

If pages are missing, contact the university which granted the degree.

Some pages may have indistinct print especially if the original pages were typed with a poor typewriter ribbon or if the university sent us an inferior photocopy.
La qualité de cette microforme dépenú grandement de la qualité de la thèse soumise au microfilmage. Nous avons tout fait pour assurer une qual'ié supérieure de reproduction.

S'il manque des pages, veuillez communiquer avec l'université qui a conféré le grade.

La qualité d'impression de certaines pages peut laisser à désirer, surtout si les pages originales ont été dactylographiées à l'aide d'un ruban usé ou si l'université nous a fait parvenir une photocopie de qualité inférieure.

La reproduction, même partielle, de cette microforme est soumise à la Loi canadienne sur le droit d'auteur, SRC 1970, c. C-30, et ses amendements subséquents.
Reproduction in full or in part of this microform is governed by the Canadian Copyright Act, R.S.C. 1970, c. C-30, and subsequent amendments.

\section{Canadä}




\title{
THE EFFECT OF FREQUENCY ON SONOCHEMICAL REACTIONS
}

\section{BY}

MOHAMMAD H. ENTEZARI, M.Sc.

\section{THESIS}

\author{
Submitted in partial fulfilment \\ of the requirements for the degree \\ of Doctor of Philosophy in Chemistry of the \\ Faculty of Graduate Studies and Research
}

\author{
Chomistry Department \\ Carleton University \\ Ottawa
}

- Copyright

M.H. Entezari, 1924 
National Library

of Canada

Acquisitions and Bibliographic Senvices Branch

395 Wellington Street Orawe Orterio

K1AONA
Bibliotheque nationale

du Canada

Direction des acquisitions of

des senvices bibliogriaphiques

295. nu Wellington

Onewa (Cinterio)

KIA ON

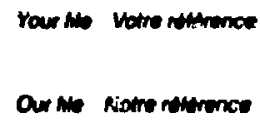

THE AUTHOR HAS GRANTED AN IRREVOCABLE NON-EXCLUSIVE LICENCE ALLOWING THE NATIONAL LIBRARY OF CANADA TO REPRODUCE, LOAN, DISTRIBUTE OR SELL COPIES OF HIS/HER THESIS BY ANY MEANS AND IN ANY FORM OR FORMAT, MAKING THIS THESIS AVAILABLE TO INTERESTED PERSONS.
L'AUTEUR A ACCORDE UNE LICENCE IRREVOCABLE ET NON EXCLUSIVE PERMETTANT A LA BIBLIOTHEQUE NATIONALE DU CANADA DE REPRODUIRE, PRETER, DISTRIBUER OU VENDRE DES COPIES DE SA THESE DE QUELQUE MANIERE ET SOUS QUELQUE FORME QUE CE SOIT POUR METTRE DES EXEMPL.ATRES DE CETTE THESE A LA DISPOSITION DES PERSONNE NTERESSEES.
IHE AUTHOR RETAINS OWNERSHIP OF THE COPYRIGHT IN HIS/HER THESIS. NEITHER THE THESIS NOR SUBSTANTIAL EXTRACTS FROM IT MAY BE PRINTED OR OTHERWISE REPRODUCED WITHOUT HIS/HER PERMISSION.
LAUTEUR CONSERVE LA PROPRIETE DU DROIT D'AUTEUR QUI PROTEGE SA THESE. NI LA THESE NI DES EXTRAITS SUBSTANTIELS DE CELLECI NE DOIVENT ETRE IMPRIMES OU AUTREMENT REPRODUITS SANS SON AUTORISATION. 
Nam M. H. Entezar.

Dissertation Abstracts International is arranged by broad, general subject calegories. Please select the one subject which most nearly describes the content of your dissertation. Enter the corresponding four-digit code in the spaces provided.

Physical chemistry

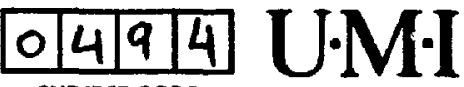

SUAECT CODE

\section{Subject Cologories}

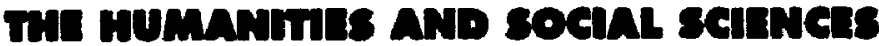

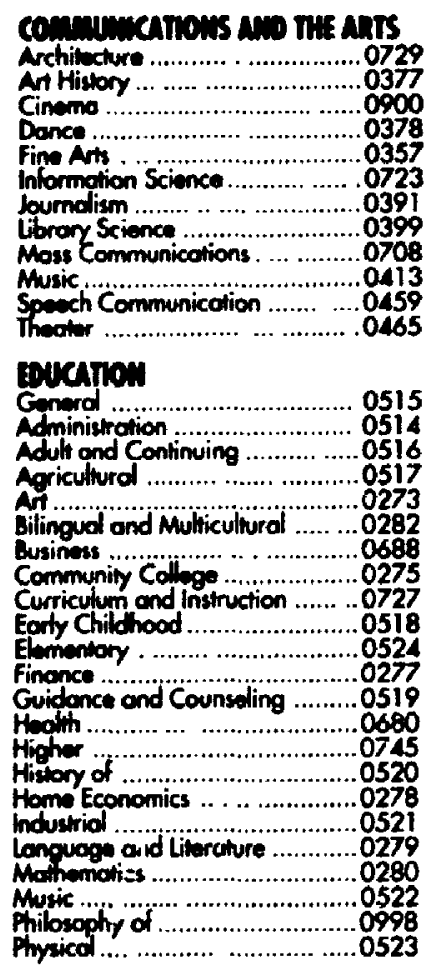

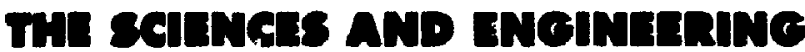

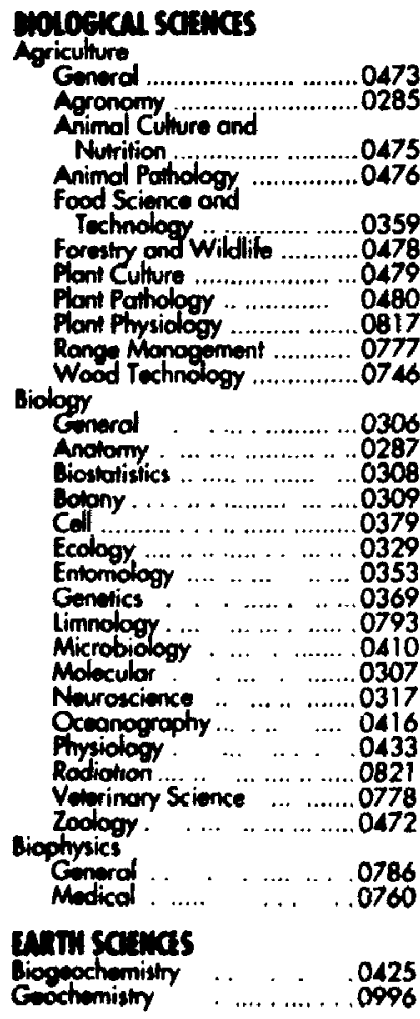

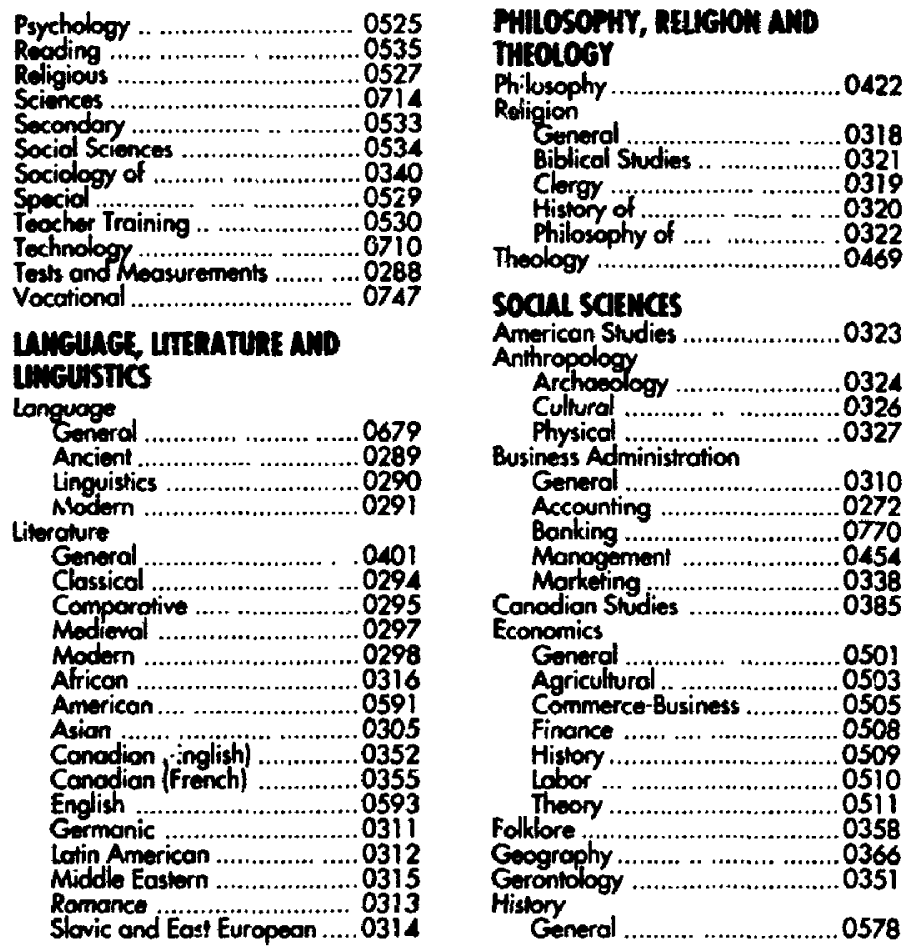

Goodesy ................................0370 Goology ..................................0372 Hydrology ....................................0388 Mineralogy .................................041 Poloobotong .............................0345 Polocecology ..........................0426 Paleontology ............................0418 Palynotogy ...............................0427 Physical Geography................... 0368 Physical Oceonogrophy .............0415 HeATH AMD EMVinommenTAL satinas

Environmental Sciences .............0768 Hoolith Sciences

General ...........................0566

Chemoterapy ............0300

Dentisty ............................0567

Eentisty ......................... 0350

Hospilol Manogement .. ... 0769

Human Development ..........0758

Immunology i.................0982

Mental Healh .. .................0347

Nursing ............................0569

Nutrition .........................0570

Obstetrics and Gynocology . 0380

Occupotional Health and

Theropy.

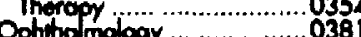

Pothology a................... 057

Phormocology .................0419

Phormact the.....................0577

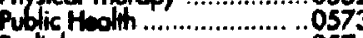

Rodiology ....................057

\section{PHYSICA Sct:ucs}

Computer Sxience ........................0984
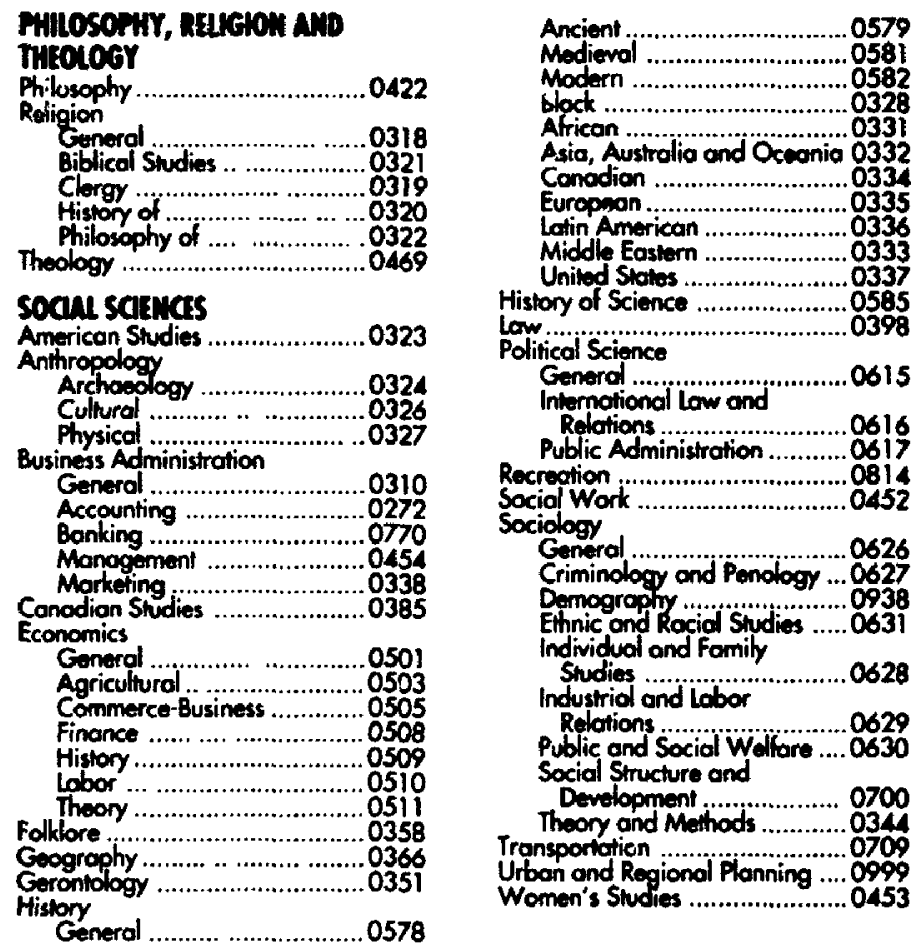

Speech Paithology ..............0460

Horne Economics .......................0386

\section{Pure Sciences}

Chemisiry

Generol ...............................0485

Agriculturol ........................0749

Analytical ............................0486

Biochernistry .....................0487

Inorganic ...........................0488

Nucheor ……….................0738

Prganic............................0491

Physical ................................ 0494

Polymer ………..................0495

Mathematies .............................0405

Physics

General ........................0605

Acoustics ............................0986

Astronomy and

Astrophysics...................0606

Almospheric Science ..............0608

Alomic …...................0748

Electronics and Eloctricily ....0607

Elementary Particles and

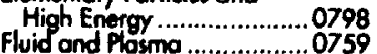

Moleculer .................................0609

Nuclear 0610

Optics ……..........................0752

Rodiotion...............................0756

Solid Store ............................... 0611

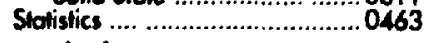

Applind Seiences

Applied Mochonics

0346
Engineering

. 0537

Aerospoce .........................0538

Agricultural ...........................0539

Automotive ..........................0541

Chemicat ................................054

Civil .....................0543

Hoot and Thermodynomics ...0348

Hydraulic.............................0545

Industrial ...................................0546

Marine ...........................0547

Materials Science ..................0794

Mochanical ...........................0548

Metallurgy ............................0743

Mining .....................05.5

Nuclear ............................0552

Packoging .............................0549

Petroleum ...........................0765

Sanilary ond Munici,uit ........055

System Science ....................0790

Geotechnology .........................0428

Operations Research ..................0796

Plastics Technology ...................0795

Proiprost

Generat ...................................0621

Behoviorai ........................................038

Clinical .....................................0622

Dovelopmentol ............................0620

Experimental ..............................0623

Industriol ...................................062

Physiological .................................0989

Psychobiology .............................0349

Psychometrics ................................6́.32

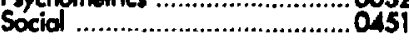


The undersigned hereby recommend to

the Faculty of Graduate Studies and Research

acceptance of this thesis,

"The Effect of Frequency on Sonochemical Reactions",

submitted by Mohammad H. Entezari, M.Sc.,

in partial fulfilment of the requirements of

the Doctor of Philosophy degree

James. Wright

Chair, Department of Chemistry

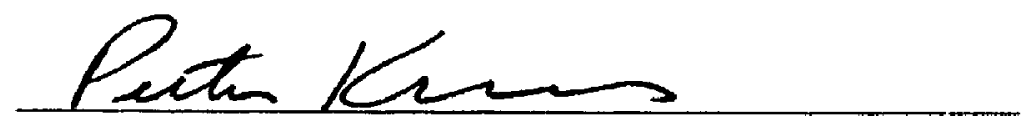

Thesis Supervisor

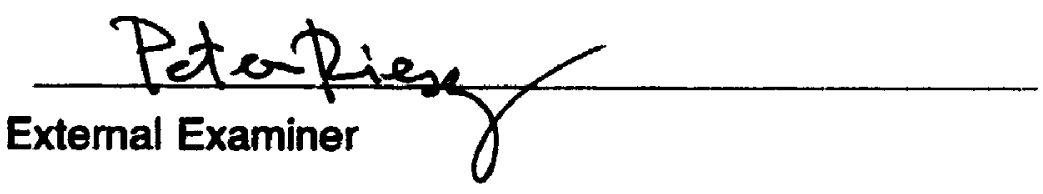

Carleton University,

December 1994 


\section{THE EFFECT OF FREQUENCY ON SONOCHEMICAL REACTIONS}

\section{ABSTRACT}

Ultrasonic irradiation, or sonication, is a unique method of activating and accelerating chemical reactions in a liquid medium through the action of cavitation. Typically, ultrasonic irradiation can increase the rates of reactions, decrease the required reaction temperature and improve product yields.

Historically, the effect of frequency on sonochemical reactions has been considered to be negligible. It was thought that when the ultrasonic power is sufficient to produce cavitation, it does not matter what frequericy is used. We focussed our study on the effect of frequency on different sonochemical reactions in order to test this assumption.

The frequencies generally used in sonochemistry are in the range of 20$100 \mathrm{kHz}$. Only a very few groups have used ultrasound with frequencies outside this range. Since cavitation is responsible for sonochemical effects, there is however no reason to restrict our studies to this normal frequency range. Our work focussed on two different frequencies far from each other, 20 and $900 \mathrm{kHz}$. The $900 \mathrm{kHz}$ apparatus was specially designed and constructed; using a commercially available power supply.

The effects of temperature, intensity, and gas were investigated at these two different frequencies. It was found that the behaviour with $900 \mathrm{kHz}$ irradiation can be very different from that with $20 \mathrm{kHz}$. For example, the sonication of potassium iodide solution under the same conditions was more 
effective with $900 \mathrm{kHz}$ than $20 \mathrm{kHz}$. Sonication of chlorobenzene in water with $900 \mathrm{kHz}$ led to a yellow solution with a high rate while with $20 \mathrm{kHz}$ this reaction was very slow. However, the sonication of liquid carbon disulfide with $20 \mathrm{kHz}$ led to a heterogeneous system, while sonication with $900 \mathrm{kHz}$ had no apparent effect. Our results suggest that the surface area of the sonicator is very important.

There seems to be a dependence of the reaction rate on irradiation frequency arising from the temporal and spatial characteristics of the cavitation bubbles produced. The bubble size and collapse time are significantly different at the two frequencies. This may have an important role in determining the different behaviours observed. A sonochemical reaction can occur in the gas phase inside the bubble, at the interface, or at some distance away from cavitating gas bubble. This may be another important consideration in explaining the difference in results with frequency. 
This thesis is dedicated to my late father, my mother, my wife Foozieh Farzin and my lovely daughter Kimia who came on the right time (Nov. 3, 1994). 


\section{ACKNOWLEDGEMENTS}

I would like to take this opportunity to appreciate the all people who directly and indirectly contributed to my graduate career.

Professor Peeter Kruus has been my advisor and mentor for four scientifically great years. I actually enjoyed working with him, and think of him not only as an advisor, but also as a friend. I have leamed more about the scientific method, writing and creativity than I dreamed. His wife, Annie also deserves special mention for her companionship.

I would like to thank Dr. Mark Watson from Cameco Corporation and Dr. Rein Otson from Health Canada for supporting financially some part of my research.

I wish to thank Dr. B.J. Jarosz, a physics professor at Carleton University for useful discussions related to the new $900 \mathrm{kHz}$ apparatus.

Professor Donald R. Wiles merits many thanks for his review of the manuscript of my thesis and his suggestions for improvements.

I wish to thank Dr. Bob Burk who made me familiar with some analytical equipments.

I want to express my gratitude to my friends in our lab: Peter, Mark, Sharon, Marc, Brian, Lorne and Rocio.

I would like to thank the personnel at the Science Technology Center and the Glass and Electrical shops of the Chemistry Department, where 
especially Michel Grenier and David Raffler have been very helpful.

I wish to thank Mr.Edward Furimsky from CANMET for $x$-ray spectrum, Mr Keith Bourque for H-NMR spectrum and Mr. Wayne England from the Biology Department for photographic services.

Many thanks to all the supporting staff of the Chemistry Department, especially the secretaries, Marilyn, Kim and Barbara, to Karl and Robert from the Chemistry Store.

I would like to thank The Ministry of Higher and Education of Islamic Republic of Iran for a scholarship to pursue my graduate study in Canada.

Finally, I am highly indebted to my mother and my late father and wish to express my sincerely thanks to them for everything. I would also like to thank my wife, Foozieh. She has always provided me with constant companionship throughout my graduate years. Without her these years would have been empty ones. 
Abstract

Acknowledgements

Table of Contents

List of Figures

xiv

List of Tables

xvii

CHAPTER 1

INTRODUCTION TO SONOCHEMISTRY

1.1 Introduction

1.2 Cavitation

1.3 Acoustic Cavitation

1.3.1 Factors Affecting Acoustic Cavitation

1.3.1.1 Gas

1.3.1.2 Liquid Properties

1.3.1.3 Bulk Temperature

1.3.1.4 Acoustic Characteristics

1.4 Acoustic Cavitation and Chemical Reactions

1.4.1 Acoustic Cavitation and Homogeneous Reactions

1.4.2 Acoustic Cavitation and Heterogeneous Reactions 
1.4.2.2 Chemical Point of View 22

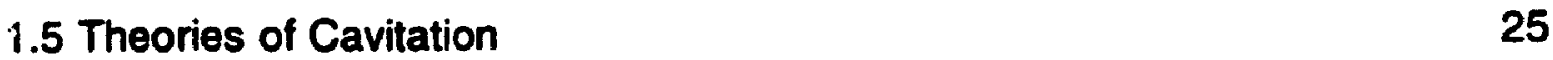

1.5.1 Electric Discharge Theory 25

1.5.2 Thermal Theory $\quad 27$

1.5.2.1 Bubble Dynamic Equation $\quad 27$

1.5.2.2 Lifetime of Bubble Collapse 31

1.5.2.3 Temp. and Press, in a Collapse Cavity 32

1.5.2.4 Resonance Radius of the Bubble 34

\section{CHAPTER 2}

APPARATUS AND SONOCHEMICAL REACTOR DESIGN 35

2. I Introduction 36

2.2 Piezoelectric Transducer 36

$\begin{array}{ll}2.3 \text { Types of Sonication } & 37\end{array}$

2.3.1 Sonication by $20 \mathrm{kHz}$ Apparatus 38

2.3.2 Sonication by $900 \mathrm{kHz}$ Apparatus 38

2.4 Measurement of Total Acoustic Power 44

2.4.1 Power Calibration for Indirect Sonication 48

\section{CHAPTER 3}

SONOCHEMICAL DISSOCIATION OF WATER IN POTASSIUM IODIDE SOLUTION

3.1 Introduction 
3.1.2 Frequency Effects

53

3.2 Experimental Procedures

54

3.2.1 Experiments at $20 \mathrm{kHz}$

54

3.2.2. Experiments at $900 \mathrm{kHz}$

56

3.3 Results and Discussion

53

3.3.1 Primary Experimental Data

58

3.3.2 Basic Corisiderations

60

3.3.3 Variation with Power

62

3.3.3.1 Effect of Tip Size (Intensity)

3.3.4 Variation with Gas

3.3.5 Variation of Sonochemical Rate with Frequency

3.3.6 Variation with Temperature

3.3.6.1 Effect of Temp.: General Considerations

3.3.6.2 Effect of Temp.: Low Frequency

3.3.6.3 Effect of Temp.: High Frequency

\section{CHAPTER 4}

4.1 Introduction 
$\begin{array}{ll}4.3 \text { Results } & 89\end{array}$

$\begin{array}{ll}\text { 4.4 Discussion } & 93\end{array}$

4.4.1 Decomposition of Chlorobenzene 93

4.4.2 Intensity Effect $\quad 96$

$\begin{array}{ll}\text { 4.4.3 Frequency Effect } & 99\end{array}$

4.5 Conclusion
99

CHAPTER 5

SONOCHEMICAL DISSOCIATION OF CARBON DISULFIDE 101

$\begin{array}{lr}5.1 \text { Introduction } & 102\end{array}$

$\begin{array}{ll}\text { 5.2 Experimental Procedure } & 103\end{array}$

$\begin{array}{lr}5.3 \text { Results } & 106\end{array}$

$\begin{array}{ll}\text { 5.3.1 Intensity Dependence } & 106\end{array}$

$\begin{array}{ll}\text { 5.3.2 Temperature Dependence } & 109\end{array}$

$\begin{array}{ll}\text { 5.3.3 Gas Dependence } & 109\end{array}$

$\begin{array}{ll}5.4 \text { Discussion } & 111\end{array}$

5.4.1 Dissociation of Carbon Disulfide 111

5.4.2 The x-ray Spectrum 111

5.4.3 Effect of Intensity 112

5.4.4 Effect of Temperature $\quad 115$

5.4.5 Effect of Gas $\quad 115$

$\begin{array}{lr}5.5 \text { Conclusion } & 118\end{array}$ 
CHAPTER 6

SUMMARY AND CONCLUSIONS

6.1 Apparatus

6.2 Temperature

121

6.3 Power and Intensity

6.4 Gas

6.5 Frequeicy

6.6 Summary

REFERENCES

APPENDIX

ULTRASONIC HYDRATION OF $\mathrm{UO}_{3}$

A.1 Introduction

A.2 Experimental procedures

A.2.1 Types of apparatus

A.2.2 Intensity calibration

A.2.3 Hydratiun of urarium trioxide

A.2.4 Experiments at $850 \mathrm{kHz}$

A.2.5 Experiments at $20 \mathrm{kHz}$

A.2.6 Experiments without ultrasound 
A.3.1 Effect of temperature $\quad 142$

$\begin{array}{lr}\text { A.3.2 Effect of shape of cell } & 143\end{array}$

$\begin{array}{ll}\text { A.3.3 Effect of } \mathrm{UO}_{3} \text { mesh size } & 144\end{array}$

A.3.4 Effect of stirring $\quad 144$

A.3.5 Effect of power $\quad 144$

$\begin{array}{ll}\text { A.3.6 Effect of hydrogen gas } & 146\end{array}$

R.4 Sonication in organic solvents $\quad 146$

$\begin{array}{lr}\text { A.5 Frequency and agitation } & 147\end{array}$

A.6 Factors affecting the size distribution

of the unhydrated UO3 $\quad 150$

$\begin{array}{ll}\text { A.6.1 Temperature } & 150\end{array}$

A.6.2 Initial particle size $\quad 151$

$\begin{array}{ll}\text { A.6.3 Shape of cell } & 151\end{array}$

A.6.4 Sonication in organic solvents $\quad 152$

$\begin{array}{ll}\text { A.7 Conclusion } & 153\end{array}$

$\begin{array}{lr}\text { VITA } & 154\end{array}$ 
xiv

\section{LIST OF FIGURES}

Figure 1.1 A comparison of different energy sources of chemical reactions

Figure 1.2 An idealized representation of the acoustic cavitation process which includes formation, growth and implosion

Figure 1.3 Laser-induced spherical cavitation bubble in water far from boundaries

Figure 1.4 Collapse of a single, spherical, laser-induced cavitation bubble near a solid boundary

Figure 1.5 Scanning electron micrograph of $\mathrm{Zn}$ powder after sonication

Figure 1.6 Radius-time curves for pulsations of air bubbles in water

Figure 2.1 A plastic sleeve which connected the reactant container to the $20 \mathrm{kHz}$ ultrasonic hom

Figure 2.2 Sonochemical reactor which designed and constructed for $900 \mathrm{kHz}$ apparatus

Figure $2.3900 \mathrm{kHz}$ apparatus with power amplifier

Figure 2.4 Indirect sonication by $900 \mathrm{kHz}$ apparatus

Figure 2.5 Acoustic pewer calibration for $20 \mathrm{kHz}$ 46

Figure 2.6 Acoustic power calibration for $900 \mathrm{kHz}$

Figure 3.1 Sonication of potassium iodide solution by $20 \mathrm{kHz}$ with Ar and air

Figure 3.2 Sonication of potassium iodide solution by $900 \mathrm{kHz}$ with Ar and air

Figure 3.3 Effect of frequency on the sonochemical oxidation of iodide in air

Figure 3.4 Variation of sonochemical oxidation of iodide with power 
Figure 3.5 Variation of sonochemical oxidation of iodide with acoustic power at $20 \mathrm{kHz}$

Figure 3.6 Variation of sonochemical oxidation of iodide vs power with different horns

Figure 3.7 Variation of sonochemical oxidation of iodide vs temperature at $20 \mathrm{kHz}$ with different horn tips

Figure 3.8 Variation of sonochemical oxidation of iodide with power under $900 \mathrm{kHz}$

Figure 3.9 A picture of the two homs with different tip size $(20 \mathrm{kHz})$

Figure 3.10 Variation of sonochemical oxidation of iodide with temperature using $20 \mathrm{kHz}$ with an $\mathrm{X}$-large tip

Figure 3.11 Variation of sonochemical oxidation of iodide with temperature using $900 \mathrm{kHz}$

Figure 4.1 Uv-Visible spectrum of yellow solution produced by sono-dissociation of chlorobenzene in a dilute aqueous solution $\mathbf{9 0}$

Figure 4.2 Chloride anion concentration vs sonication time

Figure 4.3 Absorbance of the yellow solution vs sonication time

Figure 4.4 $\mathrm{pH}$ of the sonicated solution vs sonication time

Figure 4.5 The H-NMR spectrum of the solution of chlorobenzene in deuterium oxide before sonication

Figure 4.6 The H-NMR spectrum of the solution of chlorobenzene in deuterium oxide after sonication

Figure 5.1 The Uv-Visible spectrum of yellow solution produced by sonication of carbon disulfide

Figure 5.2 Time variation of sono-dissociation of carbon disulfide using $20 \mathrm{kHz}$ with two different tip sizes

Figure 5.3 Variation of sono-dissociation of carbon disulfide vs power with two different homs 
xvi

Figure 5.4 Variation with temperature of sono-dissociation of carbon disulfide using $20 \mathrm{kHz}$ with two different horns

110

Figure 5.5 The x-ray spectrum of the products produced by sonication of carbon disulfide

113

Figure A.1 The $850 \mathrm{kHz}$ apparatus with a concave transducer

139

Figure A.2 The effect of particle size on the hydration rate of $\mathrm{UO}_{3}$

145

Figure A.3 The effect of ultrasonic frequency and stirring on the hydration of $\mathrm{UO}_{3}$

148 


\section{LIST OF TABLES}

Table 1.1 Rate of formation of free chlorine by sonication of water containing carbon tetrachloride under different saturating gases

Table 1.2 Acoustic pressure producing cavitation in various liquid under atmospheric pressure

Table 3.1 Rate of sonochemical oxidation of iodide under different gases and frequencies

Table 3.2 Comparison of temporal and spatial characteristics of cavitation bubbles with frequency in water at $300 \mathrm{~K}$

Table 3.3 Variation of the sonochemical oxidation of iodide with different homs at the same power

Table 3.4 Variation of the sonochemical oxidation of iodide with 20 and $900 \mathrm{kHz}$ under different gas conditions

Table 5.1 Variation of sono-dissociation of carbon disulfide by $20 \mathrm{kHz}$ ultrasound with different gases

Table A.1 Rate of hydration at different temperatures

Table A.2 Effect of type of vessel on the rate of hydration

Table A.3 Effect of power level on the rate of hydration of $\mathrm{UO}_{3}$

Table A.4 Particle size after sonicating at different temperatures

Table A.5 Unhydrated particle areas before and after sonication

Table A.6 Effect of type of cell used on particle size 
CHAPIER 1

INTRODUCTON TO SONOCHEMSTRY 


\subsection{Introduction}

Ultrasound is best known through its industrial and medical applications. The term refers to acoustic waves with a frequency above $16 \mathrm{kHz}$, the limit for human hearing. In industry, it is used for applizations such as welding plastics, dispersing pigments in paint and cleaning and degreasing of articles by immersion in ultrasonic baths. In medicine, high frequency ultrasound (2-10 $\mathrm{MHz})$ is used for sonographic imaging of fetuses, non-surgical removal of kidney stones and also in physiotherapy. Uitrasound is also used in tumor treatment. The sonodynamic therapy is a use of sonochemical activation of special agents by ultrasound irradiation focused into the tumor [Umemura, 1992]. Lower frequencies $(20-50 \mathrm{kHz})$ are used in the treatment of muscle strains.

Sonochemistry is the study of the interaction between the ultrasonic waves and liquids. These can be homogenous solutions or heterogeneous slurries [Rooney, 1988; Rooney, 1981; Rudenko, 1977]. This interaction is unique and quite different from the interaction of other energy sources such as light, heat or ionizing radiation, as shown in Figure 1.1 [Suslick, 1989]. The interaction can have physical effects, such as erosion and emulsification, as well as chemical effects, such as production of radicals and other excited species. These effects result from acoustic cavitation and microstreaming. The latter effect constitutes an unusual fluid flow associated with velocity gradients and streaming stresses [Rooney, 1988]. 


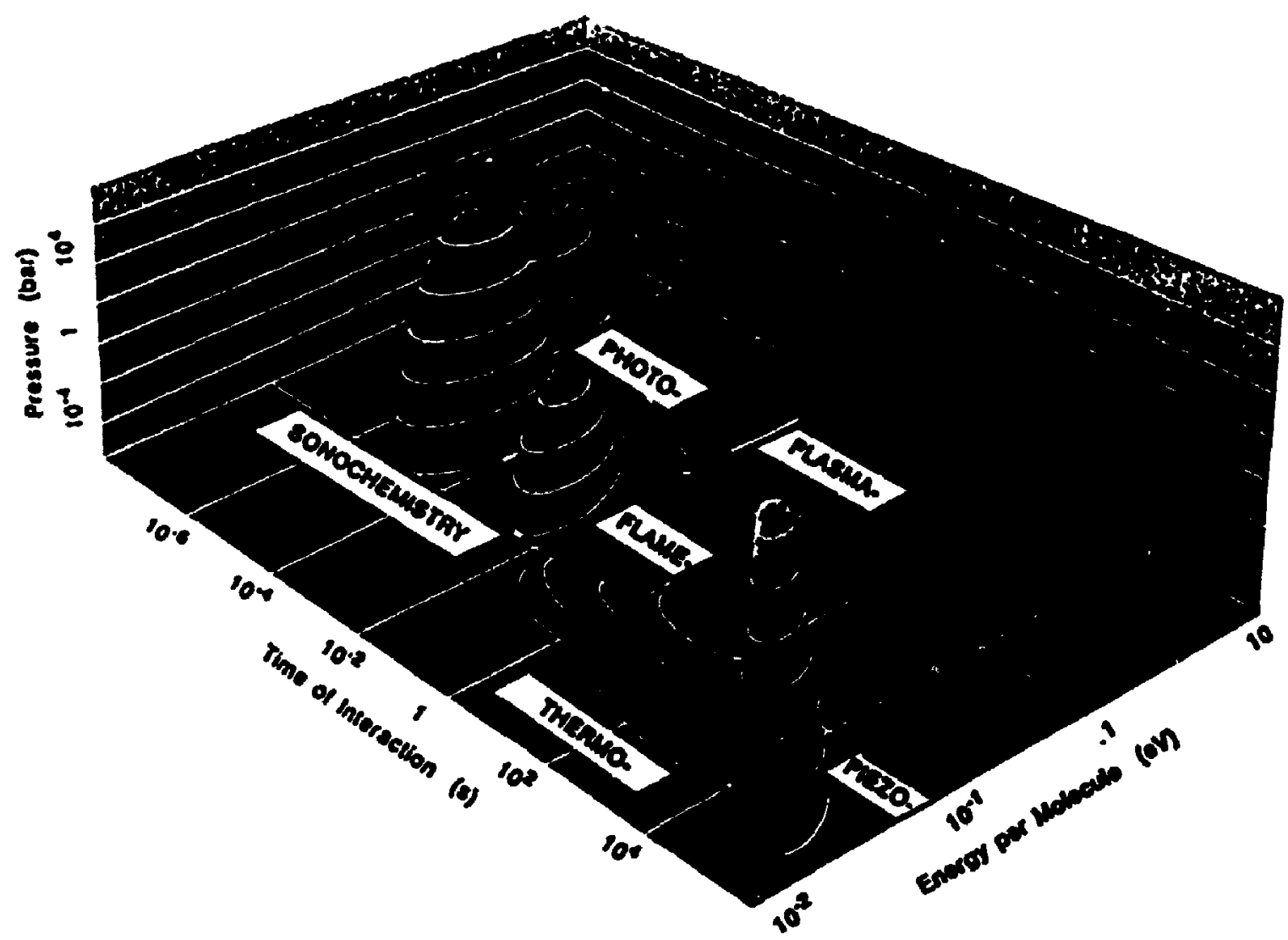

Figure 1.1: A comparison of different energy sources of chemical reactions (Suslick, 1989). 
From a historical point of view, the first chemists who discovered the unusual effects of intense ultrasonic waves in liquids, known as sonochemistry, were Richards and Loomis in 1927 [Richards, 1927]. They described two types of conventional chemical reactions in aqueous solutions which were accelerated by ultrasound. In 1935 Frenkel and Schulze reported for the first time that water emits light when exposed to intense ultrasound. They proposed that the sudden cavitation in water is accompanied by charge separation; an electrical discharge should then occur in a bubble. Brohult [1937] was the first to describe the degradation of a biological polymer in 1937. Schmid [1940] carried out the first experiments with synthetic polymers. A number of other researchers such as Boyce, Harvey and Kornfeld and Suvorov [1944] investigated various aspects of ultrasonics in the 1930s and 1940s.

There was no significant progress in sonochemistry until the 1980s, when a renaissance took place in this field. This renaissance was due to the advent of inexpensive and reliable generators of high-intensity ultrasound.

\subsection{Cavitation:}

The term "cavitation" was first used by Sir John Thomycruft and Sydney W. Bamaby in their observation of propeller inefficiency in torpedo boat destroyers [Thomycroft, 1895]. Lord Rayleigh [1917] studied this mechanical cavitation problem in 1917 and confirmed that the vibrations were due to the enormous turbulence, heat, and pressure of imploding cavities. 
Cavitation is now the name used to describe the formation and the subsequent dynamic life of bubbles (cavities) in liquids. These cavities may be filled with gas and/or vapour, and they can be produced in a wide variety of liquids under different conditions. Cavitation can occur in fluids such as water, organic solvents, biological fluids, and molten metals.

The origin of cavitation can be hydrodynamic, acoustic, thermal, or some other effect. Scientists are still seeking ways to prevent the occurrence of hydrodynamic cavitation in various installations such as pumps and valves. Cavities can have a significant effect on liquid-flow rates through pipes. More importantly, the collapse of the cavities may produce intense shock waves which can cause considerable damage to surrounding material. A good example of this provided by ships ' propellers, where the collapse of the cavities produced by the mechanical chuming of the blades causes a considerable erosion of the blades. In this present work, acoustic waves as the origin of cavitation will be focused on in more detail.

\subsection{Acoustic cavitation}

The chemical effects of ultrasound do not arise from a direct coupling of the acoustic field with the molecular species. This is because the acoustic wavelength in liquids is from 10 to $10^{-4} \mathrm{~cm}$, with associated ultrasonic frequencies of from about $15 \mathrm{kHz}$ to $1 \mathrm{GHz}$. Instead, chemical effects come from the most important nonlinear acoustic process, cavitation. Acoustic 
cavitation can be divided into three discrete stages : formation, growth and implosive collapse [Suslick, 1989, 1990; Flynn, 1964; Apfel, 1981; Mason, 1990]. Figure 1.2 shows an idealized representation of these stage in cavitation process [Suslick, 1989].

The propagation of acoustic (i.e. ultrasonic) waves in a liquid medium is accompanied by compression and expansion cycles. Compression cycles exert a positive pressure on the liquid in addition to the mean pressure in the medium, which pushes the molecules together. Inversely, expansion cycles exert a negative pressure on the liquid which moves molecules further apart. The negative pressure exerted by expansion cycles on the liquid must exceed the attractive forces between molecules, or the liquid 's tensile strength, in order to form cavities.

In theory, a negative pressure of more than 1000 atmosphere is required to cause cavitation in pure water [Crum, 1982]. Experimentally, however, we know that cavities can be formed in a liquid with a negative pressure of only a few atmospheres. The difference between theory and experiment can be explained by the presence of heterogeneous impurities. gas bubbles or solid particles, which constitute points of weakness of the liquid structure. In other words, the cohesive forces are disorganized by contaminants which can be found even in ultrapure liquids. It is generally accepted that the nucleation mechanism involves gas trapped in small crevices of hydrophobic contaminants. During the rarefaction cycle (negative pressure cycle), the liquid-gas interface 


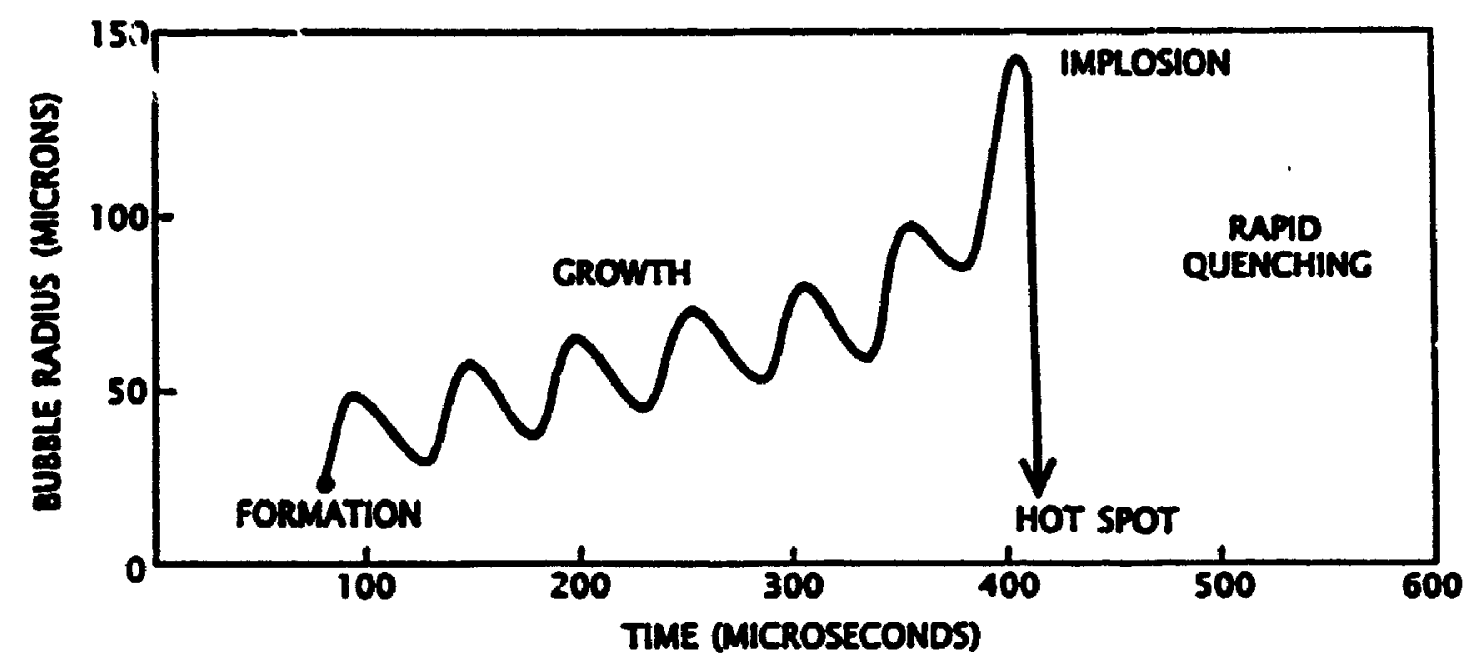

Figure 1.2: An idealized representation of the acoustic cavitation process which includes formation, growth and implosion (Suslick, 1989). 
becomes increasingly convex. At a sufficiently negative acoustic pressure, this gas is released [Crum, 1979; Winterton, 1977; Apfel, 1970], producing smaller free bubbles in the solution. It can also itself collapse violently [Crum, 1982a; 1982b].

Once a bubble is formed, three things can happen, depending on the size of the bubble. If the bubble is large, it will float away and burst at a surface; if it is very small, it will redissolve into the liquid. A bubble in a special range of size can however interact with an ultrasonic wave so that it absorbs energy from alternating cycles of the wave. Under some conditions the ultrasonic wave can continue to cause the bubble to oscillate around an equilibrium size. In some cases, however, the average size of the bubble increases.

The mechanism of cavity growth is termed "rectified diffusion"; it is important at low acoustic pressures [Flynn, 1992]. In the negative phase of the acoustic wave, gas diffuses from the liquid into the bubble, while in the positive phase, the diffusion of the gas is reversed. This process has been modelled mathematically [Strasberg, 1959; Safar, 1968; Gould, 1974; Eller, 1975; Crum, 1982c]. Since the interfacial area is greater in the negative phase than positive phase, the process leads to an overall growth of the bubble. The cavity will grow slowly over many cycles and eventually reach a resonant or critical size, where it absorbs a maximum of energy from the ultrasonic wave (see Figure 1.2). In this situation the cavity can grow rapidly and can no longer 
absorb energy efficiently from the ultrasonic wave. Under this condition the cavity can not sustain itself any longer, the liquid rushes in, and the cavity implodes. This implosion resembles adiabatic compression and creates a local "hot spot" which establishes an unusual environment for chemical reaction.

Flynn [1992] has proposed two extreme types of cavitation: stable and transient cavitation. For stable cavitation the time is sufficiently long for mass diffusion of gas, as well as thermal diffusion. If the rates of mass transfer across the gas-liquid interface are not equal, bubble growth may result. In transient cavitation, a short-lived bubble undergoes dramatic volume changes in a few acoustic cycles and terminates in a violent collapse. During the lifetime of the transient bubble, it is assumed that there is not enough time for mass transfer by diffusion of gas into or out of the bubble, whereas evaporation and condensation of liquid is assumed to take place freely. Both stable and transient cavitation may occur simultaneously in a solution, and a bubble undergoing stable cavitation may become a transient cavity [Flynn, 1992].

\subsubsection{Factors affecting acoustic cavitation}

As sonochemistry is derived from acoustic cavitation, the parameters which affect the cavitation process most certainly will alter the sonochemical reactions. The most important factors which have a significant influence on the cavitation process are: presence of gas, liquid properties, bulk temperature, and acoustic characteristics. 


\subsubsection{Gas}

The removal of gas from a liquid reduces the available nuclei and it becomes more difficult to cavitate that liquid. In addition, several properties of the gas or vapour in the bulk have dramatic affects on the cavitational collapse [Prudhomme, 1957; Yong, 1976; Suslick, 1990]. The ratio of heat capacities $\gamma=\left(C_{p} / C_{v}\right)$, is one of the important physical parameters that affects sonochemical reactions. By assuming that the gas inside the bubble behaves as an ideal gas and that the collapse is an adiabatic process, the effect of $\gamma$ on the collapse of bubbles can be modelled, as shown below:

$$
\begin{aligned}
& p_{i} V_{i}^{\gamma}=p_{f} V_{f}^{\gamma} \\
& T_{f}=\frac{T_{i}}{\left(\frac{V_{f}}{V_{i}}\right)^{\gamma-1}}
\end{aligned}
$$

Here $p_{i} V_{p} T_{i}, p_{f} V_{f}$ and $T_{f}$ are respectively the initial and final pressures, volumes and temperatures of the bubble. According to the above equation, with increasing $\gamma$, the final temperature also increases. Using gases with largo $\gamma$ values will thus provide larger sonochemical effects. Due to this reason, monatomic gases such as $\mathrm{He}, \mathrm{Ar}$ and $\mathrm{Ne}$ are used in preference to diatomic and polyatomic gases. 
Since $\gamma$ for $\mathrm{Ar}, \mathrm{He}$ and $\mathrm{Ne}$ are equivalent, their collapse should generate the same heating, if the collapse were fully adiabatic. These gases have however different solubilities in liquids. In addition, the coliapse is also affected by the thermal conductivity of the gas as it is assumed to be adiabatic. Thus, gases with the same $\gamma$ affect sonochemical reactivity differently owing to differences in solubility and thermal conductivity. For illustration, Table 1.1 shows the rate of formation of free chlorine by irradiation of water containing $\mathrm{CCl}_{4}$ in relation to the nature of the saturating gas [Yong, 1976].

A gas with higher thermal conductivity allows more energy to dissipate into the surrounding medium during collapse, reducing the adiabaticity of the collapse. Therefore, the maximum sonochemical reactivity is observed in cases of a gas with high $\gamma$ and low thermal conductivity. It is assumed that the gases do not participate directly in primary or secondary chemical reactions caused by the ultrasound.

Table 1.1: Rate of formation of free chlorine by sonication of water containing $\mathrm{CCl}_{4}$ under different saturating gases

\begin{tabular}{|c|c|c|c|}
\hline Type of Gas & $\begin{array}{c}\text { Reaction Rate } \\
(\mathrm{mM} / \mathrm{min})\end{array}$ & $\begin{array}{c}\text { Heat Capacity } \\
\text { Ratio }(\gamma)\end{array}$ & $\begin{array}{c}\text { Thermal } \\
\text { Conductivity } \\
\left(10^{-2} \mathrm{~W} \mathrm{~m}^{-1} \mathrm{~K}^{-1}\right)\end{array}$ \\
\hline $\mathrm{Ar}$ & 0.074 & 1.66 & 1.73 \\
\hline $\mathrm{Ne}$ & 0.058 & 1.66 & 4.72 \\
\hline $\mathrm{He}$ & 0.049 & 1.66 & 14.30 \\
\hline $\mathrm{O}_{2}$ & 0.047 & 1.39 & 1.64 \\
\hline $\mathrm{N}_{2}$ & 0.045 & 1.40 & 2.52 \\
\hline $\mathrm{CO}_{2}$ & 0.028 & 1.43 & 2.72 \\
\hline
\end{tabular}




\subsubsection{Liquid properties}

In sonication of a liquid, the bubbles contain not only gas but also vapour. Liquids with high vapour pressures undergo less intense cavitational effects. Tris is most easily demonstrated by the maximum temperature produced on implosion. Since liquid molecules in the vapour phase inside a bubile usualiy have a low heat capacity ratio (less than 1.2), there is a decreases in the maximum cavitational temperature attainable by the collapse of cavity. Due to compressibility of the solvent vapour, the adiabaticity of the collapse is reduced [Fujikawa, 1980]. The bubbles containing vapour molecules can also undergo chemical reactions which remove energy from the bubble, thus ciecreasing even more the final temperature attainable during collapse of cavity [Fogler, 1969].

Surface tension is the other property of liquids that can have an effect on the cavitation process. Liquids with low surface tensions should have a low cavitational threshold. However, Crum [1982d] obsenved an increase in cavitation threshold with a decrease in surface tension of distilled water by hydrophobic solids.

The viscosity of a liquid also influences the cavitation process. The formation of a cavity is more difficult in highly viscous liquids. This can be explained by the quantity of negative pressure in the rarefaction region which is required to overcome the cohesive forces acting within the liquid (see Table 1.2). 
Table 1.2: Acoustic pressure (p) producing cavitation in various liquid under atmospheric pressure [Bergmann, 1938].

\begin{tabular}{|c|c|c|}
\hline Liquid & Viscosity $\mathrm{N} \mathrm{s} \mathrm{m}^{-2}\left(25^{\circ} \mathrm{C}\right)$ & Pressure (atm) \\
\hline Castor oil & 0.630 & 3.90 \\
\hline Olive oil & 0.084 & 3.61 \\
\hline Corn oil & 0.063 & 3.05 \\
\hline Linseed oil & 0.038 & 2.36 \\
\hline $\mathrm{CCl}_{4}$ & 0.001 & 1.75 \\
\hline
\end{tabular}

\subsubsection{Bulk temperature}

Temperature variations affect the cavitation process through gas solubility, surface tension, and vapour pressure. For example, as the bulk temperature is raised, the vapour pressure of the liquid increases. The greater vapour content inside the cavities causes more cushioning action during the compression, weakens the collapse, and reduces the cavitation intensity. Thus, any effect directly related to cavitation should correspondingly decrease with an increasing temperature.

The results on the chemical and physical activity of cavitation as a function of liquid temperature can be divided into three categories: those that are initially independent of temperature changes and then decrease rapidly [Weissler,1953; Lindstrom, 1955]; those that decrease exponentially [Rosenberg, 1960; Sehgal 1980]; and finally, those that increase initially and aiter an optimum temperature decrease [lbisi, 1967]. These different types of 
behaviour might be due to the phase in which the reactions occur. The reaction zones can be in the liquid medium, in the gaseous phase within a cavity, or at a liquid-gas interface.

\subsubsection{Acoustic characteristics}

Acoustic intensity has a dramatic effect on the rates of sonochemical reaction. At very low intensities below the inreshold for cavitation, the amplitude of the sound field is not enough to induce nucleation or bubble growth. Above this threshold the reaction rate increases with ultrasonic intensity. However, several investigators have noted that there is an optimum intensity for formation of cavitation bubbles, above which further increases cause a decrease in yield [Nomoto, 1948; Bondy, 1936]. This behaviour at high intensities can be due to growth of very large bubbles which float away from solution, as well as a diminishing of the penetration of the ultrasound into the liquid due to production many bubbles near the radiating surface.

In the literature, the effect of ultrasound frequency has been considered as a negligible or secondary effect on the nature of most sonochemistry. In acoustic cavitation, most experiments have been carried out by means of frequencies in the range of $20-100 \mathrm{kHz}$. There are some works with high frequency [Henglein, 1992, 1990, 1984; Hart, 1985; Fischer, 1986; Petrier, 1992]. However, as will be shown in this thesis, sonochemistry at higher frequencies $(\mathrm{MHz})$ shows interesting aspects which differ from those at low 
frequencies.

Since the cavitation process is responsible for sonochemical effects, there is in principle no reason for restricting the sonochemical reactions to a frequency range between $20 \mathrm{kHz}$ and a few $\mathrm{MHz}$. It seems that any sound frequency which causes cavitation process can be studied regardless of its frequency. Lower frequencies have traditionally been used since equipment for its generation is more developed. Cavitation thresholds are also lower at lower frequencies.

\subsection{Acoustic cavitation and chemical reactions}

Over the past few years a large number of chemists (physical and synthetic) and engineers have worked extensively on sonochemical reactions, including a wide range of homogeneous and heterogeneous reactions and material processing.

In chemical synthesis, ultrasound has many uses, and several reviews of its applications to organic synthesis have been seen in the literature [Suslick, 1988; Einhom, 1989; Mason, 1990]. In the field of polymers, power ultrasound has been used primarily for the depolymerization effect of ultrasound [Price, 1990]. However, in a series of papers Peeter Kruus and co-workers [1983, 1985, 1987, 1988] showed that polymers such as polystyrene and poly(methyl methacrylate) could be produced simply by sonication of pure, dry monomers. Both polymerization and depolymerization by ultrasound could be a useful 
method for controlling polymer structure as well as improving the rates and yields of many common polymerization reactions [Price, 1993]. High intensity (power) ultrasound has also been used in metallurgy to improve the gas release from melts and the grain refinement of metals.

Power ultrasound influences the system through the generation and destruction of cavitation bubbles. In order to understand the mechanism through which cavitational collapse can affect chemical processes, one must consider this effect in different systems. These chemical effects of ultrasound fall into two major categories: homogeneous sonochemistry of liquids and heterogeneous sonochemistry of liquid-solid or liquid-liquid systems.

\subsubsection{Acoustic cavitation and homogeneous reactions}

The collapse of a bubble during sonication in a homogeneous liquid is spherically symmetric. Lauterborn studied the laser induced spherical cavitation of single bubbles in water far from boundaries [Lauterborn, 1973]. He was able to photograph the collapse of a single spherical bubble at a speed of 75,000 frames per second (see Figure 1.3). Lauterbom [1980] also repeatedly took photographs of the collapse of a single spherical bubble at a million frames per

second. Even at this high speed they could not fully resolved the final collapse, but the radiation of a shock wave was clearly demonstrated.

The bubble contains vapour from the solvent and any volatile reagents subjected to the enormous increases in both temperature $\left(=5000^{\circ} \mathrm{C}\right)$ and 


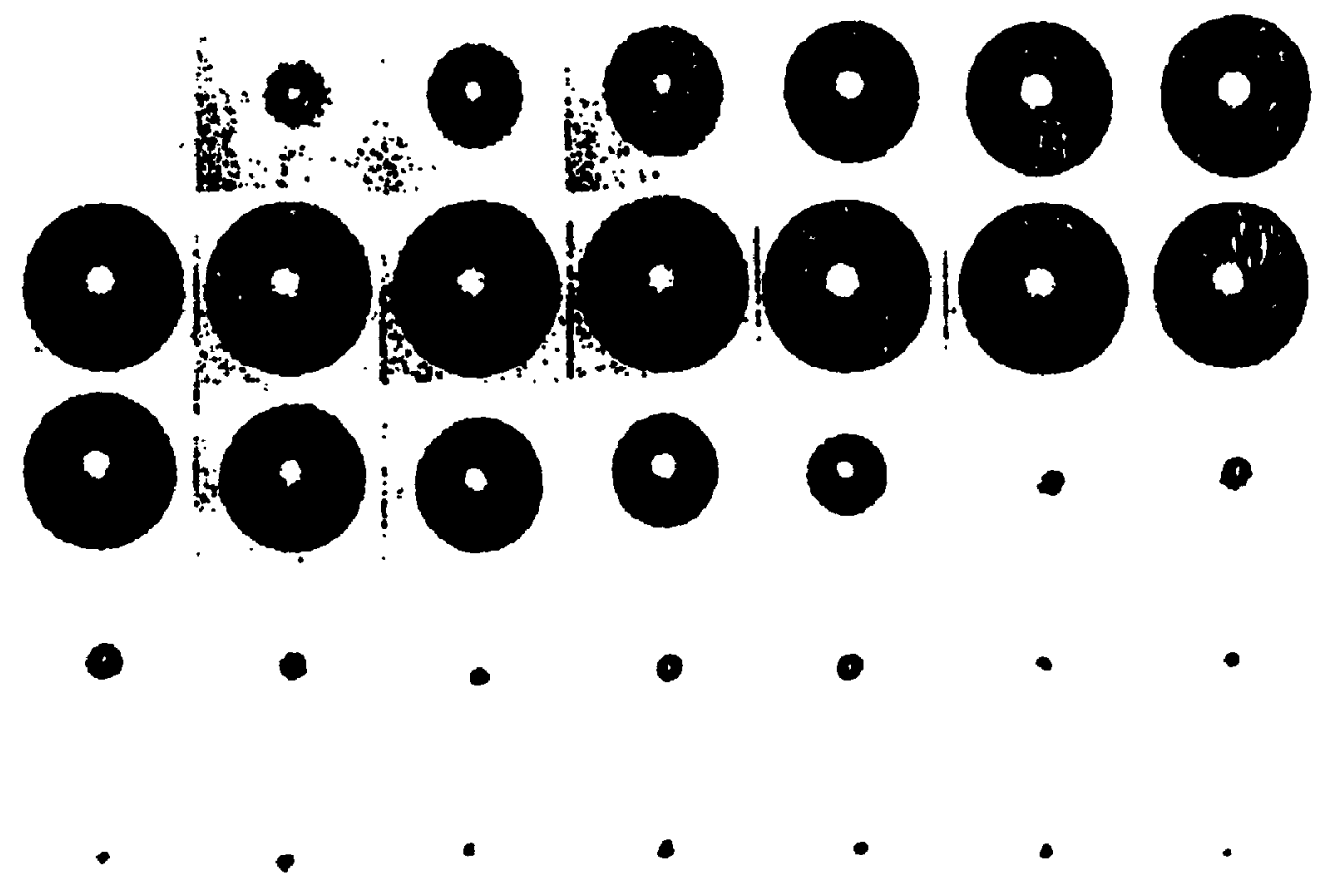

Figure 1.3: Laser-induced spherical cavitation bubble in water far from boundaries (Lauterbom, 1973). 
pressure $(\approx 500 \mathrm{~atm})$ in the collapse process. These extreme conditions produced by imploding bubbles last for less than a microsecond [Suslick, 1986], causing molecules to fragment and generating highly reactive radicals species. These radicals may either react within the collapsing bubble or migrate into the bulk liquid.

Suslick et al. [1986] determined the effective temperature reached during cavitational collapse by the use of competing unimolecular reactions for which the dependence of the rates on temperature is known. The sonochemical ligand substitutions of volatile metal carbonyls were used as the comparative rate probes. These studies revealed that there were two sonochemical reaction zones. One reaction zone occurred in the bubble 's gas phase and the second one took place in an initial liquid zone surrounding the bubble. The effective temperature of these zones was estimated at $5200 \pm 650 \mathrm{~K}$ in the gas phase $z 0 n e$ and about $2000 \mathrm{~K}$ for a zone about $200 \mathrm{~nm}$ from the bubble surface [Suslick, 1986].

Ultrasonic irradiation of water [Weissler, 1959; Lippit, 1972] was one of the first homogeneous sonochemical reactions studied. In the primary reaction, water itself decomposes with the formation of radical species $\left(\mathrm{OH}^{\circ}\right.$ and $\left.\mathrm{H}^{\circ}\right)$. Any component dissolved in the water will be subjected to chemical reaction with these ultrasonically produced radicals. Riesz and co-workers [1985] were able to detect these highly reactive radicals by using spin traps.

The presence of iodide in aqueous solution under sonication will release 
iodine molecules owing to the reaction between iodide and hydroxyl radical. Some other examples of homogeneous sonochemical reactions are: chlorine formation from carbon tetrachloride [Weissler, 1950], ammonia synthesis [Sokol 'skaya, 1957], oxidation of aldehydes [Vasilina, 1984], metal carbonyl substitution [Suslick, 1984], and iron oxidation [Price, 1993].

\subsubsection{Acoustic cavitation and heterogeneous reactions}

The bubble collapse in a heterogeneous system is completely different from that in a homogeneous one. Figure 1.4 [Lauterborn, 1975] shows a collapse of a single spherical bubble produced by laser near a plane solid boundary in water. The framing rate is 75000 frames per second. As observed in Figure 1.4, a microjet is formed in an asymmetric collapse of bubble. This jet has a velocity of roughly 100 to $200 \mathrm{~m} / \mathrm{s}$ as determined by the high-speed microcinematography [Lauterborn, 1975].

\subsubsection{Physical point of view}

The implosion of a cavity on the surface causes severe substrate damage. It has been suggested that high velocity jets forming during bubble collapse are responsible for surface damage due to their impingement on the surface [Nyborg, 1978; Tomita, 1986]. Shockwaves created by collapse of cavities in the liquid also induce surface damage. These two mechanisms (microjet and shockwave) are thought to be responsible for localized erosion 


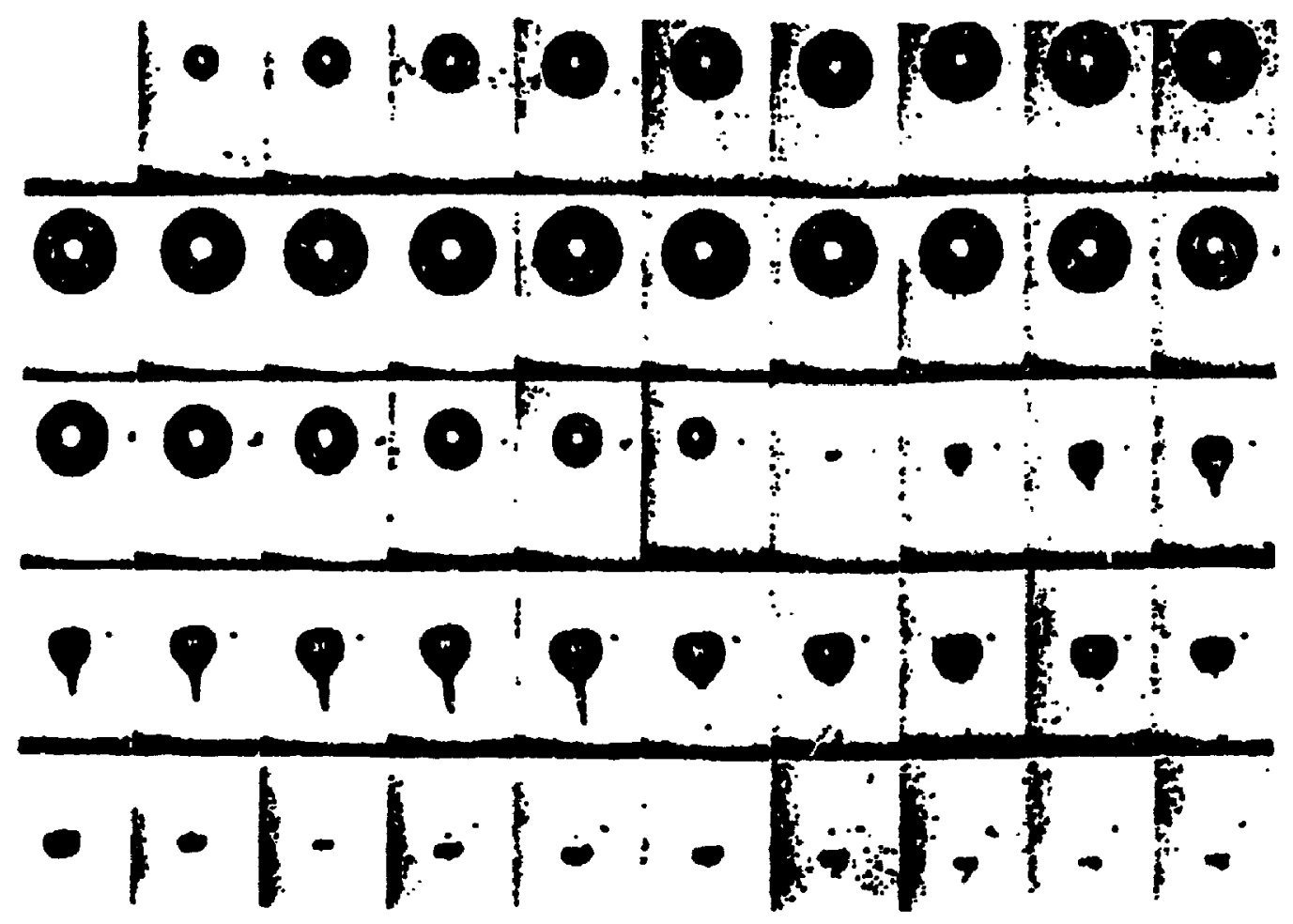

Figure 1.4: Collapse of a single, spherical, laser-induced cavitation bubble near a solid boundary (Lauterbom, 1975). 
and also the sonochemical effects on heterogeneous reactions.

Ultrasonic cleaning is a technique which is used commonly for particle removal. This technique has been successful in the removing some particular contamination from hard substrates [Kashkoush, 1990, 1992]. Surface contamination by submicron-size particles is a major problem in the semiconductor industry. As the line width in the circuits decreases to less than a micron, the problem of contamination control becomes more serious.

The main mechanisms responsible for the cleaning process in an ultrasonic field are cavitation, acoustic streaming and the formation of a pressure gradient across the particles [Kashkoush 1990, 1992; Geers, 1991]. The removal of contamination was studied by high speed photography [Rozenberg, 1960]. He determined two independent mechanisms for removal of contamination films. The first one was the partial tearing of a film from the surface by the collapse of the bubble; the second was the penetration of energetic small bubbles into all pores and gaps between the contamination layer and surface. The vibration of this bubbles facilitated the peeling, tearing off pieces of the contamination layer from the surface.

A simple model for removing a micron size spherical particle adhering to the smooth solid surface was proposed by Geers [1991]. Also Olson [1988] studied the interaction between a plane acoustic wave and a spherical particle. Both of them claimed that the pressure was the driving force responsible for particle removal from flat surfaces. 


\subsubsection{Chemical point of view}

Reactions involving solids in liquid can be divided into two groups: one in which the solid is consumed as a reagent; the other in which it acts as a catalyst in the process.

Historically, Renaud [1950] was the first to use ultrasound in heterogeneous liquid-solid reactions. He prepared some organometallic compounds with metals such as $\mathrm{Al}, \mathrm{Li}, \mathrm{Mg}$.

In the case of metal powders, there is considerable surface change and reduction in particle size. This is due to cavitational collapse on or near the surface. These effects may lead to an increased reactivity of solid reagents by: (a) removal of passivating surface coatings such as oxides; (b) reduction of particle size, which presents a much greater surface area to the liquid resulting in an enhanced rate; (c) improvements in mass transport; (d) creation of surface defects which may lead to reactive centres in some cases.

Suslick and coworkers have studied the effect of ultrasound on some metals such as zinc, nickel and copper [Suslick, 1987, 1989a, 1989b]. As a result of the effects caused by sonication, these metals have greatly increased effectiveness as catalysts [Suslick, 1986]. For example, the hydrogenation of alkene by $\mathrm{Ni}$ powders is enormously enhanced (by about $10^{5}$ times) by ultrasound irradiation [Suslick, 1987]. In these studies Suslick and coworkers observed a dramatic changes in morphology; they also confirmed that the ultrasonic irradiation effectively removed the surface oxide coating by studying 
the surface composition using an Auger electron spectroscopy.

Ultrasonic irradiation of slurries causes an acceleration of the movement of particles. These particles can collide head-on or at glancing angles and owing to high speed, the interparticle collisions can produce temperatures above the melting point. The particles can finally fuse to each others. A scanning electron micrograph of two zinc particles with average diameter of about $10 \mu \mathrm{m}$ after interparticle collision by ultrasound is shown in Figure 1.5 [Doktycz, 1990]. This micrograph also shows a neck region formed in the impact area.

Ultrasound can promote heterogeneous reactions, even those which normally are quite ineffective under normal conditions. Ando [1984], Boudjouk [1983], Luche [1980], and Suslick [1984] among others have done some work in this area. The following reactions show a few simple examples of their work.

$$
\begin{gathered}
\mathrm{C}_{6} \mathrm{H}_{5} \mathrm{CH}_{2} \mathrm{Br}+\mathrm{KCN}+\mathrm{C}_{6} \mathrm{H}_{5}-\mathrm{CH}_{3}+\mathrm{Al}_{2} \mathrm{O}_{3} \cdots \mathrm{C}_{6} \mathrm{H}_{5} \mathrm{CH}_{2} \mathrm{CN} \\
\mathrm{C}_{2} \mathrm{H}_{4}+\mathrm{HCOOH}+\mathrm{Pd} / \mathrm{C} \ldots \mathrm{C}_{2} \mathrm{H}_{6} \\
\mathrm{C}_{6} \mathrm{H}_{5} \mathrm{Br}+\mathrm{Li} \ldots \mathrm{C}_{6} \mathrm{H}_{5} \mathrm{Li}+\mathrm{LiBr} \\
\mathrm{VCl}_{5}+\mathrm{Na}+\mathrm{CO} \rightarrow \mathrm{V}(\mathrm{CO})_{6}
\end{gathered}
$$




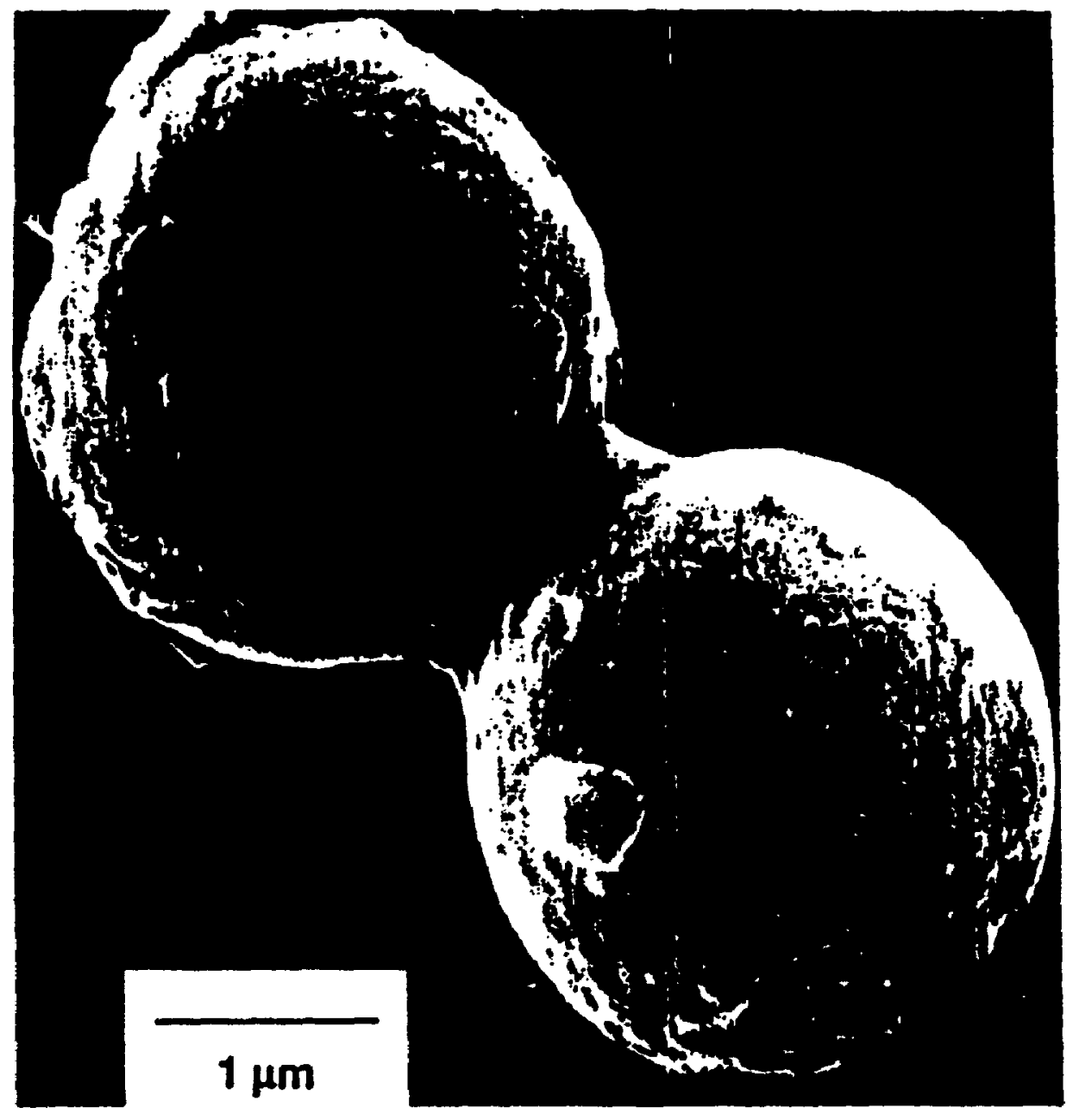

Figure 1.5: Scanning electron micrograph of two Zn particles which produces a neck from localized melting caused by sonication (Doktycz, 1990). 
The molecular intercalation in a heterogeneous system is a difficult reaction which is facilitated by high intensity ultrasound [Chatakoindu, 1987]. The intercalation of organic or inorganic compounds (guest molecules) between the atomic layers of inorganic solid (hosts molecule) produces a dramatic changes in catalytic and electronic properties of host compounds. These reactions usually are very slow and require high temperatures and long times for completion; ultrasound can increase the rate by a factor of 200 .

In the case of liquid-liquid heterogeneous systems, sonication provides rapid and efficient emulsification of any immiscible liquids, resulting in a large surface contact area for reaction.

\subsection{Theories of cavitation}

There are several theories and models for describing ultrasonic cavitation. Owing to complicating factors involved in the cavitation process, it is difficult to find a single theory or a model which is capable of giving an answer for every situation. In most sonochemical experiments there is a multitude of cavitation bubbles which can behave in different ways. Generally, it is possible to divide these theories and models into two major groups: electric discharge and thermal theories.

\subsubsection{Electric dischare theory}

In 1935 Frenkel and Schulze reporied for the first time the emission of 
light from water sonicated by intense ultrasound. They proposed that the cavitation process in water is accompanied by charge separation, similar to the charge separation that occurs in the atmosphere. The discharge theory of Frenkel [1940] involves the formation of a lens-shaped cavity with the two sides of the cavity oppositely charged. When the cavity continues to grow, the magnitude of the charge on each side of the cavity increases, and the electrical field within the cavity increases until a discharge across the cavity occurs. Such a discharge is assumed to be accompanied by a flash of light, ionization and chemical reactions.

This model remained a significant influence for a long time so that it was believed to be the major cause of sonochemical effects [El 'piner, 1964]. This was one reason why only a few sonochemical investigations were done on organic liquids. Such liquids have low dielectric constants and were predicted by the theory to be sonochemically unreactive.

Margulis [1991] has proposed a new electrical theory of cavitation phenomena. He claimed recently [1994] that the "hot spot" theory can not explain many experimental results, such as the dependency of the sonochemical rate on temperature near the boiling point, on hydrostatic pressure near the saturated vapour pressure of the liquid, and on high viscosity. He concludes that his new electrical theory provides a good alternative to the "hot spot" theory. 


\subsubsection{Thermal theory}

Rayleigh [1917] first described theoretically the collapse of a spherical cavity. The first systematic study of acoustic cavitation was carried out by Blake [1949], followed by Noltingk and Neppiras [1951]. This model did not involve electric effects. It focused on describing the size, temperature and pressure of the bubbles in an acoustic field. There is a useful review of such models of cavitation in Flynn's paper [1964]. More recent reviews are available in a series of papers in Ultrasonics INeppiras, 1980; Prosperetti, 1984; Apfel, 1984].

\subsubsection{Bubble dynamic equation}

The following equation is known as the Rayleigh-Plesset equation, developed by Plesset [1949]. It governs the motion of the bubble in the applied acoustic field in liquid.

$$
R \ddot{R}+\frac{3}{2} \dot{R}^{2}=\frac{1}{\rho}\left[p_{L}-p_{-}(t)\right]
$$

Here, $\boldsymbol{R}$ is the instantaneous bubble radius, $\dot{\boldsymbol{R}}$ the velocity of the bubble wall, $\ddot{\boldsymbol{A}}$ the bubble wall acceleration, $p_{L}$ the pressure at the bubble-liquid interface, $p_{-}(t)$ the pressure due to the acoustic field, and $\rho$ the liquid density.

A bubble with radius $A$ at equilibrium in a liquid has on it the pressure of 
the bubble walls arising from the hydrostatic pressure $\left(p_{L}\right)$ within the liquid and the surface tension $(\sigma)$. For equilibrium, this must equal the internal pressure $\left(p_{i}\right)$ responsible for attempting to expand the bubble; $p_{i}$ has contribution from the trapped gas $\left(p_{\rho}\right)$ and vapour $\left(p_{v}\right)$ of the liquid. This explanation is shown in the following equation:

$$
p_{L}=p_{i}-\frac{20}{R}=p_{g}+p_{v}-\frac{20}{R}
$$

The gas pressure inside the bubble is changed when there is a change in the radius. When it is assumed that the gas is ideal and that the total amount of gas in the bubble remains constant, then the bubble radius and the gas pressure are related by

$$
p_{g}=p_{g 0}\left(\frac{R_{0}}{R}\right)^{3 \kappa}
$$

Here, $p_{\infty o r} R_{0}$ are the initial pressure and radius and $p_{g}, \boldsymbol{R}$ are the final ones respectively. The value of $\alpha$ is unity for an isothermal process, while it is equal to the heat capacity ratio $(\gamma)$ for an adiabatic process.

The acoustic pressure $\left(p_{m}\right)$, the time-varying pressure field, is obtained from the characteristics of the ultrasonic radiation. If it is a sinusoidal function 
of time, then it can be written as

$$
p_{w}(t)=p_{0}-p_{A} \sin \omega t
$$

which $p_{0}, p_{A}$ and $\omega$ are ambient pressure, maximum pressure amplitude and angular frequency, respectively. Substituting equations [1-4], [1-5], and [1-6] into equation [1-3] and rearranging, we obtain

$$
\ddot{R}=\frac{1}{\rho}\left[p_{g 0}\left(\frac{R_{0}^{3 E}}{R^{3 k+1}}\right)+\frac{p_{V}}{R}-\frac{20}{R^{2}}-\frac{\left(p_{0}-p_{A} s i n \omega t\right)}{R}\right]-\frac{3 \dot{R}^{2}}{2 R}
$$

This equation describes the radial motion of an isolated gas-filled bubble in an incompressible liquid with specific physical characteristics $\left(p, \sigma, \gamma, p_{v}\right)$ under an acoustic pressure. Figure (1.6) shows a set of solutions of equation [1-7] for increasing values of the ratio $p_{A} / p_{0}[$ [Akulichev, 1967]. At low intensities the motion is stable, but it becomes transient at a certain threshold $p_{A}$. When $p_{A}$ exceeds this threshold, the bubble grows too large and can collapse completely during the first acoustic cycle. At higher intensities the collapse may happen during the second, the third or subsequent cycles. Eventually, a point is reached where the bubble grows so large that it can never collapse as a transient (upper threshold). 


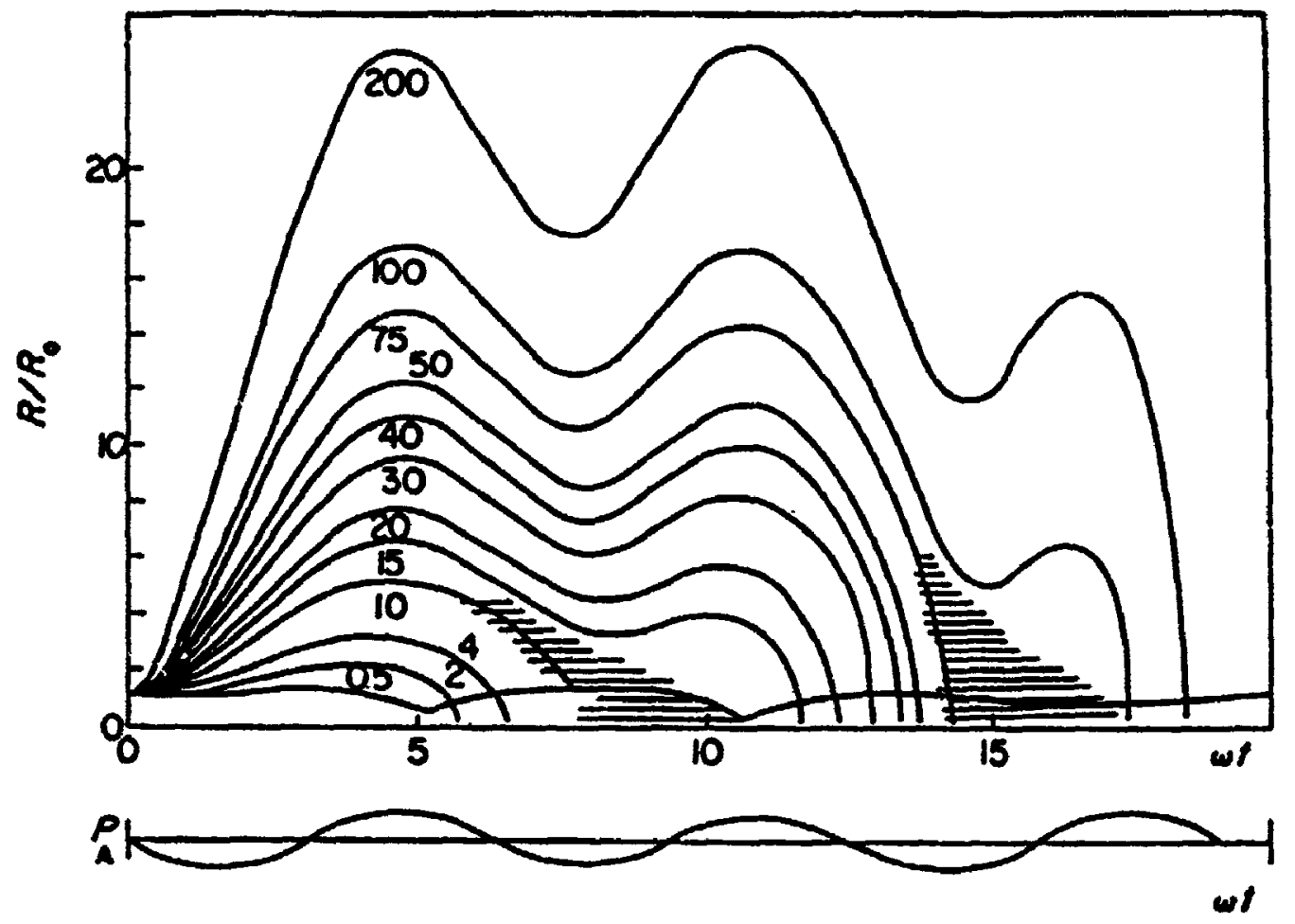

Figure 1.6: Radius-time curves for pulsations of air bubbles in water (the numbers on the curves refer to $p_{\AA}\left(p_{d}\right) . R_{0}=5 \times 10^{4} \mathrm{~cm} ; \omega=4.2 \times 10^{6} \mathrm{~s}^{-1} ; p_{0}=1$ bar. 
More exact models which are more complicated and difficult to handle have also been derived. These take account of viscosity, thermal exchanges, and liquid compressibility to various extents [Flynn, 1964; Akulichev, 1971; Neppiras, 1980]. However, equation [1-7] is realistic for all ordinary stable cavitation conditions, in the threshold region, and also for transient cavitation up to the point where the collapse velocity approaches the velocity of sound.

\subsubsection{Lifetime of bubble collapse}

Rayleigh [1917] deduced the cavity collapse time $(\tau)$ by considering the total collapse of an empty void (radius of $\boldsymbol{R}_{m}$ to zero) under the action of a constant pressure $\left(p_{0}\right)$. The collapse time is given as

$$
\tau=0.915 R_{m}\left(\frac{p}{p_{0}}\right)^{\frac{2}{2}}
$$

where $R_{m}$ is the radius of the cavity at the start of collapse. This equation [1-8] can be modified for a bubble being filled with either gas or vapour, giving

$$
\tau=0.915 R_{m}\left(\frac{\rho}{p_{m}}\right)^{\frac{2}{2}}\left(1+\frac{p_{v g}}{p_{m}}\right)
$$


Here, $p_{m}$ is the sum of atmospheric $\left(p_{0}\right)$ and acoustic pressure $\left(p_{2}\right)$, and $p_{v g}$ is the pressure inside the bubble (vapour and gas).

The range of the collapse lifetimes is estimated to be from $5 \mathrm{~ns}$ to $5 \mathrm{~ms}$ [Margulis, 1991, 1985, 1982; Benkovskii, 1974]. A collapse lifetime less than 100 ps has, however, been reported by Barber and Putterman [1991]. They determined the lifetime by monitoring the sonoluminescence from a single bubble in a $20 \mathrm{kHz}$ acoustic field.

1.5.2.3 Temperature and pressure in a collapse cavity

The maximum temperature and pressure at the collapse of the bubble can be derived from the bubble dynamic equation.

$$
\begin{gathered}
p_{\max }=p_{g}\left[\frac{p_{m}(\gamma-1)}{p_{g}}\right] \frac{\gamma}{(\gamma-1)} \\
T_{\max }=T_{0}\left[\frac{p_{m}(\gamma-1)}{p_{g}}\right]
\end{gathered}
$$

Here, $p_{g}$ is the initial gas pressure in a bubble, $p_{m}$ is the sum of atmospheric and acoustic pressures, $\gamma$ is the heat capacity ratio of gaseous components inside the bubble, and $T_{0}$ is the ambient temperature. At the point of bubble collapse, high temperature and pressure will result in the liquid, giving rise to 
effects such as molecular degradation, dispersion and erosion.

Since the early calculations of Rayleigh, the temperature of the collapsed bubble has been predicted by various hydrodynamic models to be as low as $1000 \mathrm{~K}$ and as high as $10,000 \mathrm{~K}$ [Raleigh, 1917]. Suslick and Hammerton [1986] for the first time measured experimentally the temperature of the collapsed cavity by using comparative rate thermometry. They determined two regions with temperature of $=5100 \mathrm{~K}$ in gas phase inside the bubble, and $\approx 2000 \mathrm{~K}$ in a shell of liquid around the collapsed bubble [Suslick, 1985, 1986]. They derived the gas- and liquid-phase rate coefficients $\left(k_{g}\right.$ and $\left.k_{1}\right)$ from the obsenved first-order rate constants for the sonolysis of $\mathrm{Fe}(\mathrm{CO})_{5}$ vs its vapor pressure. The average effective temperature reached in each site was calculated from the Arthenius exppression. They used the activation parameters determined by high-temperature gas-pnase laser pyrolysis in their calculations. These temperatures are of course dependent on the nature of the liquid, the bulk temperature etc.

Flint and Suslick [1991] have directly determined the sonoluminescence emission temperature of excited state $C_{2}$ produced during acoustic cavitation. The best computational fit to their raw data was at an emission temperature $5125 \mathrm{~K}$, at $20 \mathrm{kHz}$ in silicone oil under Ar with a vapour pressure of $\approx 0.01$ torr. It should be emphasized that one single temperature can not explain all aspects of cavitation. The local conditions inside the bubble are extraordinarily dynamic. The spatial and temporal temperature profile of a cavitating bubble is 
consideration, as there is no thermal equilibrium during the cavitation process.

\subsubsection{Resonance radius of the bubble}

In stable cavitation, a bubble oscillates in size for several periods in an acoustic field. This oscillation can be carried out by bubbles with different sizes, but the greatest effect will occur for bubbles with a resonant radius. When the bubble contains gas with heat capacity ratio of $\gamma$ and is in a liquid with density $\rho$ at pressure $p$, then the resonant radius $R_{r}$ in an acoustic field with radial frequency $\omega$ is:

$$
R_{I}=\left(\frac{3 \gamma p}{\rho \omega^{2}}\right)^{\frac{1}{2}}
$$


CHAPTER 2

APPARATUS AND SONOCHEMICAL REACTOR DESIGN 


\subsection{Introduction}

An ultrasonic apparatus must have a device capable of converting some form of energy into high frequency acoustic waves, i.e. a transducer. Ultrasonic transducers are designed to convert either mechanical or electrical energy into ultrasound. There are three main types of transducer: gas driven, liquid driven and electromechanical. The last type is the most common. Electromechanical transducers are based on Gither piezoelectric or magnetostrictive effects. Piezoelectric transducers are those most commonly used to power bath and probe type sonicator system.

\subsection{Piezoelectric transducer}

A thin plate of a crystal such as quartz (x-cut quartz) shows two complementary effects. The first one is the piezoelectric effect. When a physical pressure is applied on the surfaces of the thin plate, an equal but opposite charge is generated cn each side. Polarity is reversed if tension is applied across the surfaces. This generation of an electrical potential on the crystal surfaces by mechanical stress was discovered in 1880 by the Curie brothers Pierre and Jacques. The second effect is the reverse piezoelectric effect. When an electrical potential is applied across the faces of the crystal, then there is a mechanical deformation of the crystal (expansion or contraction depending on the polarity of the applied voltage).

A piezoelectric transducer generally consists of a thin plate of 
piezoelectric material such as quartz, barium titanate $\left(\mathrm{BaTiO}_{3}\right)$, lead metaniobate $\left(\mathrm{PbNb}_{2} \mathrm{O}_{6}\right)$, the mixed crystal lead zirconate titanate, or several other ceramics. These plates are coated with thin metallic films on their faces, forming two electrodes. The front electrode, which is in contact with the liquid medium, is usually grounded to prevent shock. In continuous wave operation, an oscillating electrical potential is then applied to the back electrode to vibrate the crystal and produce ultrasonic waves.

It is not possible to vibrate a piezoelectric crystal plate at every frequency. Each crystal plate lias an optimum performance at the natural resonance frequency, which is related to the crystal dimension. For example, a transducer with thickness of $2.88 \mathrm{~mm}$ (x-cut quartz) has a natural frequency of $1 \mathrm{MHz}$ whereas for $0.288 \mathrm{~mm}$ it has a natural frequency at $10 \mathrm{MHz}$. This is a reason why any conventional ultrasonic equipment (bath or probe) has its own specific frequency.

\subsection{Types of sonication}

Ultrasonic waves can be introduced into a system directly or indirectly. The ultrasonic source can be put directly inte the reaction medium, or a container with the system can be immersed in a tank containing a sonicated liquid (usually water).

In ultrasonic probe systems which sonicate a solution directly, the acoustic hom is the essential part for leading the acoustic energy from the 
transducer to the reaction mixture. The amount of transferred energy is related to the shape of the horn. Horns magnify the vibrational amplitude by a factor which is dependent on the type of taper [Mason, 1988].

\subsubsection{Sonication by the $20 \mathrm{kHz}$ apparatus}

The $20 \mathrm{kHz}$ ultrasound was produced by a Vibra-Cell VC375 ultrasonic processor. The ultrasound was introduced directly into the sample solution through a titanium hom as in similar apparatuses described earlier [Kruus, 1987].

To improve the reproducibility of the sonication results, a plastic sleeve was constructed for connecting the reactant container to the hom in a reproducible manner. This technique also made it possible to control the gas present (Figure 2.1).

Three different homs with tip areas of $1.1 \mathrm{~cm}^{2}$ (referred to as "small"), $2.48 \mathrm{~cm}^{2}$ ("medium"), and a special horn provided by Vibra-Cell with a tip area of $8.04 \mathrm{~cm}^{2}$ ("X-large") were used for determining the effect of intensity $(W \mathrm{~cm}$. ${ }^{2}$ ) on the reactions.

\section{E.3.2 Sonication by the $900 \mathrm{kHz}$ apparatus}

An apparatus was constructed which produces $900 \mathrm{kHz}$ ultrasound through a flat transducer mounted at the bottom of a reaction vessel holding the solution. The details of the sonication cell are shown in Figure 2.2. The power 


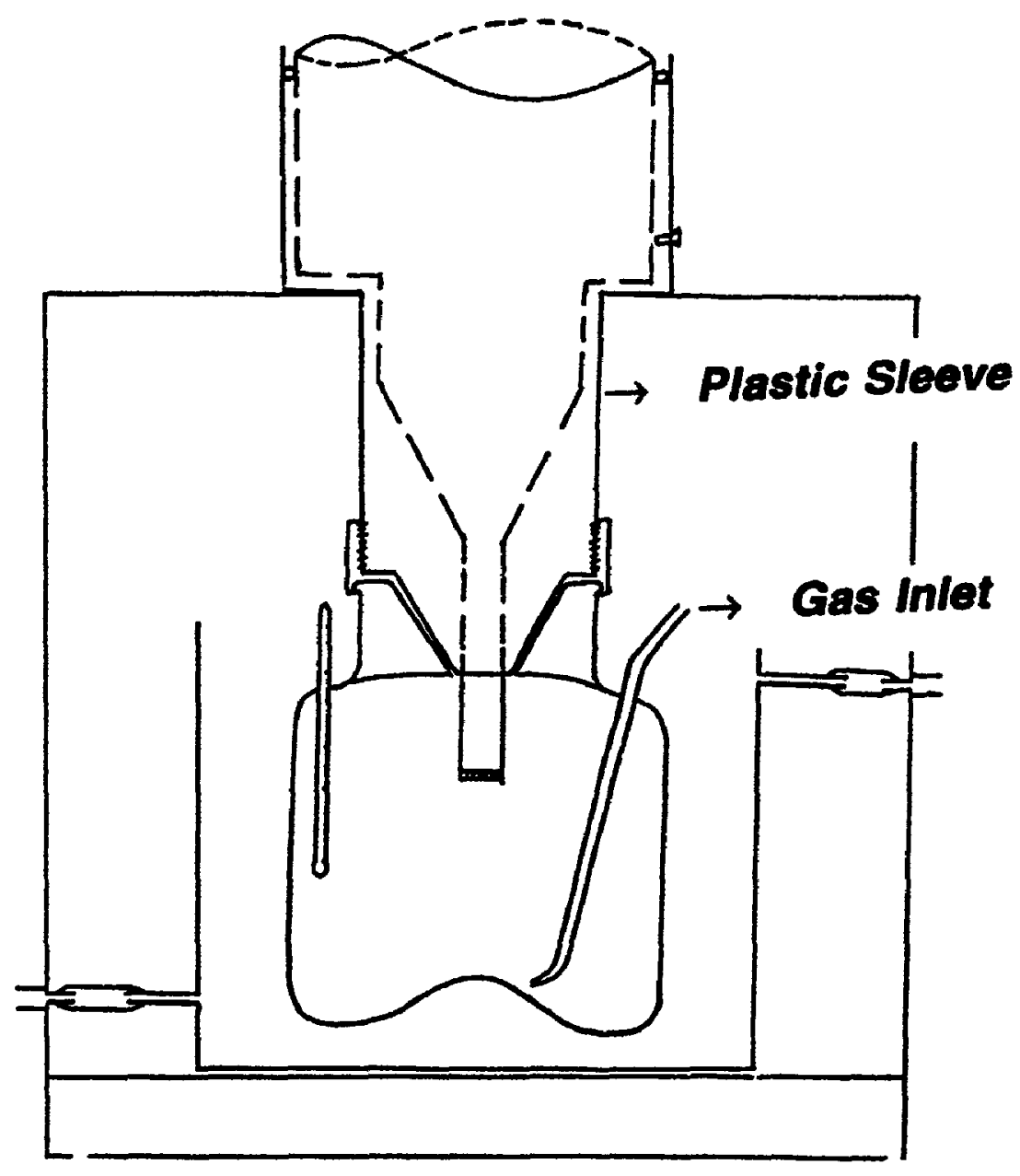

Figure 2.1: A plastic sleeve which connected the reactant container to the 20 kHz ultrasonic hom. 


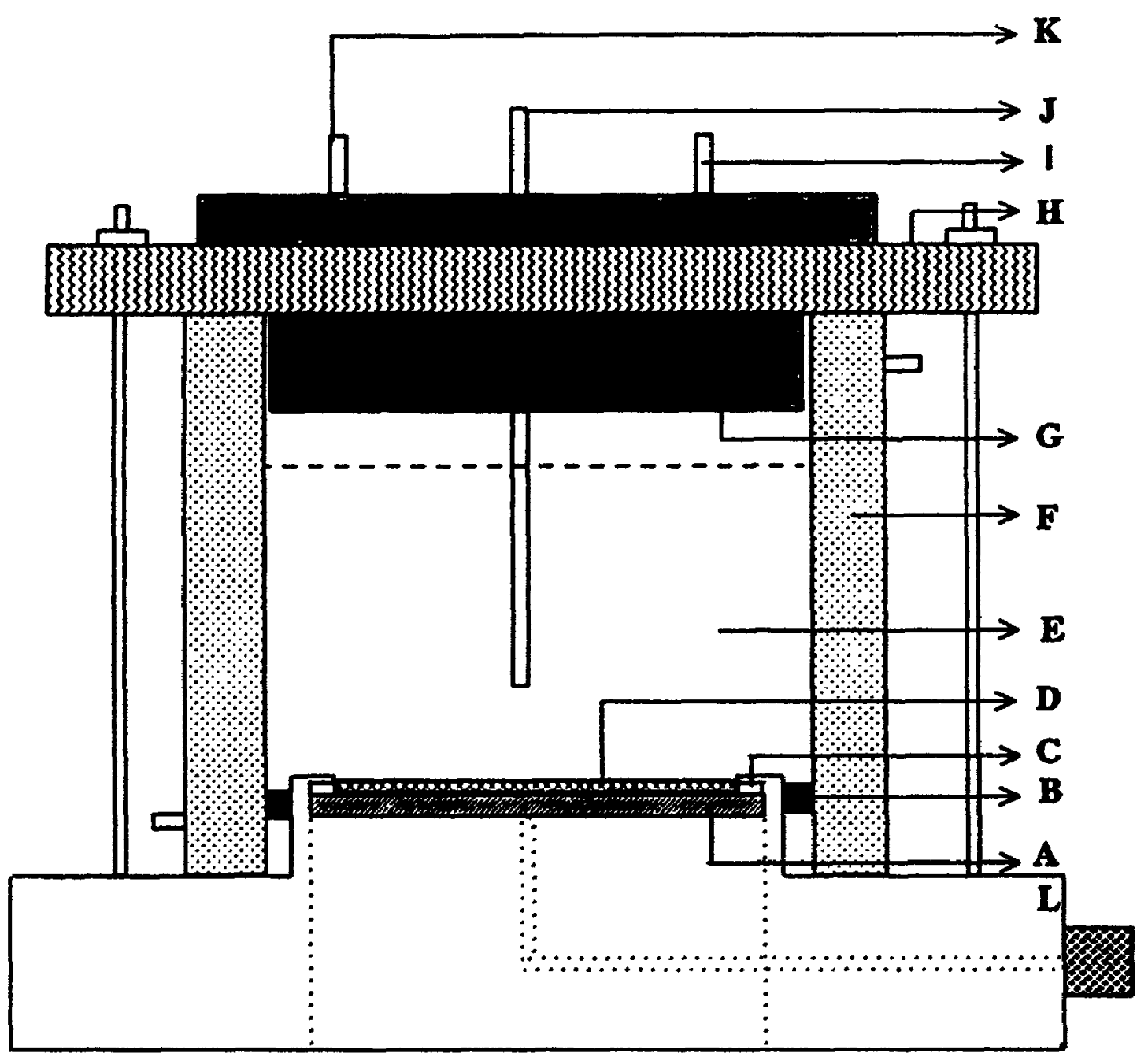

Figure 2.2: Sonochemical reactor which designed and constructed for $900 \mathrm{kHz}$ apparatus.

A: transducer (EBL \#1 (PZT-4) 2.125 in diameter from Staveley Sensors Inc, Connecticut), B: $O$ ring (Buna-N), C: silver conducting epoxy cement (Chomerics), D: protective resin (RTV 11 white), E: reaction solution (typicaliy $150 \mathrm{~mL}$ ), F: circulating themostating bath, G: lid (plastic), H: support frame (plastic), l: entry for thermocouple, J: inlet for gases (stainless steel tube with a perforated end), K: outlet for gases, L: stainless steol base. 
amplifier for this apparatus was from an apparatus supplied by Meinhardt Ultrasonics, Leipzig, Germany (Figure 2.3). In this new apparatus the ultrasound can enter the system directly when the solution studied has a negligible effect on the RTV resin used in the apparatus. The sonication of aqueous potassium iodide solution can be carried out in this way for short periods. The ultrasound must be introduced indirectly when there is an effect between the reactants and RTV resin. In this case the position of the vessel inside the sonication cell is important.

A holder was attached to a standing device equipped with a micrometer, and then the reactant container was coupled to the holder. With this equipment it is possible to fix the position of the container with respect to the ultrasonic source at the same position in different runs (Figure 2.4).

During sonication, heat is dissipated in the solution. The sonication cell was thus equipped with a circulating water bath for controlling the temperature. In the case of low intensity, there was a good temperature control during the sonication with a temperature increase of about $2^{\circ} \mathrm{C}$. At high intensity, however, there was a significant increase in the temperature of more than $10^{\circ} \mathrm{C}$. A glass coil was thus constructed for inside the sonication cell such that it is immersed in the sonicated liquid. The temperature control of the system was thus improved owing to the cooling of the system from both outside and inside by a thermostat. 


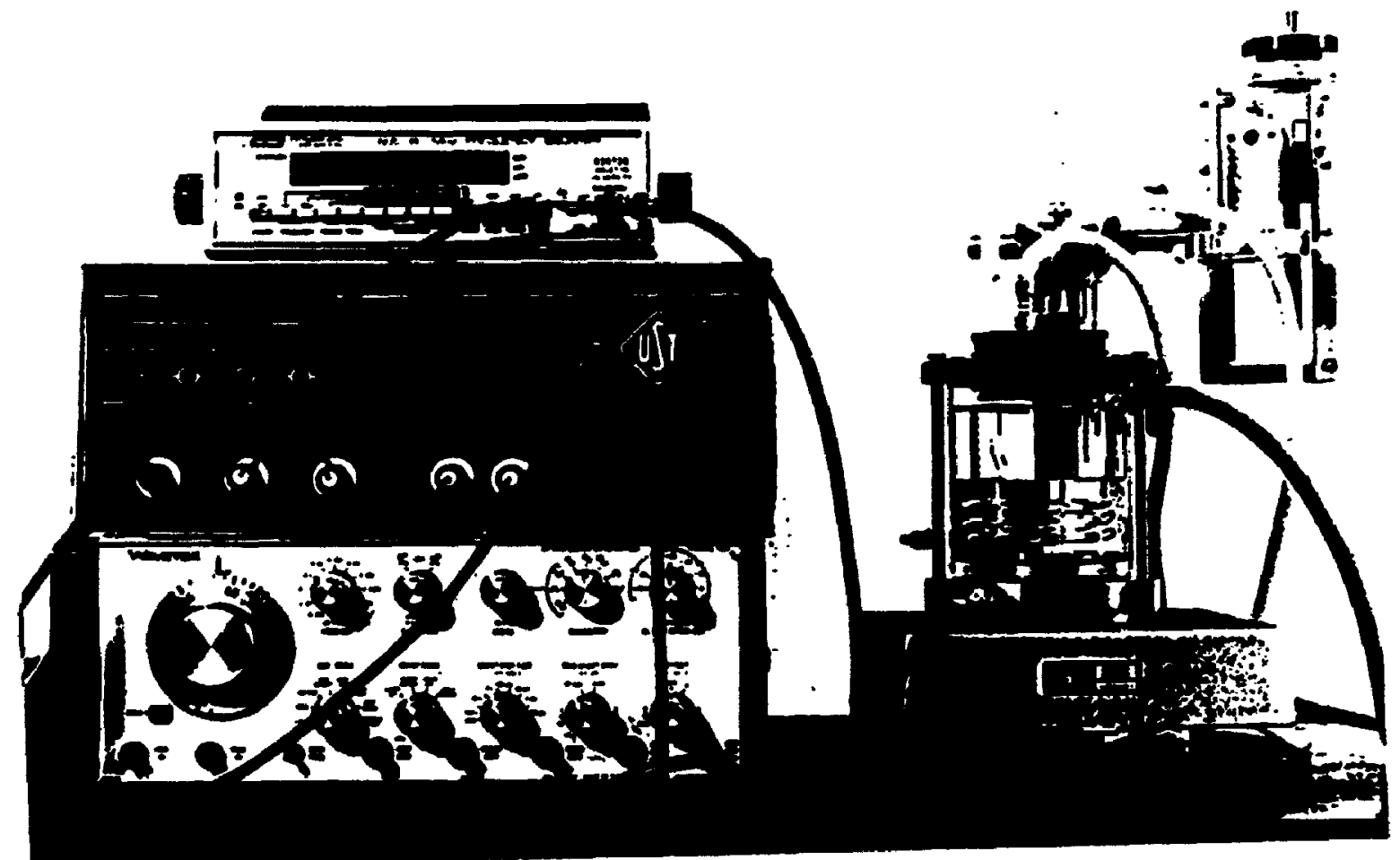

Figure 2.3: $900 \mathrm{kHz}$ apparatus (power amplifier from an apparatus supplied by Meinhardt Ultrasonics and sonochemical reactors) and direct sonication. 


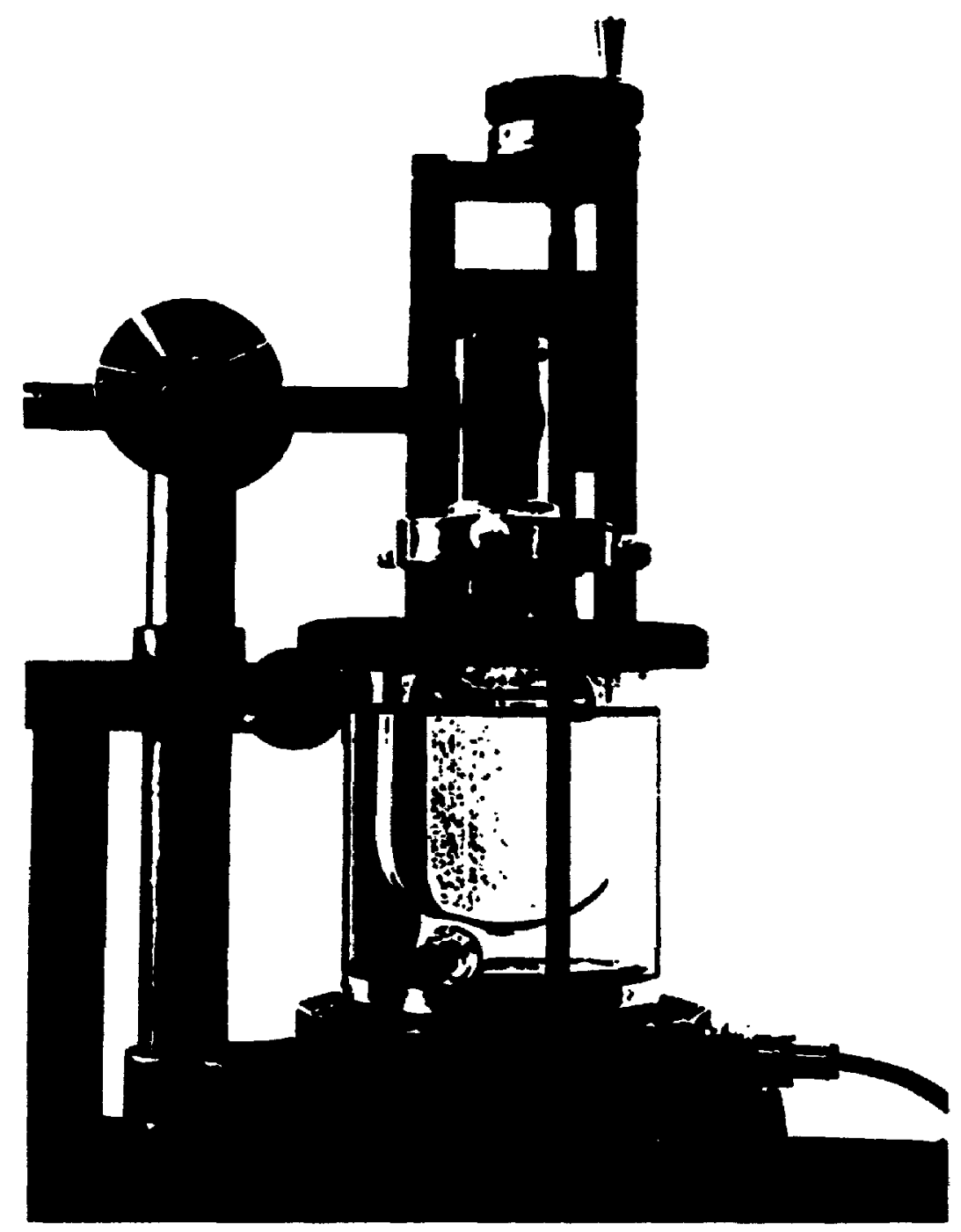

Figure 2.4: Indirect sonication by $900 \mathrm{kHz}$ apparatus. 


\subsection{Measurement of total acoustic power}

The two common methods for measuring the acoustic power are through the use of the radiation force and through calorimetry.

In the radiation force method, the acoustic beam is directed to an absorbing or reflecting target. A microbalance can show the change produced by the radiation force. The following formula shows the relationship between the radiation force and other parameters:

$$
F=D \frac{p}{v}
$$

Here, $p$ is the total acoustic power at the target point, $v$ is the velocity of sound in the medium, and $D$ is a constant depending on the design of the target and the shape of the acoustic field. The measurement of radiation force is rather easy to perform, but microstreaming produced around the target may cause some inaccuracy in the results.

The absolute measurement of acoustic power through calorimetric methods is based on determining the amount of heat produced by ultrasound. In this method, the acoustic beam is directed into an adiabatic chamber (e.g. a Dewar flask) filled with an absorbing liquid. By measuring the temperature rise of the liquid inside the Dewar, the total power can be calculated according to the following formula: 


$$
\text { Power }=m c_{p}\left(\frac{d T}{d t}\right)
$$

where $C_{p}$ is heat capacity of the liquid $\left(\mathrm{J} \mathrm{kg}^{-1} \mathrm{~K}^{-1}\right), m$ is the mass of liquid used $(\mathrm{kg})$, and $d T / d t$ is the temperature rise per second at time zero $\left(\mathrm{K} \mathrm{s}^{-1}\right)$. If this power $(W)$ is dissipated into the system from a probe tip with surface area $A$ $\mathrm{cm}^{2}$, then the intensity of power $\left(\mathrm{W} \mathrm{cm}^{-2}\right)$ produced by the source of ultrasound can be determined.

The use of the calorimetric method for the case of $20 \mathrm{kHz}$ is very easily done by simple immersion of ultrasonic horn into a dewar. Figure 2.5 shows the acoustic power calibration curve for $20 \mathrm{kHz}$. However, it is not possible to measure the acoustic power of $900 \mathrm{kHz}$ by use of a dewar. For this measurement, the thermostat water was evacuated from the sonication cell (Figure 2.2) and then the temperature rise was recorded from inside the sonicated cell. It is clear that the loss of heat during the sonication at $900 \mathrm{kHz}$ is more than from a Dewar at $20 \mathrm{kHz}$ (Figure 2.6).

When the ultrasonic power setting on the generator is constant, the change in the reaction temperature results in a change in the sonochemical reaction rate. It should be emphasized that with changing the temperature the intensity also changes [Mason, 1992]. At a constant power selting, the acoustic power actually measured varies somewhat with temperature. The greatest variation of power with temperature was for the X-large horn: the 


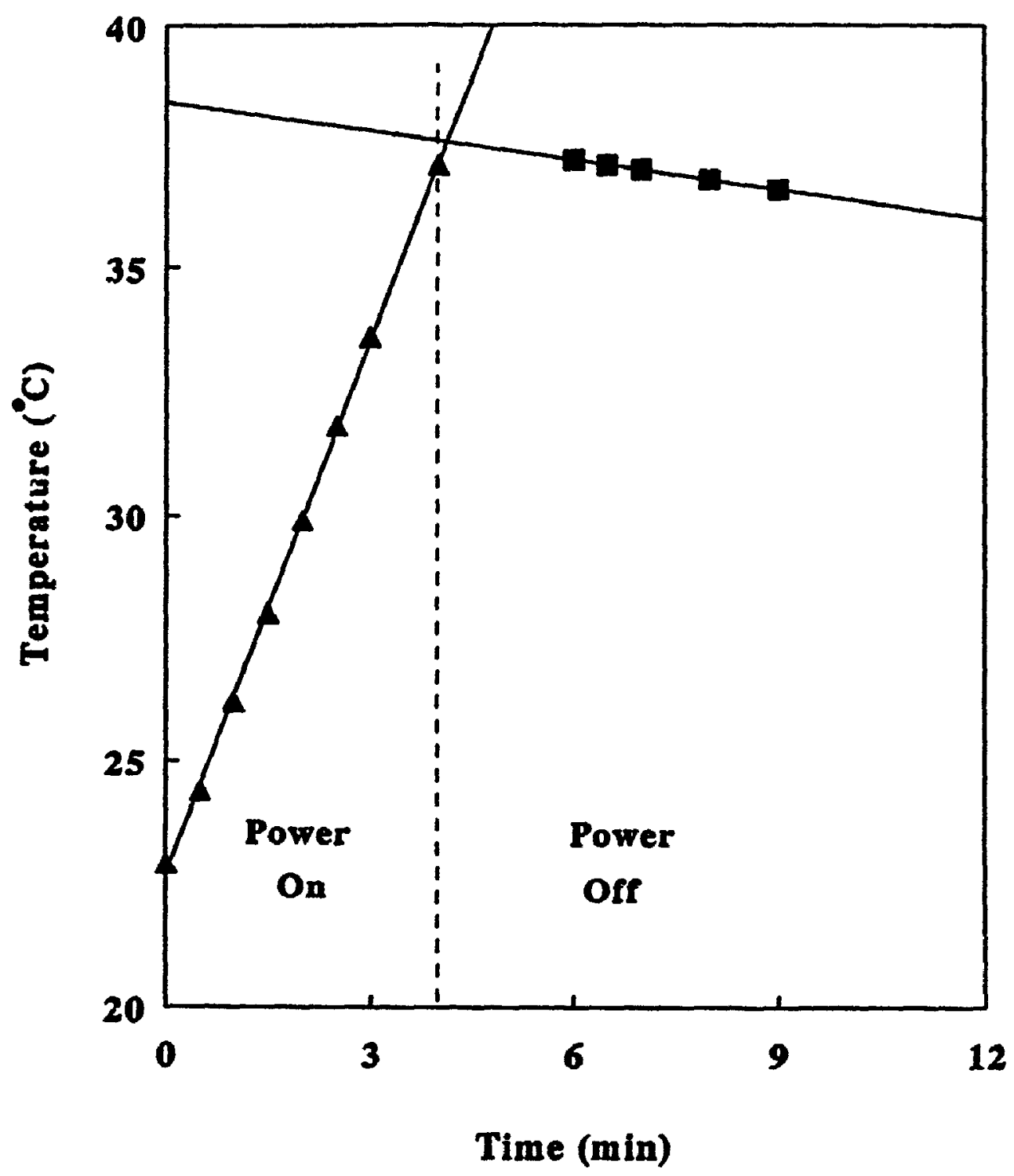

Figure 2.5: Acoustic power calibration curve for $20 \mathrm{kHz}$. 


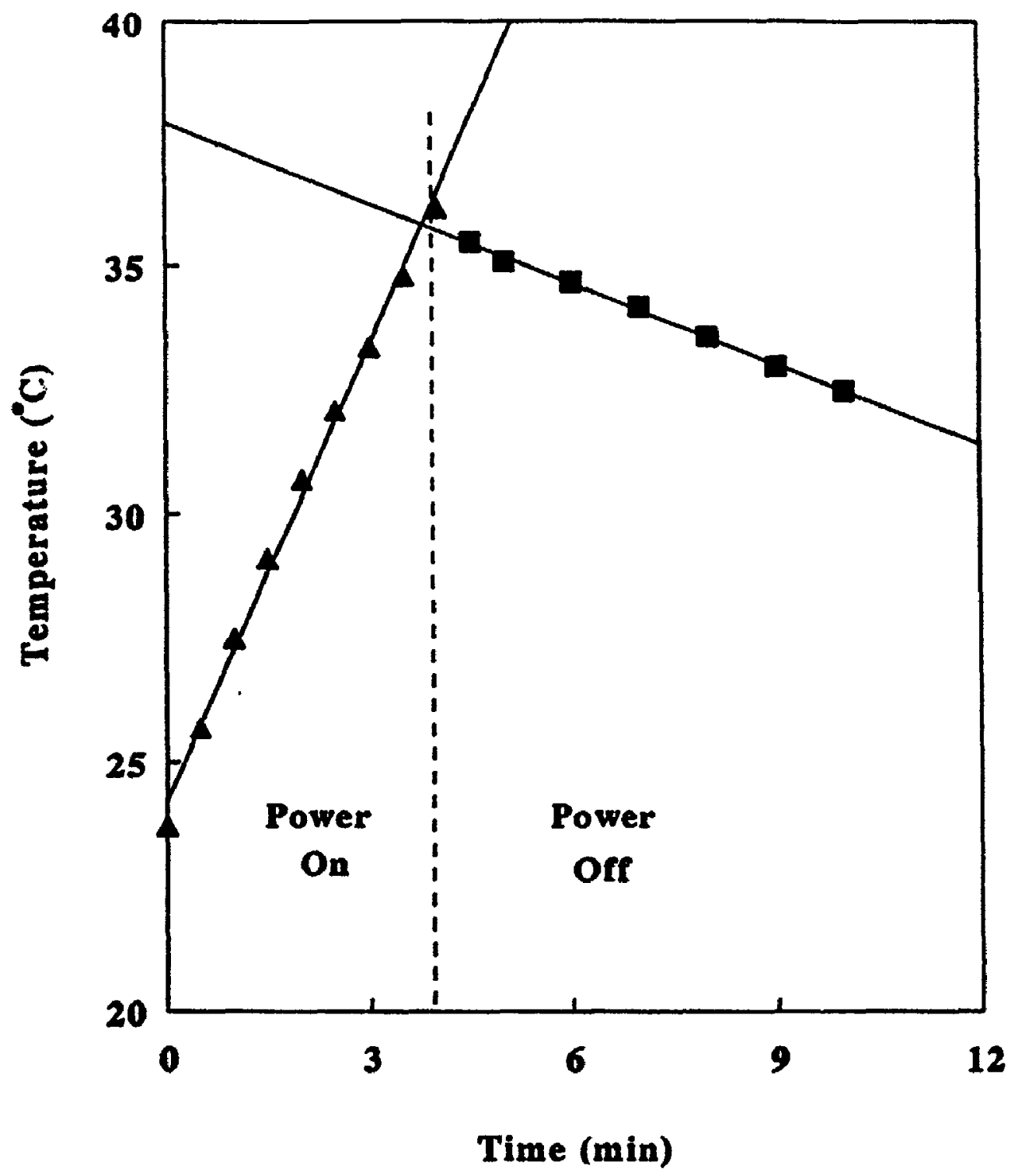

Figure 2.6: Acoustic power calibration curve for $900 \mathrm{kHz}$. 
power is 33 watt at $5^{\circ} \mathrm{C}$ and 34 watt at $50^{\circ} \mathrm{C}$ when it is set to give 42 watt at $25^{\circ} \mathrm{C}$ [Entezari, submitted for publication].

\subsubsection{Power calibration for indirect sonication}

Acoustic power calibration for $900 \mathrm{kHz}$ has been performed previously. Here the sample was sonicated indirectly; it is therefore necessary to determine the actual power which comes into the sample for sonochemical dissociation of carbon disulfide.

This calibration was performed by using the oxidation of potassium iodide. The total acoustic power with the $900 \mathrm{kHz}$ apparatus was measured by calorimetry to be $29 \mathrm{~W}$ at room temperature. This produced $2.35 \mu \mathrm{mol}$ iodine when $50 \mathrm{~mL}$ of iodide solution was directly sonicated for 3 minutes at $298 \mathrm{~K}$. Indirect sonication of a $50 \mathrm{~mL}$ sample in an Eflenmeyer (125 mL) under the same condition produced different amounts of iodine depending on the volume of water used for a coupling medium. With $170 \mathrm{~mL}$ water, $1.40 \mu \mathrm{mol}$ iodine was produced in 3 minutes; with $100 \mathrm{~mL}$ water, $1.63 \mu \mathrm{mol}$; and with $75 \mathrm{~mL}$ water, $1.93 \mu \mathrm{mol}$.

These differences might be due to differences in the mass of sonicated liquid. It means that vibration of larger amount of water is more difficult than smaller one. In another way, in the presence of fluid loading, the applied force encounters the sum of the mechanical impedance of the source and the radiation impedance of the fluid. The mechanical impedance of the sonicator is 
increased by the load of the medium and the radiation impedance is also increased by increasing the mass of the medium [Kinsler, 1982].

It should be mentioned that the position of Enenmeyer with respect to piezo-ceramic transducer was constant in all experiments $(\approx 1 \mathrm{~cm}$ above the transducer). As our experiments were done with about $100 \mathrm{~mL}$ water as a coupling medium, it is possible to conclude that the actual power which came to the sample was about $20 \mathrm{~W}$. This means that around two thirds of the acoustic power was transmitted to the sample. 


\section{CHAPTER 3}

\section{SONOCHEMICAL DISSOCIATION OF WATER}

IN POTASSIUM IODIDE SOLUTION 


\subsection{Introduction}

The major products from the ultrasonic irradiation of water itself are $\mathrm{H}_{2} \mathrm{O}_{2}$ and $H_{2}$. Various data suggest that the initial step is the cleavage of water to form radicals. Various inorganic and organic compounds have been subjected to ultrasonic irradiation either as aqueous solutions or as suspensions in water. Since extremely reactive species $\left(\mathrm{H}^{-}\right.$and $\left.\mathrm{OH}^{\circ}\right)$ formed from the sonolysis of water itself (homolytic cleavage), a wide range of seccndary sonochemistry in aqueous solutions can be expected; this has teen repeatedly observed.

\subsubsection{Sonolysis of aqueous solutions}

The first homogeneous sonochemical experiments showed that reactive species such as $\mathrm{H}^{\circ}, \mathrm{OH}^{\circ}, \mathrm{H}_{2} \mathrm{O}_{2}$ were formed during ultrasonic irradiation of water [Lindstrom, 1951; Del'Duca, 1958; Weissler, 1959; Lippit, 1972]. The first suggestions of the mechanism for this reaction were made already in 1951 by Lindstrom. Riesz and co-workers [1985] were able to observe the highly reactive radicals produced during cavitation by using spin traps. The radicals formed in the sonolysis of water are capable of causing secondary oxidation and reduction reactions, in this case the oxidation of iodide to iodine.

The reactions postulated to take place in such a system are summarized below. The primary reaction is known to be:

$$
\mathrm{H}_{2} \mathrm{O} \cdots \mathrm{H}^{\circ}+\mathrm{OH}^{\circ}
$$


In presence of air, the $\mathrm{O}_{2}$ molecule can act as a scavenger, and:

$$
\mathrm{H}^{\cdot}+\mathrm{O}_{2} \cdots \rightarrow \mathrm{OOH}^{\cdot}
$$

Another radical reaction can take place:

$$
\mathrm{OOH}^{\cdot}+\mathrm{OH}^{\cdot} \cdots \mathrm{H}_{2} \mathrm{O}+\mathrm{O}_{2}
$$

The final reaction observed through visible spectroscopy is:

$$
2 \mathrm{OH}^{-}+3 \mathrm{I}^{-} \cdots \cdots \mathrm{OH}^{-}+\mathrm{I}_{3}^{-}
$$

The hydrogen molecule and hydrogen peroxide are also produced by the sonolysis of aqueous solution. They are formed by the combination of $\mathrm{H}$ atom and $\mathrm{OH}$ radicals respectively. The products, i.e. $\mathrm{H}_{2} \mathrm{O}_{2}$ and $\mathrm{I}_{3}{ }^{-}$, can react in neutral or alkaline solutions:

$$
\mathrm{H}_{2} \mathrm{O}_{2}+\mathrm{I}_{3}^{+}-\cdots \rightarrow 3 \mathrm{I}^{+}+\mathrm{O}_{2}+2 \mathrm{H}^{+}
$$

According to Henglein [1991], the concentration of $\mathrm{H}_{2} \mathrm{O}_{2}$ produced by sonication of $0.200 \mathrm{M}$ aqueous potassium iodide solution is very low. Therefore, the rate of reaction [3-5] should be negligible. 


\subsubsection{Frequency effects}

Lorimer [1990] noted that ultrasound at higher frequencies is attenuated more rapidly than that at lower frequencies. He concluded that this is the reason why most sonochemistry is traditionally performed in the low frequency (20-50 kHz) region. Only a few researchers, e.g. Henglein [1993], have used higher-frequency apparatus for studies of sonochemical reactions.

Cum et al [1992] have investigated the effect of frequency in the range of $20-80 \mathrm{kHz}$ on the oxidation of iodide to iodine. They ascertained that there is an intermediate frequency $(59 \mathrm{kHz})$ which is capable of driving a sonochemical reaction at its maximum rate.

Weissler [1950] has also examined the effect of frequency on the oxidation of iodide in the range of $400-1500 \mathrm{kHz}$. He noted an irregular variation in iodine yield with increasing frequency at constant power input. He attributed this not to an intrinsic frequency sensitivity of the reaction, but rather to variation of the transparency of the test-tube containing the reacting solution with the frequency of the ultrasound used.

The effect of frequency on the rates of sonochemical reactions has thus not been explored carefully in the literature. This work represents the results of experiments where the absolute sonochemical rates at two widely differing frequencies (20 and $900 \mathrm{kHz}$ ) are compared. In order to make an absolute comparison, a new high-frequency ultrasonic apparatus suitable for sonochemistry was designed and constructed. 


\subsection{Experimental procedures}

\subsubsection{Experiments at $20 \mathrm{kHz}$}

In a typical experiment, $150 \mathrm{~mL}$ of aqueous potassium iodide solution $\left(0.2 \mathrm{~mol} L^{-1}\right)$ was poured into a vessel designed specifically for $20 \mathrm{kHz}$ scnication. The vessel was fixed by an adaptor to the horn, so that the position of the cell relative to the hom was exactly reproducible. The vessel was then immersed in the bath and allowed to reach thermal equilibrium. All experiments were done at $30 \pm 3^{\circ} \mathrm{C}$ unless otherwise indicated. This temperature was reached after 5 minutes of sonication. This procedure was used for the data presented in Figures 3.1, 3.2, 3.3, 3.4 and 3.5.

In another series of experiments (other Figures), $100 \mathrm{~mL}$ of aqueous potassium iodide solution $\left(0.2 \mathrm{~mol} \mathrm{~L}^{L^{-1}}\right)$ was poured into a Rosette cell for sonication with $20 \mathrm{kHz}$ using different horn sizes. The position of different horns was the same with respect to the Rosette cell. The runs were done under a normal atmosphere with no gases bubbled through the solution, unless otherwise indicated.

After sonication for a selected time, the intensity of color due to the production of iodine was measured by a Beckman DU-7 spectrophotometer at $355 \mathrm{~nm}$. It should be noted that a new solution was used to obtain data for each point in the iodine vs time graphs (see Figure 3.1). Removing portions of sample changed the volume sufficiently to cause differences. In the examples of the experimental results shown in Figure 3.1, the standard deviations of the 


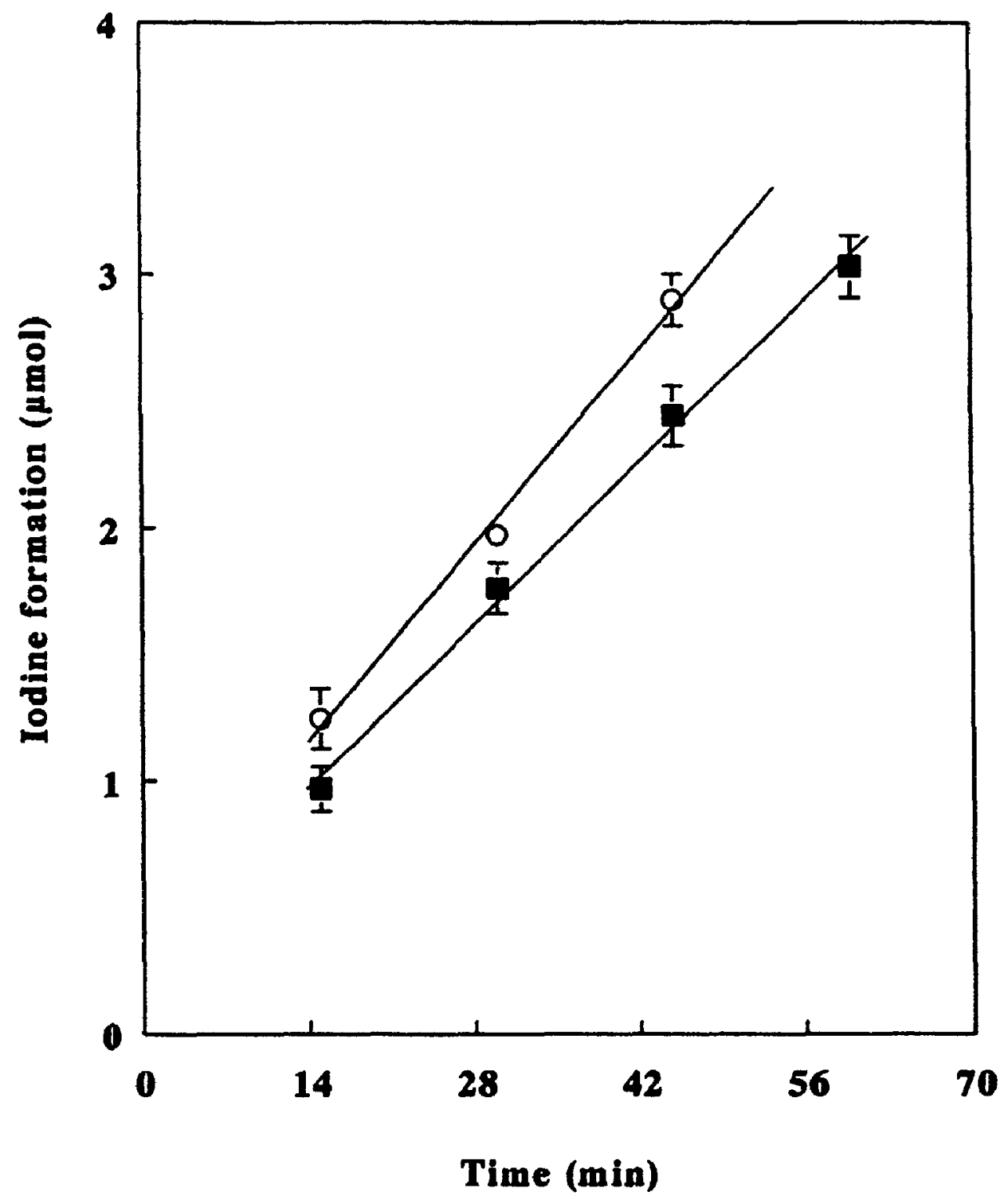

Figure 3.1: Sonication of aqueous solutions of potassium iodide $\left(0.2 \mathrm{~mol} \mathrm{~L}^{-1}\right)$, $303 \mathrm{~K}, 39$ Watt acoustic power, $20 \mathrm{kHz}$. in the presence of air, 0 : in the presence of Ar 
averages of between 3 and 7 determinations of each point are shown.

In some experiments, a gas (e.g. argon) was bubbled into the solution for 15 minutes before sonication through a side-arm mounted on the cell. The solutions were then irradiated.

\subsubsection{Experiments at $900 \mathrm{kHz}$}

The conditions and experimental procedures for $900 \mathrm{kHz}$ were the same as $20 \mathrm{kHz}$, with the solutions irradiated directly as in the case of $20 \mathrm{kHz}$. The sonochemical rate was not sensitive to a change in volume with this frequency. An example of a rate determination is shown in Figure 3.2. Sonication with 900 $\mathrm{kHz}$ was under a normal atmosphere, except for some runs where an argon atmosphere was maintained and others for which degassed solutions were used. In order to improve the temperature control in the reaction solution, a coiled glass tube was immersed in it. Water from the thermostat was directed through this tube.

Each rate was obtained from the slope of a plot of absorption at $355 \mathrm{~nm}$ vs time using four or five data points. The reproducibility of the rate data was generally better than $5 \%$. Limits of uncertainty are shown in the figures for data with greater imprecision. During a rate determination, the temperature varied somewhat depending on the acoustic power. At low power, it was $\pm 1{ }^{\circ} \mathrm{C}$ during a run, while at the highest power it could vary up to $\pm 10^{\circ} \mathrm{C}$.

The behaviour of the solutions during sonication differs markedly at 900 


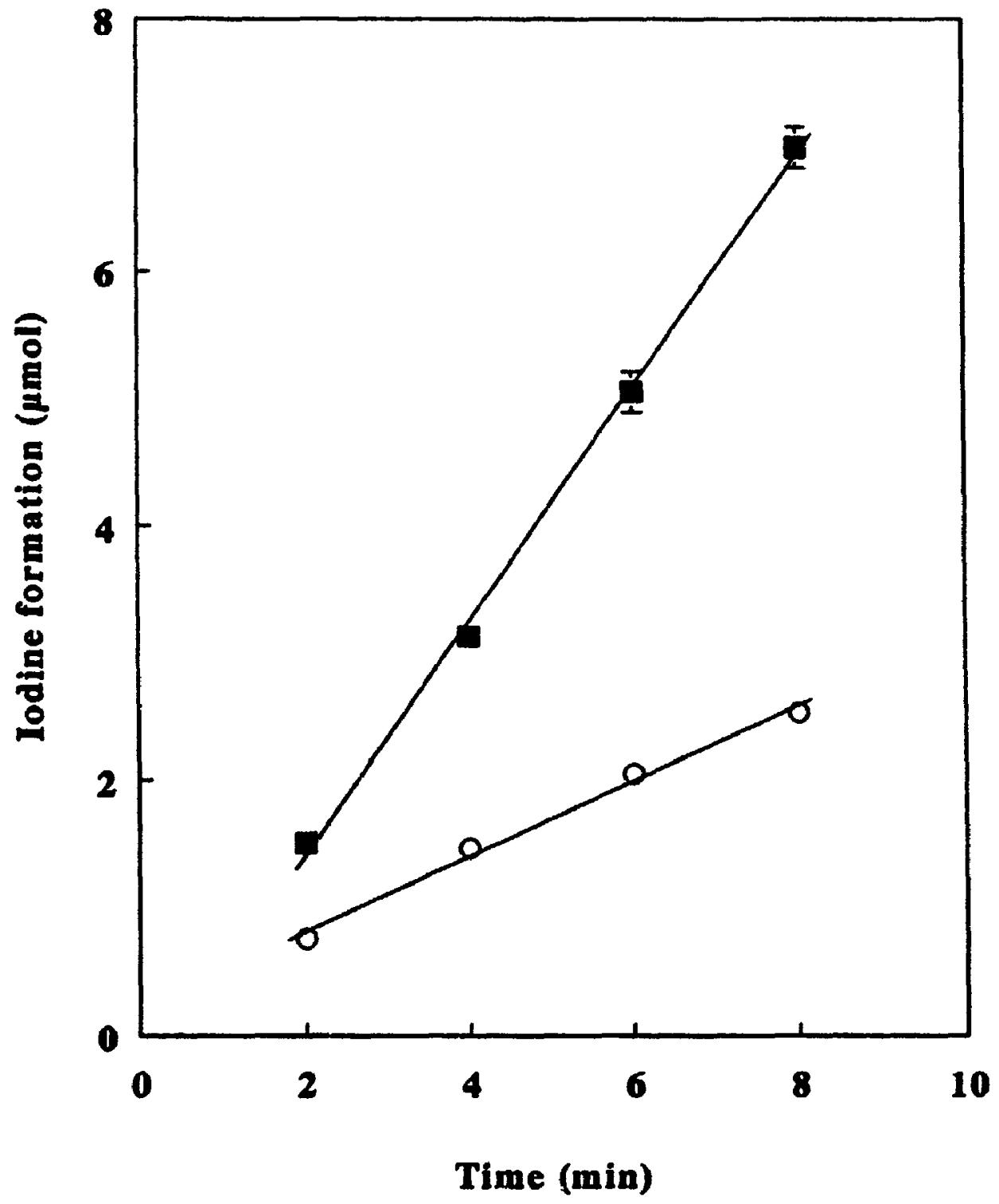

Figure 3.2: Sonication of aqueous solutions of potassium iodide $\left(0.2 \mathrm{~mol} \mathrm{~L}^{-1}\right)$, $303 \mathrm{~K}, 25$ Watt acoustic power, $900 \mathrm{kHz}$. presence of Ar 
kHz. There is no cavitation noise to be heard; at $20 \mathrm{kHz}$, this could be very harsh and irritating to the ears even with ear protection. Any cavitation bubbles that were visible were also much smaller, and very few migrated to the top of the solution to leave it.

\subsection{Resulte and discussion}

\subsubsection{Primary experimental data}

The types of primary data obtained are shown in Figures 3.1 and 3.2. Each point in these graphs is the average of at least 3 determinations. Note that in all cases for $20 \mathrm{kHz}$, only one point was taken per run, as the results were sensitive to any variation of solution volume. The geometry was kept the same for all runs, as data also varied with position of the ultrasound source relative to the reaction vessel.

The results obtained for the oxidation of iodide to iodine under argon or air by ultrasonic sonication at two different frequencies are summarized in Table 3.1. These data are derived from the graphs shown in Figures 3.1 and 3.2.

Figure 3.3 emphasizes the large frequency effect possible in the rate of sonochemical oxidation of aqueous iodide in the presence of air (experiments 1 and 2 in Table 3.1). 


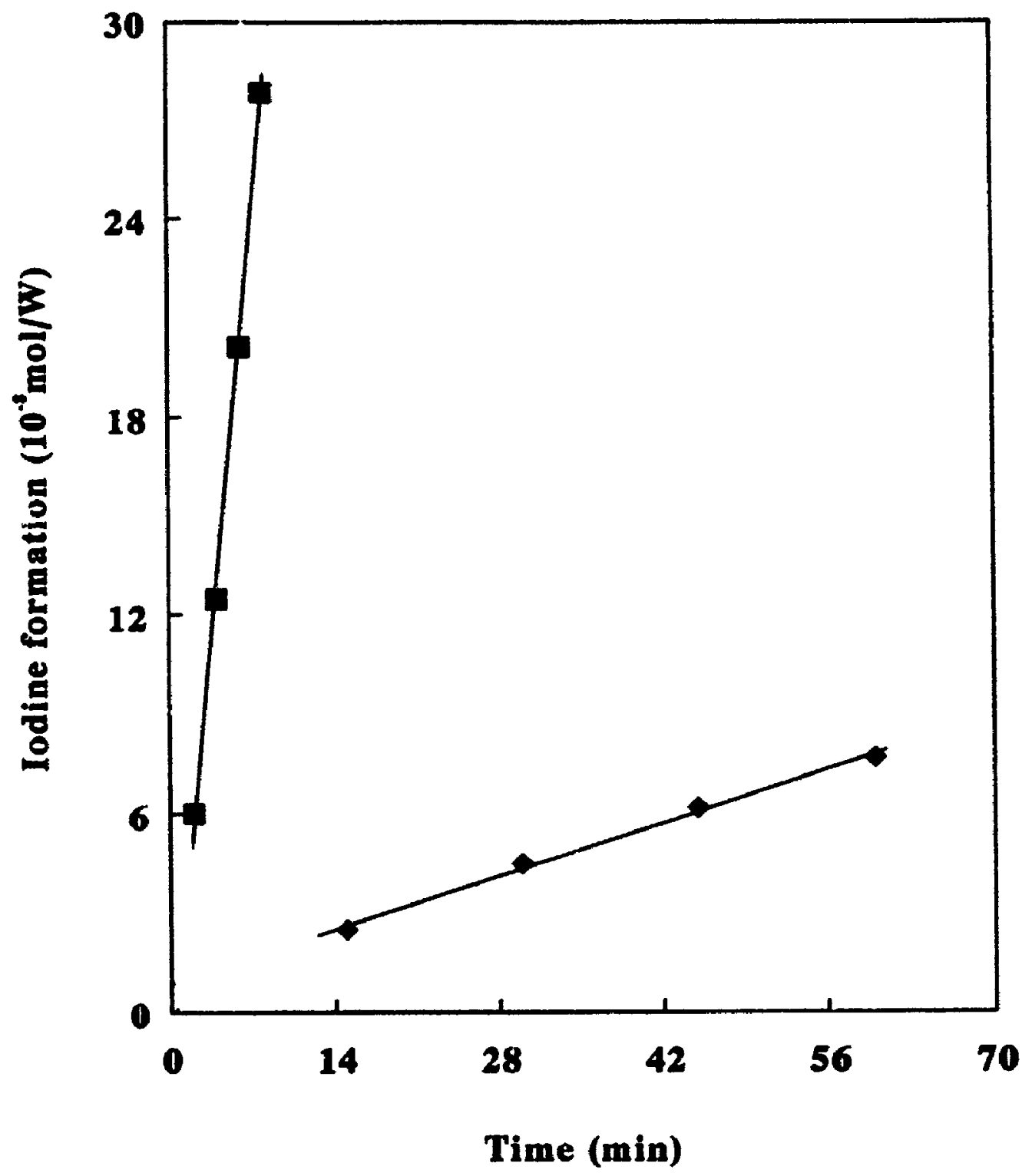

Figure 3.3: Effect of frequency on the sonochemical oxidation of iodide in the presence of air. :900 kHz, $\quad: 20 \mathrm{kHz}$ 
Table 3.1: The rate is in units of $10^{8} \mathrm{~mol}_{2} h^{-1} W^{\prime}$.

\begin{tabular}{|c|c|c|c|c|}
\hline Exp. No. & $v / \mathrm{kHz}$ & Gas & Rate & Ratio \\
\hline 1 & 20 & air & $7.1 \pm 0.5$ & $2: 1=31$ \\
\hline 2 & 900 & air & $219 . \pm 7$ & $2: 4=3.1$ \\
\hline 3 & 20 & $\mathrm{Ar}$ & $8.1 \pm 0.5$ & $1: 3=0.9$ \\
\hline 4 & 900 & $\mathrm{Ar}$ & $70 . \pm 0.8$ & $4: 3=8.6$ \\
\hline
\end{tabular}

\subsubsection{Basic considerations}

Several factors are likely to be influential in

determining the effectiveness of cavitation produced by ultrasound in promoting chemical reactions.

It is visually apparent that the size of the cavitation bubbles are different at the two frequencies. The cavitation bubbles whose collapse causes the initiating reaction [3-1] will be of varying sizes. Their radii are however likely to be of the order of the radius of a bubble resonant in the applied acoustic field (Equation 1-12). For $20 \mathrm{kHz}, R_{r}$ at $300 \mathrm{~K}$ in water is $164 \mu \mathrm{m}$, while for $900 \mathrm{kHz}$ it is $3.6 \mu \mathrm{m}$. There is thus a vast difference in the sizes of the cavitation bubbles present at $20 \mathrm{kHz}$ as compared to $900 \mathrm{kHz}$.

The rate of heat transport out of a bubble is dependent on the surface area, i.e. larger $(20 \mathrm{kHz})$ bubbles would lose energy at a greater rate. The rate that the temperature drops is however dependent on the surface to volume ratio. As this ratio varies as the reciprocal of the radius, the smaller $900 \mathrm{kHz}$ bubbles should cool more rapidly than the larger $20 \mathrm{kHz}$ bubbles after being 
heated during compression.

The temperatures reached and maintained in cavitation bubbles also depend on temporal characteristics, as well as the spatial aspects discussed above. Some of these characteristics are summarized in Table 3.2. It is obvious that the rate of contraction and expansion of a bubble in a $900 \mathrm{kHz}$ acoustic field is much greater than at $20 \mathrm{kHz}$ (Table 3.2).

The collapse time for the cavitation bubbles can be calculated from equation [1-8], and the collapse pressure is the sum of the hydrostatic and the acoustic pressure. The values used are given in Table 3.2.

The collapse time calculated from [1-8] for $900 \mathrm{kHz}$ bubbles is less than for $20 \mathrm{kHz}$, but by a ratio of 23 , rather than 45 , the ratio of frequencies. The collapse is primarily inertia-driven, and is not affected to any great extent by the acoustic pressure variations present. The time available for transport of heat out of the collapsing bubble is thus about 20 times more for a $20 \mathrm{kHz}$ cavity compared to one at $900 \mathrm{kHz}$. The calculated collapse times as shown in Table 3.2 are of the order of microseconds. However, collapse times of the order of picoseconds have been reported in the literature [Barber, 1991].

Table 3.2: Comparison of temporal and spatial characteristics of cavitation bubbles with frequency in water at $300 \mathrm{~K}$.

\begin{tabular}{||c|c|c|c|c|}
\hline \hline$/ \mathrm{kHz}$ & $\begin{array}{l}\text { Period time } \\
/ \mu \mathrm{s}\end{array}$ & $\begin{array}{l}\text { p(collapse) } \\
/ \mathrm{atm}\end{array}$ & $\begin{array}{l}t(\text { collapse) } \\
/ \mu \mathrm{s}\end{array}$ & $\mathrm{R}_{\mathrm{r}} / \mu \mathrm{m}$ \\
\hline 20 & 50 & 11.2 & 4.5 & 164 \\
\hline 900 & 1.1 & 2.9 & 0.19 & 3.6 \\
\hline
\end{tabular}


The difference in the noisc caused by collapse of the cavitation bubbles is very noticeable. There is essentially no noise in the audible range with 900 $\mathrm{kHz}$ irradiation, while the noise with $20 \mathrm{kHz}$ is loud, harsh and irritating. This suggests that the nature of the cavitation may have considerable differences. It may be that there is more transient cavitation occurring at $20 \mathrm{kHz}$, and more stable cavitation at $900 \mathrm{kHz}$.

In the case of this reaction, resonant (stable) cavitation might not produce temperatures high enough to cause significant dissociation of the water molecules. The temperatures reached can be described in an idealized system according to the equation [1-11]. It has been shown that resonant cavitation can give rise to temperatures of $1,800 \mathrm{~K}$ [Saksena, 1970]. This is still rather small as compared to the "characteristic temperature" (bond energy/R) of $60,000 \mathrm{~K}$ for the breaking of an $\mathrm{O}-\mathrm{H}$ bond $\left(498 \mathrm{~kJ} \mathrm{~mol}^{-1}\right)$.

A transient collapse can cause temperatures in the cavities of the order of $5,000 \mathrm{~K}$ and the surrounding liquid of the order of $2,100 \mathrm{~K}$ [Suslick, 1986]. The factor exp $\{$-(bond energy)/RT\} that can be achieved at $5,000 \mathrm{~K}$ is thus of the order of $6 \times 10^{-5}$, i.e. a significant fraction of the molecules would have sufficient energy for dissociation.

\subsubsection{Variation with power}

The variation of the rate with acoustic power is shown in Figure 3.4. In the case of the $900 \mathrm{kHz}$, the rate is linear with power in the range available 


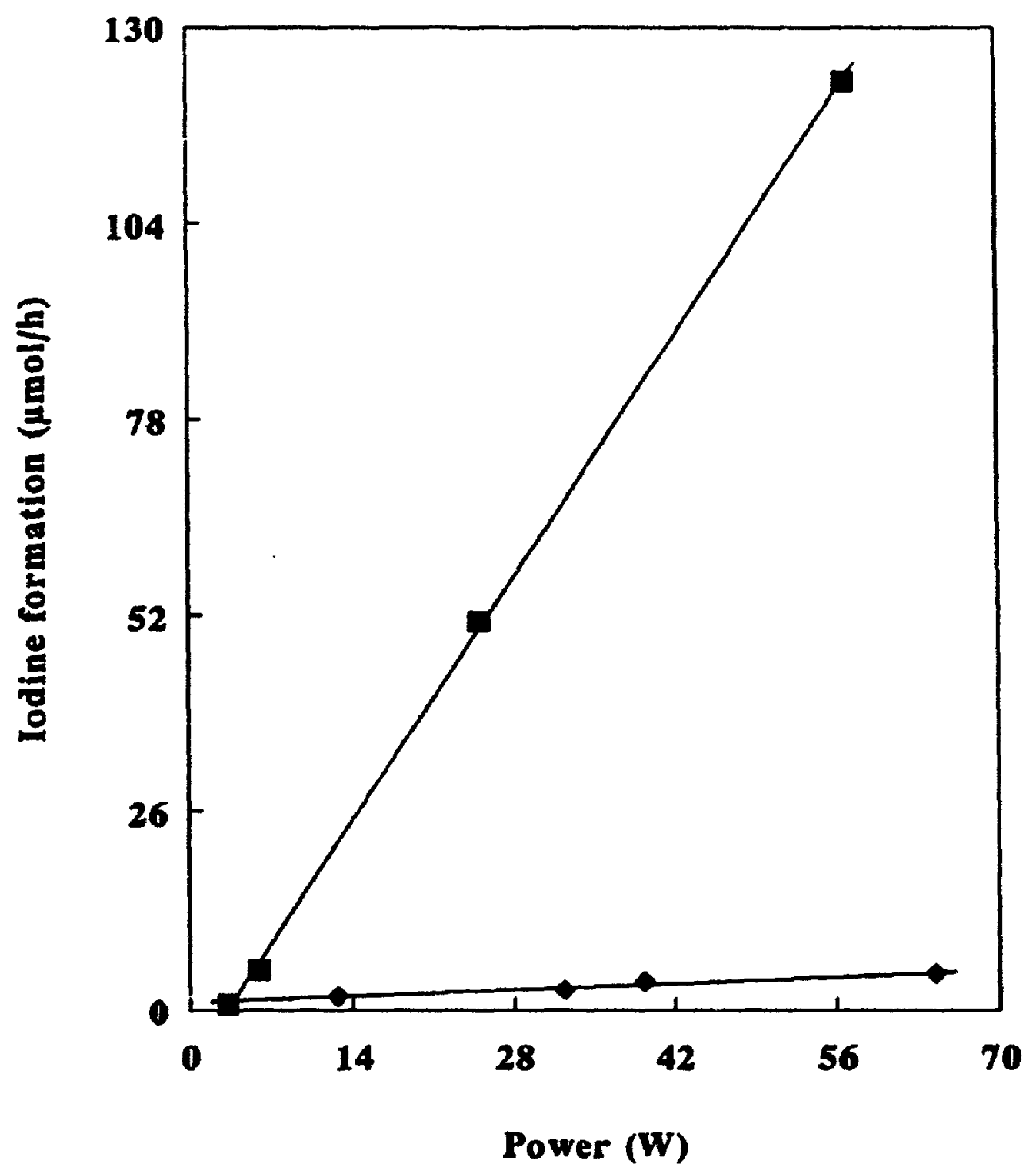

Figure 3.4: Variation of sonochemical rates with acoustic power. Aqueous potassium iodide $\left(0.2 \mathrm{~mol} \mathrm{~L}^{-1}\right), 303 \pm 6 \mathrm{~K},-: 900 \mathrm{KHz},: 20 \mathrm{kHz}$. 
experimentally, and there is a clear cavitation threshold at 3 watt

$\left(0.14\right.$ watt $\left.\mathrm{cm}^{-2}\right)$. Most experiments were done with a power of 25 watt, corresponding to 1.2 watt $\mathrm{cm}^{-2}$. In the case of $20 \mathrm{kHz}$, there are traces of cavitation on parts of the surfaces of the $20 \mathrm{kHz}$ tip even at the lowest possible settings, so that a clear cavitation threshold is not evident.

It is evident from Figure 3.5 that the variation of the rate at $20 \mathrm{kHz}$ is not linear with power. At higher power, the reaction rate per unit power drops off, most likely because a large fraction of the visible bubbles migrate out of the solution. Many bubbles can be seen close to the transducer tip. These must interfere with the introduction of ultrasound into the liquid. This is a possible explanation of the "saturation" of the sonochemical effect at higher powers. A small part of the nonlinearity is probably due to a variation in solution temperature with power.

The tip used in most experiments had a surface area of $1.1 \mathrm{~cm}^{2}$, so that at a power of 39 wait, there was 36 watt $\mathrm{cm}^{-2}$. It is obviously necessary to investigate the effect of power density (intensity) rather than power alone by using ultrasonic sources with different area. The areas were 1.1 and $21 \mathrm{~cm}^{2}$ for the 20 and $900 \mathrm{kHz}$ apparatus respectively. It is possible that there is a dependence of the rate on power density as well as on total power. As showin in the following, for the reaction studied here, sonolysis seems to be more effective at lower power densities, with total power kept constant.

The variation of the reaction rate with acoustic power at $20 \mathrm{kHz}$ is shown 


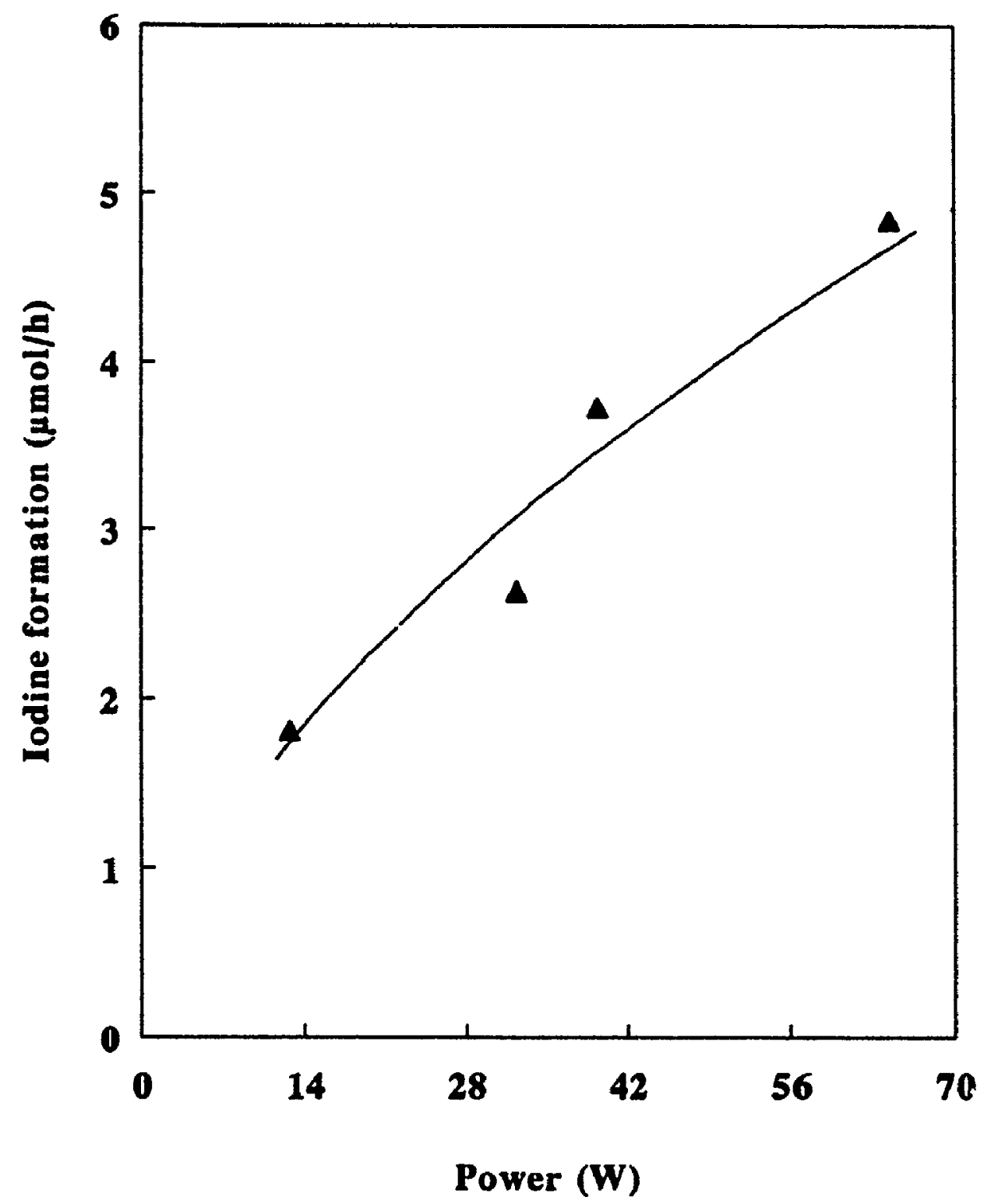

Figure 3.5: Variation of sonochemical rates with acoustic power at $20 \mathrm{kHz}$ (Fig. 3.4) on an enlarged scale. 
in Figure 3.6 for the three tip sizes available. It is evident that the variation is not linear with power. The non-linearity of the rate vs power relation decreases with increase in the tip size, i.e. decrease in the intensity.

\subsubsection{Effect of tip size (intensity)}

Table 3.3 summarizes the effect of tip size on the rate of iodide oxidation. According to this table the rate is greatest with the X-large tip, i.e. with the lowest intensity. This table gives data for cases when the power is of the order of $\mathbf{4 0}$ watt. The generality of the dependence of the rate with tip size can be seen in Figures 3.6 and 3.7. The data in Figure 3.7 was obtained with power settings which gave $\mathbf{4 2}$ watt at room temperature. A correction for this power variation is shown for the $\mathrm{X}$-large horn (Figure 3.7). As seen in Figure 3.6, the sonochemical rate varies essentially linearly with power for that horn, so that such a correction is reasonably easy to make.

In the case of the $900 \mathrm{kHz}$, the rate is linear with power in the range available experimentally (Figure 3.8). There is also a clear cavitation threshold at 8 watt $\left(0.37\right.$ watt $\left.\mathrm{cm}^{-2}\right)$ at $5^{\circ} \mathrm{C}$.

Figure 3.6 also shows that the curves become increasingly linear with increasing hom tip area. With $900 \mathrm{kHz}$ the irradiation area is larger, giving an even lower intensity. As can be seen in Figure 3.8, the rate is linear with power.

The reasons for these results must be related to the cavitation bubble 


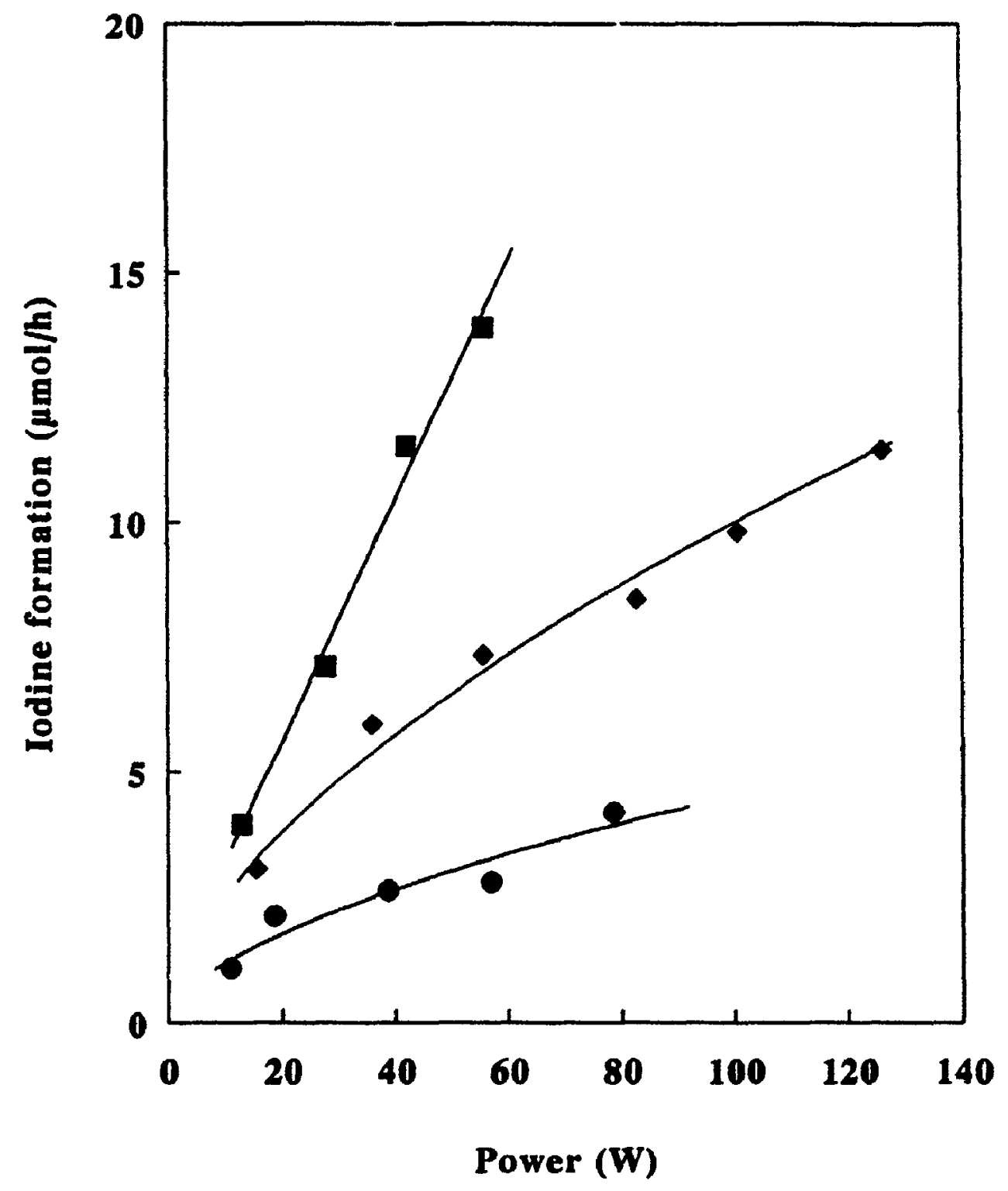

Figure 3.6: Variation of the rate of sonochemical oxidation of iodide vs power at $20 \pm 5^{\circ} \mathrm{C}$ with different horns. Each point is the average of at least two independent determinations, with an estimated reproducibility of $\pm 3 \%$. - small tip $\left(1.10 \mathrm{~cm}^{2}\right) ; \bullet$ medium tip $\left(2.46 \mathrm{~cm}^{2}\right) ; \backsim$ X-large tip $\left(8.04 \mathrm{~cm}^{2}\right)$. 
Table 3.3: The variation of the sonochemical reaction rate (in $\left.\mu \mathrm{mol} h^{-1}\right)$ at 20 $\mathrm{kHz}$ at $5 \pm 3^{\circ} \mathrm{C}$ with different horns.

\begin{tabular}{|c|c|c|c|c|}
\hline Tip type & $\begin{array}{r}\text { Size } \\
\mathrm{cm}^{2} \\
\end{array}$ & $\begin{array}{c}\text { Power } \\
\text { W }\end{array}$ & $\begin{array}{l}\text { Intensity } \\
\mathrm{W} \mathrm{cm}^{-2}\end{array}$ & $\begin{array}{c}\text { Rate } \\
\mu \mathrm{mol} \mathrm{h} h^{-1}\end{array}$ \\
\hline Small & 1.10 & 38. & 34. & 2.7 \\
\hline Medium & 2.46 & 37. & 15. & 7.1 \\
\hline$X$-large & 8.04 & 36. & 4.5 & 12.7 \\
\hline
\end{tabular}




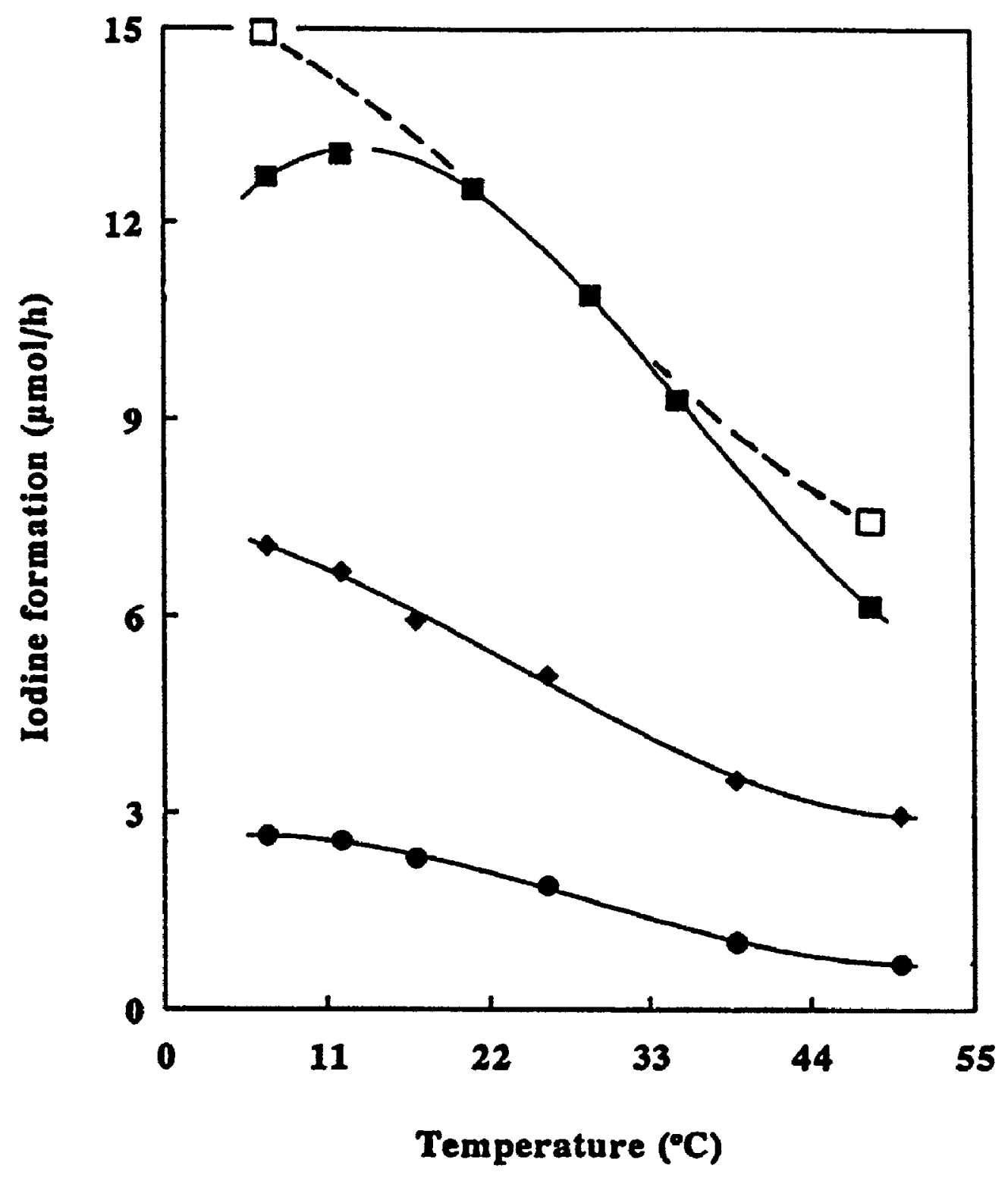

Figure 3.7: Variation of the rate of sonochemical oxidation of iodide vs temperature at $20 \mathrm{kHz}$ with different hom tips. - small tip $\left(1.10 \mathrm{~cm}^{2}\right)$; medium tip (2.46 $\left.\mathrm{cm}^{2}\right) ; \quad X$-large tip $\left(8.04 \mathrm{~cm}^{2}\right)$. The power was in each case set to be $42 \pm 2 W$ at room temperature. It was however as much as $20 \%$ less at the lowest and highest temperatures. A correction for this power variation is shown for the $X$-large tip - 0 -. . Each point is the average of at least two independent determinations, with an estimated reprcducibility of $\pm 3 \%$. 


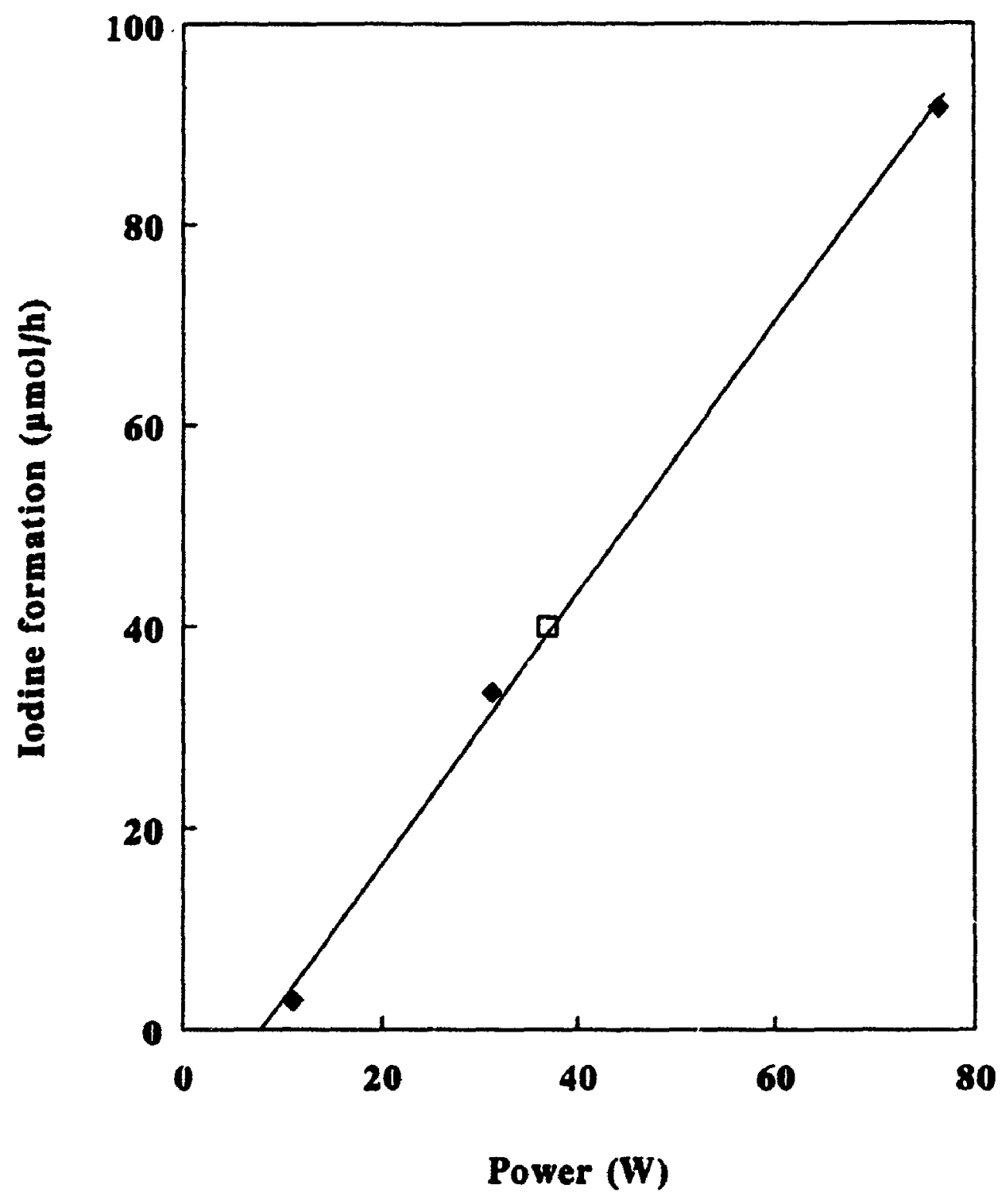

Figure 3.8: Variation of the rate of sonochemical oxidation of iodide with power under $900 \mathrm{kHz}$ irradiation at $5^{\circ} \mathrm{C}$, where the $20 \mathrm{kHz}$ effect is greatest. are points from the experimental data in Fig. 3.10; shows the rate at the same power and temperature with $20 \mathrm{kHz}$ irradiation using the X-large tip. 
field which appears under the tip of the $20 \mathrm{kHz}$ homs. It can be seen to differ markedly with the tip area (Figure 3.9).

The number of cavitation bubbles (i.e. reaction sites) present is important in the efficiency of the reaction. A larger horn produces more bubbles since it can contact a larger surface area of liquid. It therefore also irradiates a larger volume of liquid.

Bubble interaction is also important in affecting the rate of the reaction. In the case of a larger hom, the collision probability of bubbles is lower, leading to a lower probability of combination of bubbles, forming larger bubble which float away to the surface of the liquid. Such large bubbles do not contribute to chemical activity. When a larger hom is used, the irradiated volume of liquid thus loses fewer chemically ineffective bubbles during sonication.

As can be seen in Figure 3.10, at very high intensities, the application of more power may be counterproductive. There are so many large cavities under the tip that the contact between tip and liquid is poorer, and the acoustic energy is dissipated to a greater extent into heating the hom.

Intensity is a very important factor. As indicated, irradiation at two different intensities can give completely different results.

\subsubsection{Variation with gas}

The oxidation of potassium iodide in : queous solution is 1.1 times greater with argon than with air at $20 \mathrm{kHz}$ (see Table 3.1). This can be 


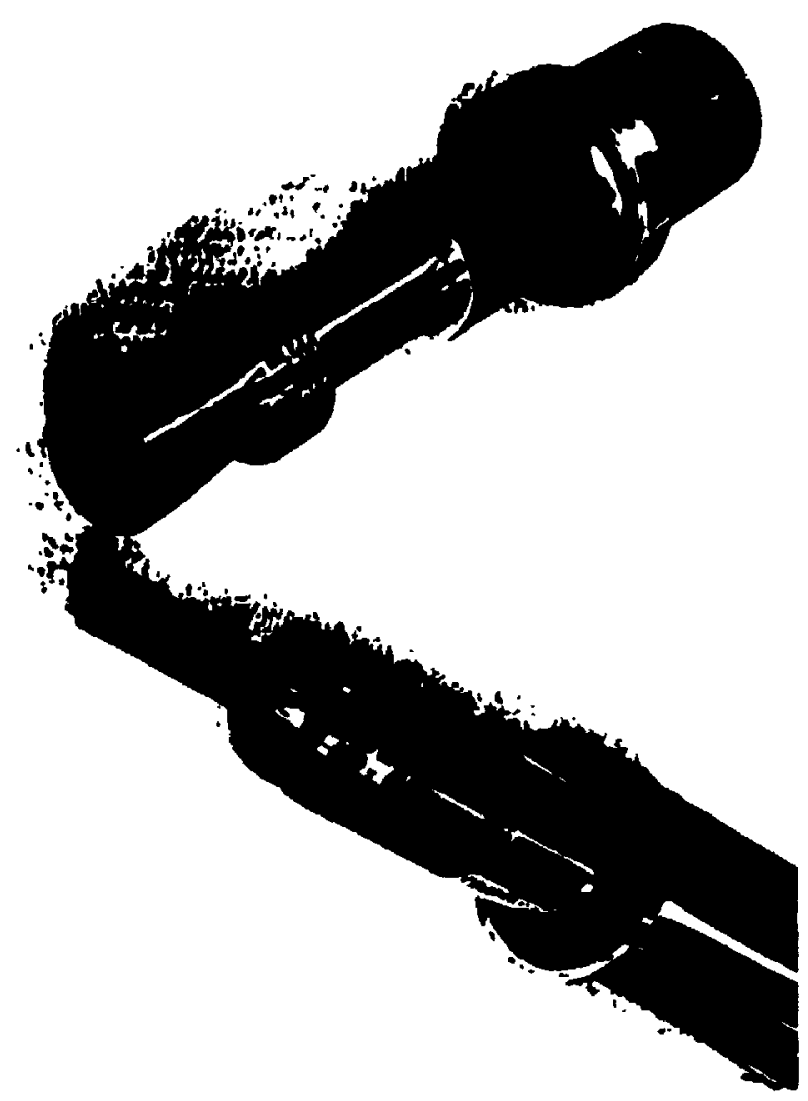

Figure 3.9: A picture of the two horns with different tip size (20 $\mathrm{kHz})$. 
explained through the greater heat capacity ratio for argon as compared to air, together with the greater heat conductivity of air as compared to argon. The implosion of bubbles with argon produces a higher temperature [Equation 1-11], and this thermal energy is dissipated more slowly. Table 3.1 also shows that the rate of oxidation is smaller by a factor of 0.3 with argon compared to air with $900 \mathrm{kHz}$.

Table 3.4 also shows the change in the sonochemical rate under different conditions of gas. The reaction rates with argon present are definitely lower at $900 \mathrm{kHz}$. The data in Table 3.4 also includes the results for solutions which were degassed by freeze-pump-thaw cycles. The rate with $900 \mathrm{kHz}$ irradiation in a solution made up with water which had been boiled for $10 \mathrm{~min}$ and subsequently cooled was also $62 \mu \mathrm{mol} \mathrm{h}{ }^{-1}$.

It was not possible to measure the actual gas content in such "degassed" solutions. Some authors have reported that they still contain considerable amounts of gases after the degassing procedure [Pickworth, 1988].

Table 3.4: Variation of the sonochemical reaction rate $\left(\mu \mathrm{mol} \mathrm{h}^{-1}\right)$ with $20 \mathrm{kHz}(X$ large tip, $70 \mathrm{~W}$ ) and $900 \mathrm{kHz}(76 \mathrm{~W}$ ) irradiation with different gas conditions. The degassing was done through three freeze-pump-thaw cycles. (B) indicates bubbling for 20 min before sonication; (B\&D) indicates bubbling before and during sonication. The data are the averages of at least two determinations.

\begin{tabular}{|l|l|l|l|l|}
\hline Frequency & \multicolumn{1}{|c|}{ Air } & Degassed & Argon (B) & Argon(B\&D) \\
\hline $900 \mathrm{kHz}$ & $92 . \pm 1$. & $62 . \pm 2$. & $20 . \pm 2$. & $32 . \pm 0.5$ \\
\hline $20 \mathrm{kHz}$ & 14. & 9.5 & $47 . \pm 0.6$ & 46. \\
\hline
\end{tabular}


With $20 \mathrm{kHz}$ irradiation, the reaction rate in a degassed solution is lower than in an aerated solution. However, the rate with argon present is greater than with air, and independent of whether there is continuous introduction of argon. The nature of the gas present does therefore affect the reaction rate, and any degassing during ultrasonic irradiation does not seem to be significant.

The gas affects the ratio of specific heats and the thermal conductivity of the bubble contents. When $\mathrm{O}_{2}$ is present, then it can also participate in the reactions that can occur inside the cavitation bubble.

As can be seen in Table 3.4, the order of the rate with $20 \mathrm{kHz}$ is: argon $>$ air > degassed, while with $900 \mathrm{kHz}$ it is air > degassed > argon. This difference between the 20 and $900 \mathrm{kHz}$ results can be explained according to the radical reactions proposed by Petrier [1992]. The collapse time of bubbles in a $900 \mathrm{kHz}$ acoustic field is shorter than with $20 \mathrm{kHz}$. In the presence of air, reaction [3-2] reduces the back reaction of reaction [3-1]. Therefore the concentration of hydroxyl radicals is greater with air than with argon. We can conclude that the rate of oxidation with air is greater than with argon with 900 $\mathbf{k H z}$. But in the case of $20 \mathrm{kHz}$, the collapse time of bubbles is enough for reaction [3-3] to occur. This reaction reduces the concentration of hydroxyl radicals; therefore the rate of oxidation with air will be lower than with argon at $20 \mathrm{kHz}$. One of these possible secondary reactions was the scavenging of $\mathrm{H}^{*}$ with $\mathrm{O}_{2}$ to form $\mathrm{OOH}$.

A considerable amount of gas may be left in the degassed solutions 
[Pickworth, 1988], so that there is still likely to be some $\mathrm{O}_{2}$ available for the above scavenging reaction. The rate in a degassed solution would thus be expected to be intermediate between the argon and the air, as is the case with $900 \mathrm{kHz}$.

The low rate of reaction in degassed solutions using $20 \mathrm{kHz}$ ultrasound also might be due to a fewer nucleation sites.

\subsubsection{Variation of sonochemical rate with frequency}

In the new $900 \mathrm{kHz}$ apparatus, the rate of oxidation was much faster (more than 30 times) than in the $20 \mathrm{kHz}$ apparatus (see Table 3.1 and Figure 3.3).

It was thought that the increased rate may be related to the standing waves which may form from the reflection of the ultrasound from the solution surface. This was examined by placing a plate on the surface and varying its position using a micrometer by amounts less than the wavelength of $900 \mathrm{kHz}$ ultrasound in water $(1.7 \mathrm{~mm})$. The results showed that standing wave can not be a reason for this increase in the oxidation rate.

The tip area of ultrasonic irradiator is another pararneter which certainly has an effect on the rate of reaction. We tried to provide the same conditions for both apparatuses (20 and $900 \mathrm{kHz}$ ), but there was an intrinsic difference between them, the surface area of ultrasonic irradiator. The surface area for $900 \mathrm{kHz}$ was $21 \mathrm{~cm}^{2}$ and for $20 \mathrm{kHz}$ at most $8.04 \mathrm{~cm}^{2}$. Even when the total 
power was the same, the power per surface area (intensity) was considerably different.

Figure 3.8 (p. 70) shows the rate of oxidation versus acoustic power with $900 \mathrm{kHz}$ under the same conditions as with $20 \mathrm{kHz}$. It is possible to interpolate to the rate for a power of $37 \mathrm{~W}$, for which data with $20 \mathrm{kHz}$ irradiation is available in Table 3.3. The rate is $40 \mu \mathrm{mol} \mathrm{h}$. Extrapolation of the data in Table 3.3 to a tip size of $21 \mathrm{~cm}^{2}$ gives a rate of between 20 to $30 \mu \mathrm{mol} \mathrm{h}^{-1}$, depending on the type of extrapolation (linear or polynomial).

With this method we can estimate the rate of oxidation of iodide with 20 $\mathrm{kHz}$ with a tip area equal to the $900 \mathrm{kHz}$ apparatus. Comparison the results shows that the real effect of frequency on the oxidation rate is 1.3 to 2 times greater with $900 \mathrm{kHz}$ than with $20 \mathrm{kHz}$.

Why is the sonochemical reaction rate greater at $900 \mathrm{kHz}$ than at 20 $\mathrm{kHz}$ ? Some reasons for this may be the following:

The transformation of acoustic energy to thermal energy in the regions of chemical activity may be more efficient in the $900 \mathrm{kHz}$ apparatus. It is obvious that less energy is being lost at $900 \mathrm{kHz}$ through large bubbles floating to the top, as observed in the $20 \mathrm{kHz}$ apparatus. There may be many more cavitation bubbles ("mini-reactors") of appropriate size at $900 \mathrm{kHz}$.

It is in this case unlikely that the resonant cavitation which seems to be more prominent at $900 \mathrm{kHz}$ may be more effective in dissociating the water molecules. Resonant cavitation is more effective for the initiation of 
polymerization [Kruus, 1991], but this is only because transient cavitation produces "hot spots" which have such a high temperature that undesirable pyrolysis reactions occur. In the oxidation of iodide, the only initial reaction possible is the dissociation of water.

In addition, the temperature variation is definitely dependent on the irradiation frequency. The reason for this dependence is however not readily explained. It may be due to the spatial and temporal characteristics of the cavitation processes occurring at the two frequencies. For constant power, a larger irradiation surface (lower intensity) and a higher frequency provide more cavitation bubbles which act as "mini-reactors".

\subsubsection{Variation with temperature}

The sonochemical reaction rate of oxidation of iodide was measured at different temperatures $\left(0-50^{\circ} \mathrm{C}\right)$ with different ultrasonic horns at low frequency (20 $\mathrm{kHz})$, and with high frequency $(900 \mathrm{kHz})$ apparatus.

Figure 3.10 shows the results with $20 \mathrm{kHz}$ irradiation using the X-large tip hom. As the temperature of the solution is increased, the reaction rate generally decreases. The shape of the rate vs temperature relation is however dependent on the power.

At sufficiently high power, there is no further increase in the reaction rate with power. This is in agreement both with other sonochemical reactions such as the initiation of polymerization [Patraboy, 1985], and with evidence from 

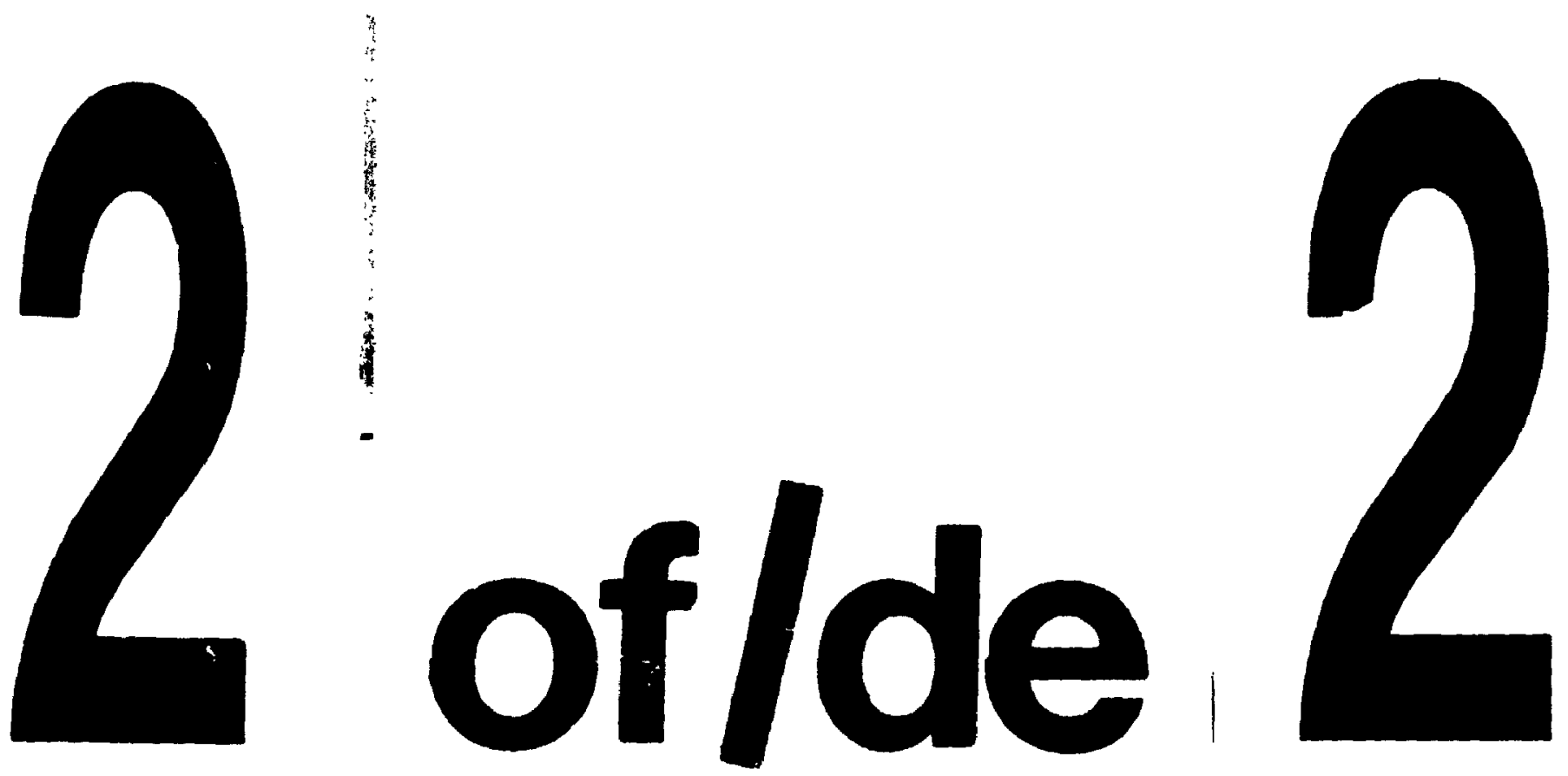

PM-1 3\%"XA" PHOTOGRAPHIC MICROCOPY TARGET MBS 10103 ANSIISO \#2 EQUIVALENT

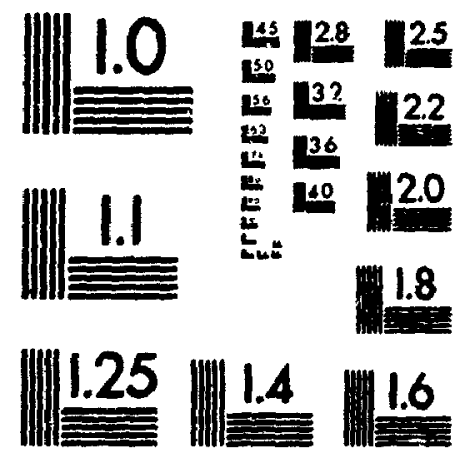

PRECISIONEM RESOLUTION TARGETS 


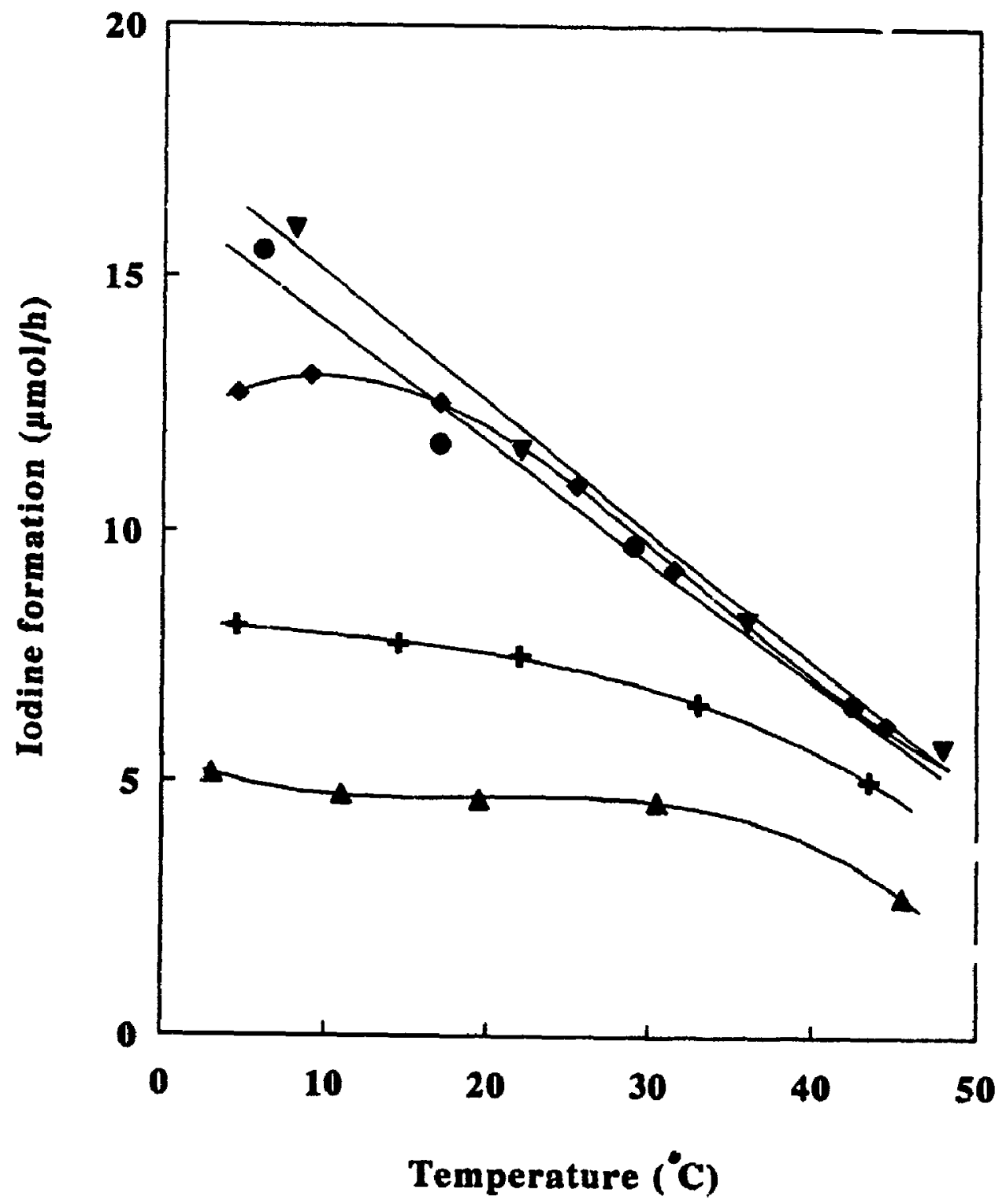

Figure 3.10: Variation with temperature of the rate of sonochemical oxidation of iodide using $20 \mathrm{kHz}$ irradiation with an X-large tip. $₫ 21$ watt; +32 watt; $\$ 42$ watt; -56 watt; -72 watt. Each point is the average of at least two independent determinations, with an estimated reproducibility of $\pm 3 \%$. The power data indicated are those measured at room temperature. The power can be as much as $20 \%$ less than this at 0 and $50^{\circ} \mathrm{C}$, a correction for this does not change the basic shapes of the curves (see figure 3.7 for an example of the magnitude of the correction). For easier viewing, the points are joined by curves which are third order polynominal fits. 
sonoluminescence experiments [Didenko, 1991].

In contrast, as seen in Figure 3.11, with irradiation at $900 \mathrm{kHz}$, the reaction rate shows a maximium at a temperature intermediate between 5 and $50{ }^{\circ} \mathrm{C}$ in this system, dependent on power level. Only four discrete power settings were available with the $900 \mathrm{kHz}$ equipment, and since the lowest produced negligible reaction, only three curves arn availatie.

At a specific setting, the power output of both pieces of equipment varied somewhat with temperature, more significantly with the $20 \mathrm{kHz}$ apparatus. Such variation is however not sufficient to change the generai shapes of the curves in Figures 3.10 and 3.11 (Figure 3.7 shows the magnitude of the correction).

\subsubsection{Effect of temperature: general considerations}

In a discussion of temperature effects, it must be remembered that there is a temperature dependence for the initial reaction caused by the collapse of the cavitation bubble. Subsequent reactions, both those which interfere and those which lead to the final product (here $I_{3}{ }^{\circ}$ ), are however also temperature dependent.

The primary reaction taking place in such a system is believed to be the rer.-ion [3-1], and the final reaction observed through visible spectroscopy is the reaction [3-4]. As explained below, rate of the primary reaction could increase or decrease with temperature; rates of all subsequent reactions should 


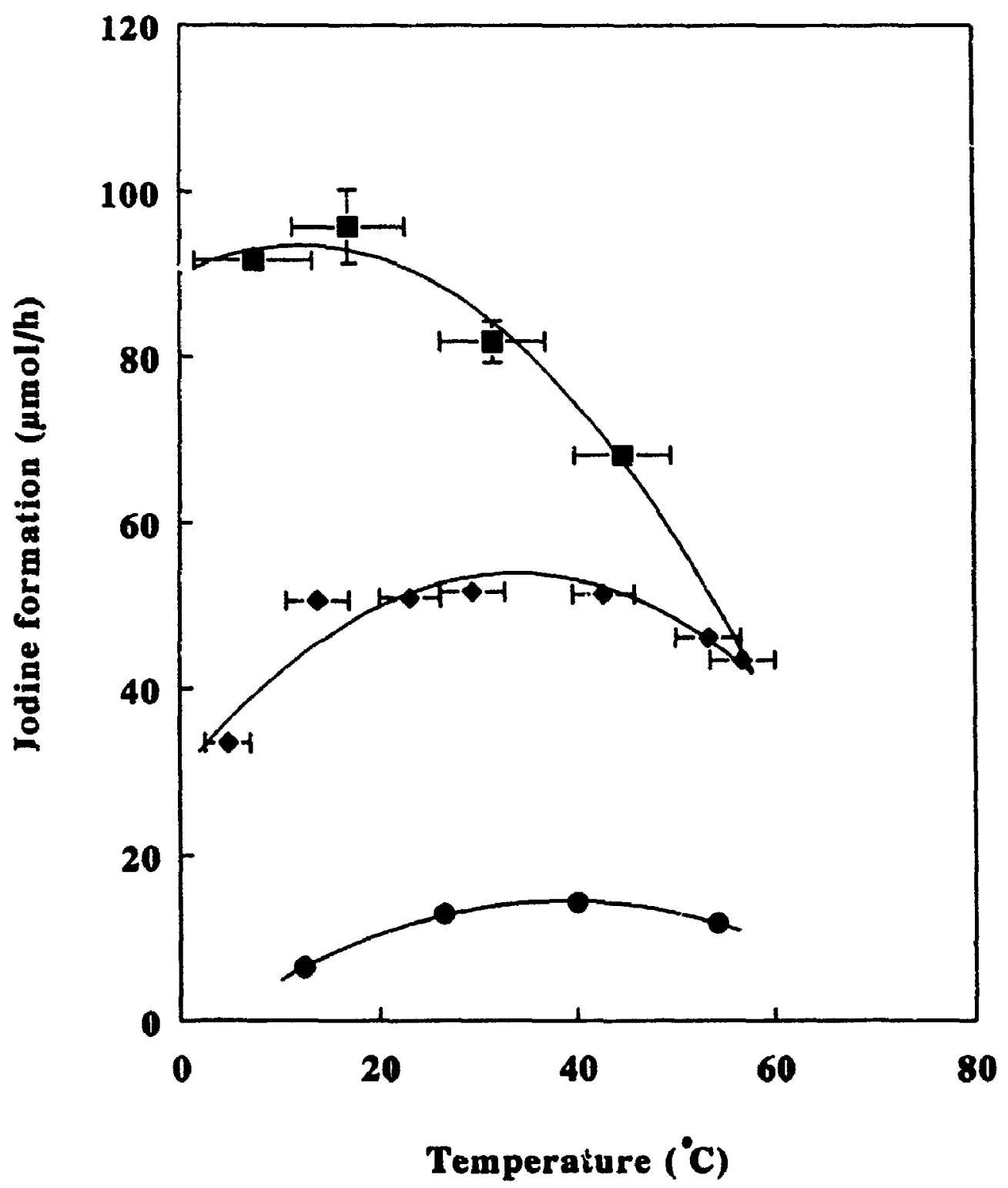

Figure 3.11: Variation with temperature of the rate of sonochemical oxidation of iodide using $900 \mathrm{kHz}$ irradiation.

- 7 watt; 25 watt; 76 watt (measured at room temperature). Each point is the average of at lsast two independent determinations, with the estimated reproducibilities shown. The power varies at most $\pm 10 \%$ from 0 to $50^{\circ} \mathrm{C}$ from that measured at rocm temperature. For easier viewing, the points are joined by cunves which are thiid order polynomial fits. 
increase with temperature.

The temperatures reached in the collapse of a cavitation bubble can be described in an idealized system as the equation [1-11].

As the temperature of the liquid is increased, its vapour pressure is also increased, but much more dramatically than the temperature. As a result the final temperature of a collapsing cavity is decreased. The vapour which enters the bubble during its formation cushions the collapse of the bubble. This "vaporous" or "transisnt" cavitation is expected to be the predominant effect when little dissolved gas is present. This predicts that as the bulk temperature increases, the temperature of the "hot spot" formed by the cavity collapse decreases. As a result the rate decreases as bulk temperature increases.

When there is abundant gas present, then the cavitation is more likely to be "stable" or "gaseous". Contrary to "vaporous" cavitation, the effective Arrhenius activation energy should in this case not be negative. By changing the solution conditions, it is thus possible to obtain different chemical environments during the collapse of a cavitation bubble.

\subsubsection{Effect of temperature: low frequency}

The noise given off by the cavitation at $20 \mathrm{kHz}$ suggests that there is more likely transient (mixture of vapour and gases) cavitation occurring. This is confirmed by the decrease in the reaction rate with temperature.

A possible explanation of the temperature effect at $20 \mathrm{kHz}$ would thus be 
that the solution is somewhat degassed by the formation of large bubbles which rise to the surface. With an increase in the temperature, both the amount of gas (lower solubility at high temperature) and vapour pressure are increased. Therefore, the composition of the bubble content is varied from the high ratio of $p_{g a d} / p_{w}$ at low temperature to the low ratio at high temperature. It means that the final temperature in the collapse of a cavity is lower at higher temperature than at lower temperature owing to the presence of much more vapour inside the bubbles. This explanation is also consistent with the experimental data presented in Table 3.4.

\subsubsection{Effect of temperature: high frequency}

The quiet nature of the $900 \mathrm{kHz}$ cavitation suggests a more stable (mixture of vapour and gases) cavitation. This may however be to a large extent because the sub-harmonics at this higher frequency are above the normal hearing frequency threshold. The increase in the rate with temperature, at least at lower temperature and low power, also suggests that vaporous cavitation is not as predominant.

With $900 \mathrm{kHz}$, there is a maximum in the rate vs temperature relations at each power in Figure 3.11. An increase in the power moves this maximum toward a lower temperature. The maximum may even disappear at powers higher than those available in our laboratory.

The shapes of the curves at $900 \mathrm{kHz}$ (Figure 3.11) can be explained by 
the ratio of partial pressures $p_{g a r} / p_{w}$ inside the bubble. In the section of the curves where the rate is increasing (low temperature, lower power), the vapour pressure of water is lower and the solubility of gas higher. At low intensities, there are fewer bubbles which can rise to the surface so that there is enough gas to make $p_{g a s} / p_{w}$ large enough to give the cavitation a more "gaseous" nature, i.e. no decrease in rate with temperature. The collapse is sufficiently intense to produce enough $\mathrm{OH}^{-}$[3-1]; increasing the temperature thus causes an increase on the final reaction [3-2].

In contrast, at higher temperatures and higher intensities, there is less dissolved gas, and more cavitation bubbles may be formed. The vapour pressure of the water is also greater. Thus $p_{g a d} / p_{w}$ is smaller and the cavitation has a more "vaporous" nature, i.e. a decrease in the rate is expected with an increase in temperature. The collapse would be not be as intense as that at lower temperature; the concentration of $\mathrm{OH}^{\cdot}[3-1]$ would decrease as the temperature is increased.

According to the experimental results, we can conclude that the negative effect on the reaction rate of the decreasing concentration of $\mathrm{OH}^{\cdot}[3-1]$ with increasing temperature is greater than the positive effect of temperature on the rate of subsequent reactions leading to the final products [3-2]. Therefore, the rate should be decreased at high temperature and intensities.

These results are supported by the data of both Didenko et al [Didenko, 1994] and Pickworth ot al [1988], even though these have been considered 
contradictory. Didenko et al. [1994], used 1.1 MHz ultrasound with an intensity of $10 \mathrm{~W} \mathrm{~cm}^{-2}$ to measure the sonoluminescence intensity at various temperatures. They found the sonoluminescence to decrease with temperature, in agreement with the majority of the previous results. Pickworth ef al. [1988], using $1 \mathrm{MHz}$ ultrasound obtained seemingly contradictory results, as there was an increase in sonoluminescence with temperature in the range of $22-45^{\circ} \mathrm{C}$. However, Pickworth et al. [1988], used a much lower ultrasound intensities 1 and $3 \mathrm{~W} \mathrm{~cm}^{-2}$.

\subsection{Conclusions}

The major aspect of this work is to demonstrate a new high-frequency sonochemical apparatus and to show that it is more effective in accelerating the rate of at least one chemical reaction. The effect of gas in high frequency is different than low frequency. These surprising results are difficult to explain on the basis of current understanding of the fundamentals of cavitation and sonochemistry.

Many questions are left unanswered: Is this a general phenomenon? Or is it something valid only for homogeneous reactions? Or are these observations specific only to the reaction we chose for our initial study?

The major contribution of this chapter is also to emphasize that there is considerable potential in increasing the efficiency of sonochemical reactions. The reaction conditions can be optimized by changes which may seem counter- 
intuitive. It may be better to: (i) use a higher frequency; (ii) increase the irradiation area, decreasing the intensity; (iii) introduce some gas; and (iv) decrease the temperature in case of high intensity.

These "rules of thumb" may however not be generally valid. There is also uncertainty about the fundamental reasons for these trends. More research on heterogeneous and other homogeneous reactions is required to assess the generality of these results.

The evidence we have presented suggests that the geometry of the apparatus and the method of introducing the ultrasound are of importance, but that these are not the primary aspects responsible for the greater effectiveness of the $900 \mathrm{kHz}$ irradiation. There seems to be a dependence of the reaction rate on irradiation frequency arising from the temporal and spatial characteristics of the cavitation bubbles produced.

The results do however indicate some very obvious advantages for studying and utilizing sonochemistry at a higher frequency: a higher reaction rate, better reproducibility, and less noise. 


\section{CHAPTER 4}

SONOCHEMICAL DECOMPOSTION OF MONO-CHLOROBENZENE IN DILUTE AQUEOUS SOLUTIONS 


\subsection{Introduction}

Aromatic compounds are stable and common contaminants of waste water in chemical industries. There are some traditional methods for destroying or eliminating of these organic contaminants from aquatic ecosystems such as ultrafiltration, extraction and incineration. Some relative new techniques such as photochemical [Ollis, 1989], supercritical [Thonton, 1992] and ultrasonic methods [Kotronarou, 1991; Serpone, 1992; Berlan, 1994] have been investigated regarding to the decomposition of these undesired compounds. The last method is a strong altemative to the other methods as it can be carried out easily and under mild conditions.

Cavitation produced by sonication brings about instantaneous local high temperature and pressure in liquid [Flint, 1991]. These rather extreme conditions are very short lived, but have been shown to produce several reactive species in aqueous systems such as $\mathrm{OH}^{\circ}$ and $\mathrm{H}^{\circ}$ [Riesz, 1985]. Therefore, sonolytic decomposition of pollutants might be related to the thermal decomposition in cavitation bubbles or reactions by $\mathrm{OH}$ radicals or $\mathrm{H}$ atoms.

Chlorinated hydrocarbons are persistent in the environment owing to their resistance to decomposition. These compounds have attracted a public attention due to the pollution of ground and river water by them [Kerfoot, 1987].

Zechmeister and coworkers [1955] showed that the sonication of a mixtures of halobenzene, halothiophene and halofuran in a silver nitrate solution led to precipitation of silver halide that contained some silver acetylide and 
diacetylide. Other aromatic and heterocyclic rings can be cleaved by ultrasonic irradiation [Zechmeister, 1956].

Sonolysis of some chlorinated hydrocarbon such as methylene chloride, carbon tetrachloride, 1,1,1-trichloroethane and trichloroethylene [Cheung, 1991; Inazu, 1993], and chlorophenol [Gondrexon, 1993] in aqueous solutions have been studied. The reaction mechanisın and decomposition products have not completely been elucidated [Cheung, 1991].

The aim of this work is to study the decomposition of chlorobenzene in dilute aqueous solution by ultrasonic irradiation at two different frequencies (20 and $900 \mathrm{kHz}$ ). This study also deals with the ultrasonic degradation under different intensities at a constant power with changing the tip size area.

\subsection{Experimental procedures}

A dilute solution of chlorobenzene was prepared by adding $0.200 \mathrm{~mL}$ chlorobenzene (Fisher) into d 3 -ionized water in a one liter volumetric flask. This solution was stirred for several hours by a magnet.

The ultrasonic irradiation of aqueous solution of chlorobenzene was carried out in a Vibra-Cell VC375 that was operated at $20 \mathrm{kHz}$ with a power of 35 Watts (Power Position $=5$ ) at zero degrees. Sonication with this apparatus was done with two different hom sizes $\left(1.1\right.$ and $\left.8.04 \mathrm{~cm}^{2}\right)$ at the same power. The reaction vessel was a cylinder glass containing $50 \mathrm{~mL}$ of aqueous solution which immersed into a ice bath. Another sonicator was the newly designed 900 
$\mathrm{kHz}$ apparatus with a power of 33 Watts (Power position $=3$ ) at zero degrees. In this case the reaction vessel was a $125 \mathrm{~mL}$ Erlenmeyer containing $50 \mathrm{~mL}$ of aqueous solution which sonicated indirectly at zero degree. These sonications were carried out under an air atmosphere.

Sonication of this solution resulted in the formation of a yellow color with a maximum absorption at wavelength of $253 \mathrm{~nm}$ (Figure 4.1). The sonodegradation was mr,nitored at intervals by measuring the intensity of the yellow color by a Uv-Visible spectrophotometer (Perkin-Elmer, Lambda 4B); by the concentration of the chloride ion which was measured with a Dionex $4000 \mathrm{i}$ ion chromatography unit with a Dionex AS4-A column. The IC eluents were 1.7 $\mathrm{mM} \mathrm{NaHCO}$ and $1.8 \mathrm{mM} \mathrm{Na}_{2} \mathrm{CO}_{3}$. The $\mathrm{pH}$ of the solution was monitored by a digital pH meter.

\subsection{Rosults}

The variation of the decomposition rate of chlorobenzene in water with two different tip sizes at $20 \mathrm{kHz}$ was followed by the formation of chloride anion (Figure 4.2) and the intensity of yellow solution (Figure 4.3). Both measuraments confirmed that the rate of dissociation is larger with the larger tip. It means that lower intensity (X-large hom) is more effective than higher intensity (small hom) under the same power. This comparison was done under the same conditions and the only variable was the size of the tip. The results in Figures 4.2 and 4.3 were obtained with the power setting at position 5 ( $35 \mathrm{~W}$ ) 


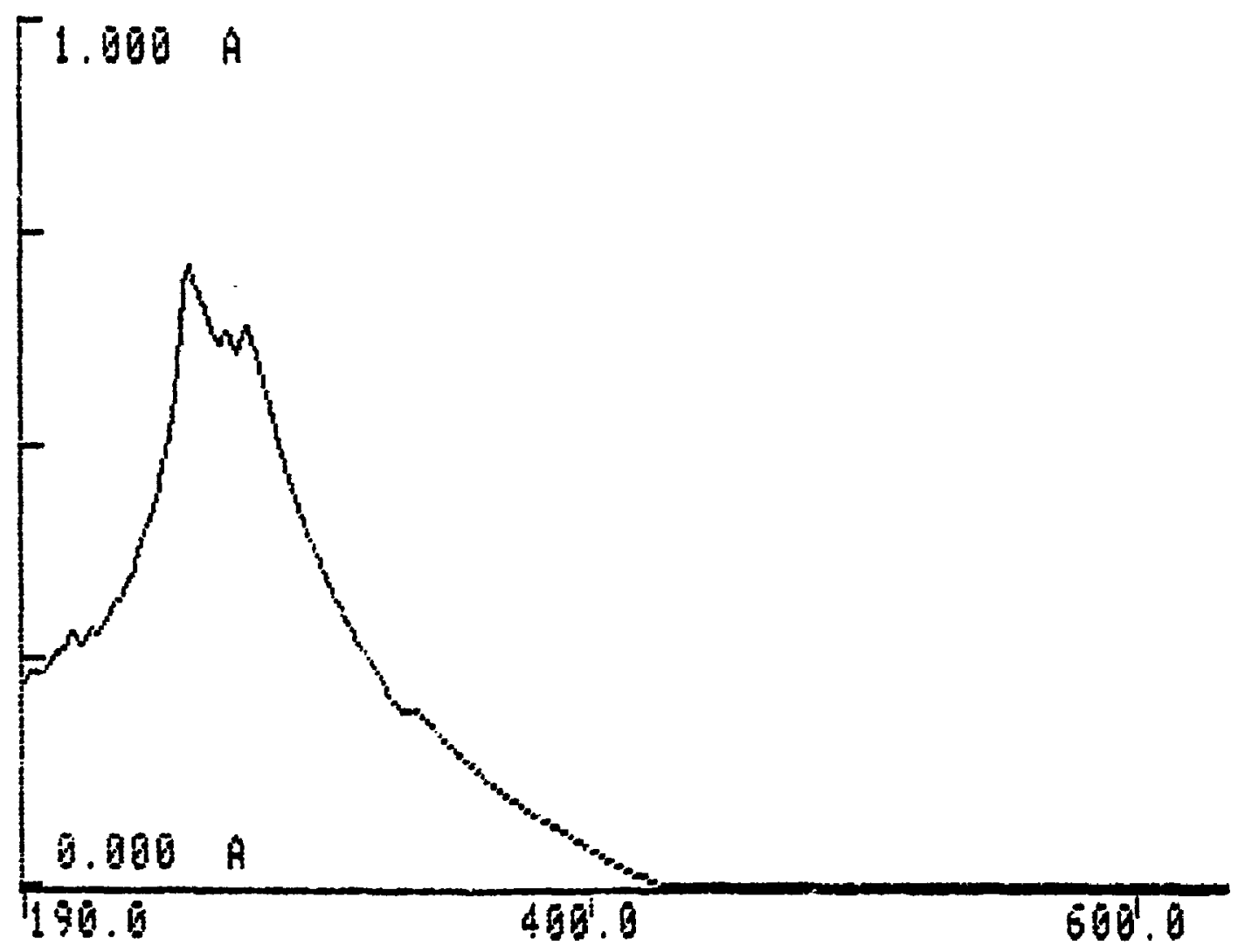

Figure 4.1: Uv-Visible spectrum of yellow solution produced by sonodissociation of chlorobenzene in a dilute aqueous solutiz $n$. 


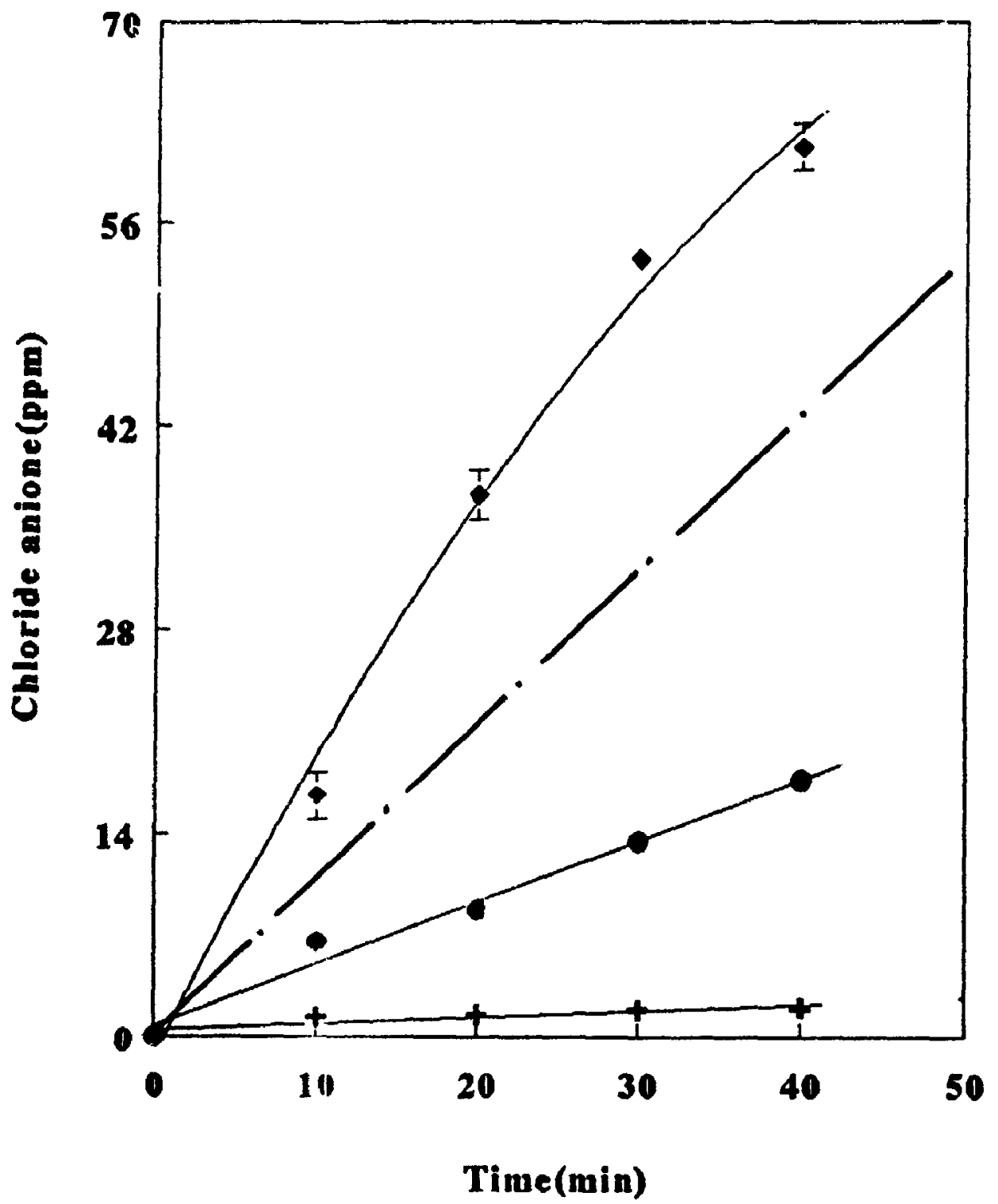

Figure 4.2: Chloride anion concentration (ppm) vs sonication time. + $20 \mathrm{kHz}$ with small hom, - $20 \mathrm{kHz}$ with X-large hom,

- $900 \mathrm{kHz}$. An estimated curve - - for the case of $20 \mathrm{kHz}$ with hom the same size as $900 \mathrm{kHz}\left(21 \mathrm{~cm}^{2}\right)$. 


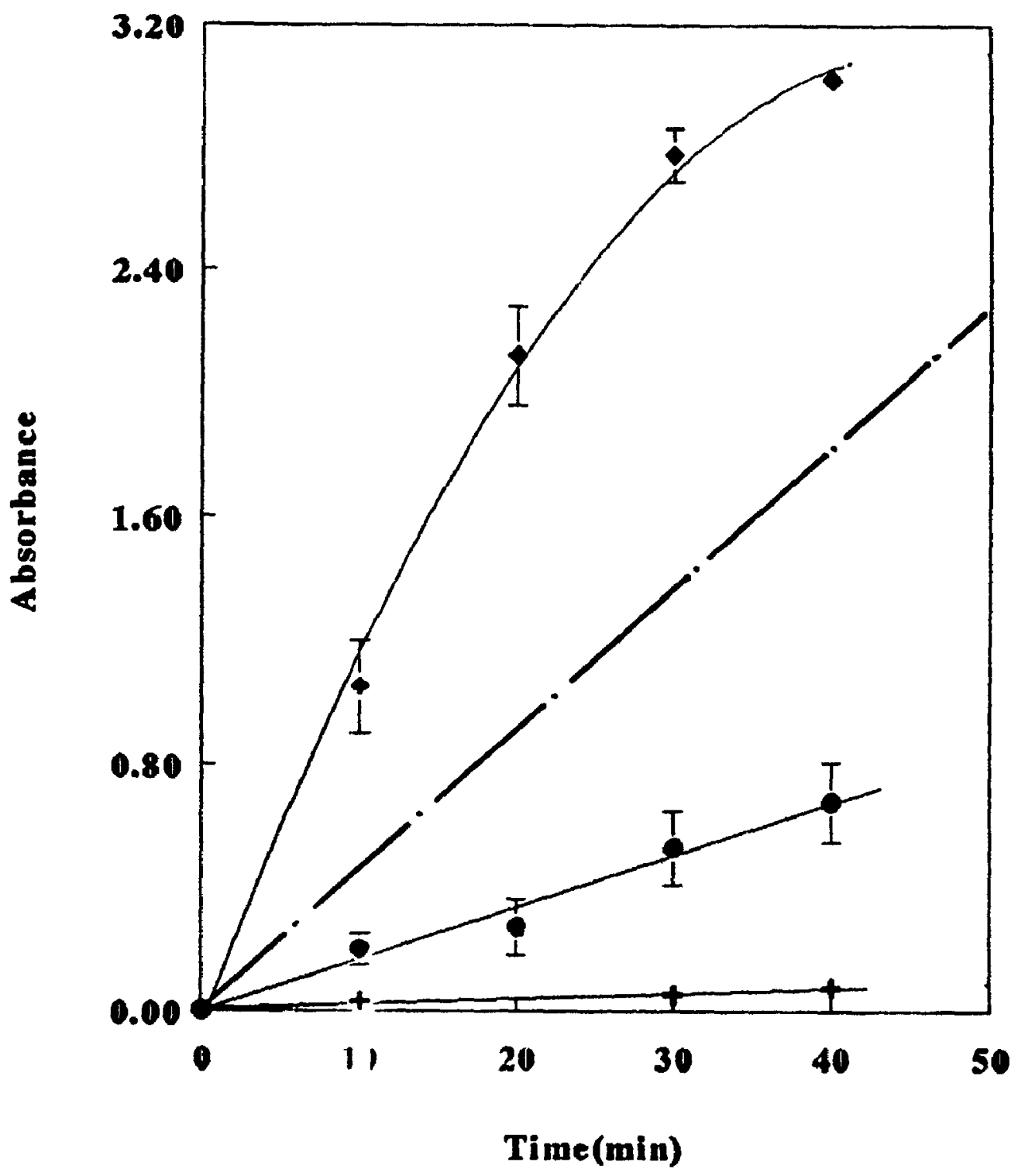

Figure 4.3: Absorbance of the yellow solution vs sonication time. $+20 \mathrm{kHz}$ with small hom, - $20 \mathrm{kHz}$ with X-large hom,

- $900 \mathrm{kHz}$. An estimated curve - - for the case of $20 \mathrm{kHz}$ with hom the same size as $900 \mathrm{kHz}\left(21 \mathrm{~cm}^{2}\right)$. 
for both homs and the temperature was set at zero degrees. For a better comparison, the results obtained with $900 \mathrm{kHz}$ apparatus under the same conditions are also presented in Figures 4.2 and 4.3. The power setting at 900 $\mathrm{kHz}$ was set at postition 3 which delivered 33 acoustic watts inside the sonicated vessel.

The $\mathrm{pH}$ of the solution was monitored by a $\mathrm{pH}$ meter after each sonication time. Figure 4.4 shows the change of $\mathrm{pH}$ against the sonication time.

\subsection{Discussion}

\subsubsection{Decomposition of chlorobenzene}

Sonication of dilute aqueous solutions of chlorobenzene led to the following observations: (a) the concentration of chloride anion is increased by increasing the sonication time (Figures 4.2), (b) the intensity of a yellow color produced by sonication is increased by increasing the sonication time; it became slightly cloudy after prolonged sonication, (c) the $\mathrm{pH}$ of the sonicated solution decreased rapidly except for $20 \mathrm{kHz}$ with the small horn (Figure 4.4) and (d) the HPLC results indicated a corresponding rapid decrease in the concentration of chlorobenzene. These observations confirmed the decomposition of chlorobenzene and also indicated the probable formation of $\mathrm{HCl}$ from sono-dissociation of chlorobenzene.

There are three possible places for this decomposition process: (a) 


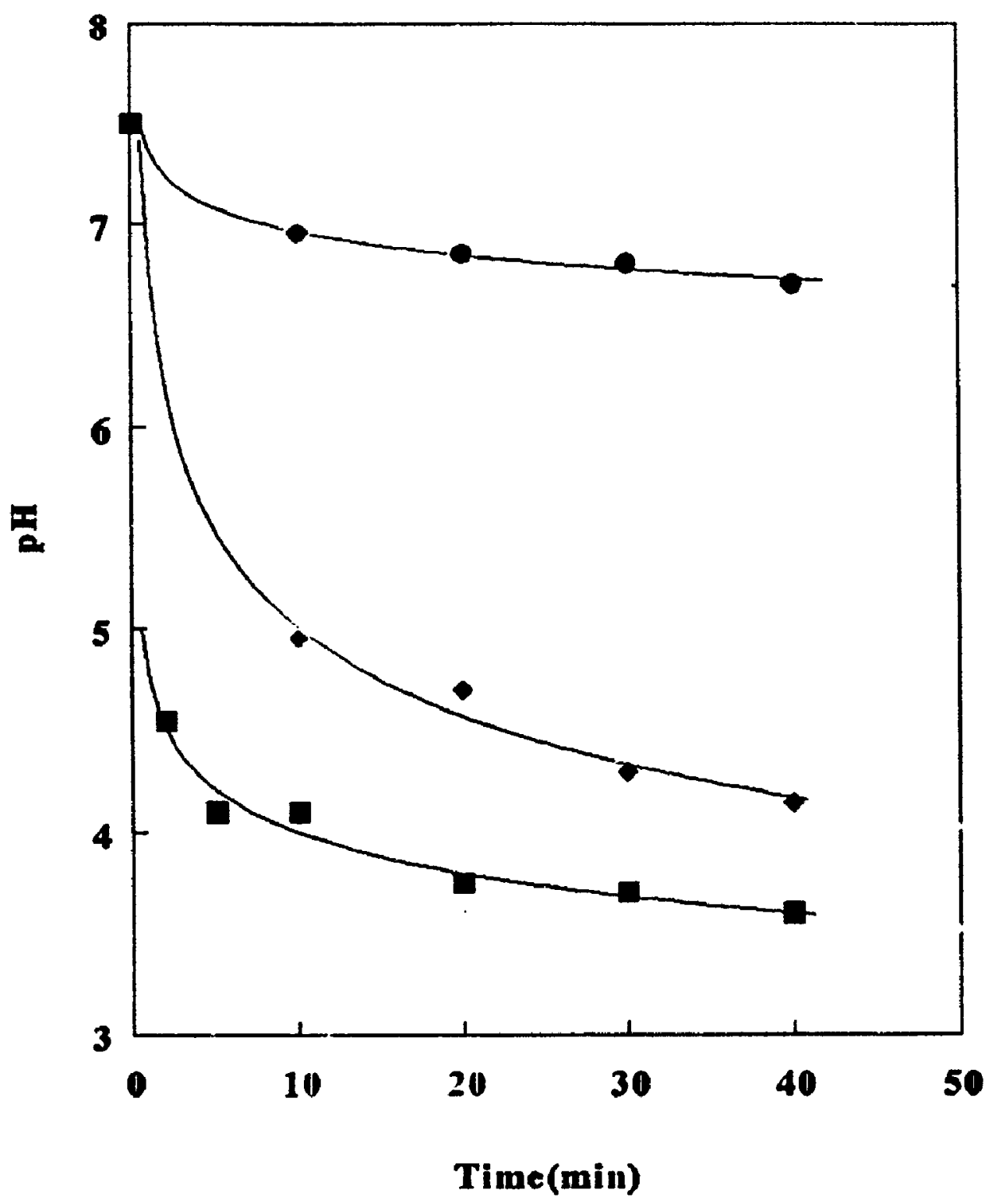

Figure 4.4: $\mathrm{pH}$ of the sonicated solution vs sonication time.

- $20 \mathrm{kHz}$ with small hom, $\quad 20 \mathrm{kHz}$ with X-large horn, - $900 \mathrm{kHz}$. 
inside the bubble during the collapse of the cavity, (b) in the solvent layer surrounding the bubble and (c) in the bulk solution phase. In cases (a) and (b), the pyrolysis and radical reactions occurred simultaneously and in the case of (c) free radical reactions (derived from the dissociation of water) are likely to predominate.

It can be suggested by the following observations that the main decomposition reaction occurred as a second reaction inside the bulk of solution. This can be done through the reaction of chlorobenzene with $\mathrm{OH}$ radical derived from the dissociation of water inside the bubble during the collapse of the cavity. The degradation rate was increased by decreasing the acoustic intensity through different tip sizes at constant power. Owing to the low concentration of solute and its lower vapour pressures than water; they are therefore unable to diffuse into the cavity and are not affected by the critical conditions generated by the cavitational collapse. Instead, neat chlorobenzene itself undergoes sonochemical reactions. Peeter Kruus et al have done some sonications on the pure substituted benzenes for the formation of polymers. They suggested a free-radical mechanism for polymerization which initiated through a thermal decomposition in a cavitation bubble [Kruus, 1983; Diedrich, 1972].

One of the main products of this decomposition is a yellow compound which is not identified yet. With increasing the time of sonication, the concentration of this unknown compound was increased. In short time 
sonication, the solution was a clear yellow solution, but after longer times it became slightly cloudy. In case of long time sonication, an orange precipitate appeared to settle out of the solution after a day. It seems that the solution can be saturated by the unknown compound after a short time of sonication.

The H-NMR spectrum of the solution of chlorobenzene in deuterium oxide before (Figure 4.5) and after sonication (Figure 4.6) was different. Before sonication, there was a small triplet peak above $7 \mathrm{ppm}$ which belongs to the chlorobenzene. In the spectrum after sonication, there was a strong doublet peak above $7 \mathrm{ppm}$ and also a small peak around $10 \mathrm{ppm}$. This means that chlorobenzene had decomposed and produced another aromatic compound. According to the spectrum, the products could be either $1,2,3,5$ tetrachlorobenzene or a mixture of benzene and 1,3,5 trichlorobenzene.

\subsubsection{Intensity effect}

At the same overall power, the rate of decomposition was greater with the $\mathrm{X}$-large tip than with the small tip at $20 \mathrm{kHz}$ irradiation. This means that the decomposition rate was more efficient at low intensity than at high intensity at the same power.

According to Figures 4.2 and 4.3 , it is possible to estimate a curve for a horn with tip area the same size as $900 \mathrm{kHz}\left(21 \mathrm{~cm}^{2}\right)$ by assuming a linear relationship between the rate and the tip sizes. 


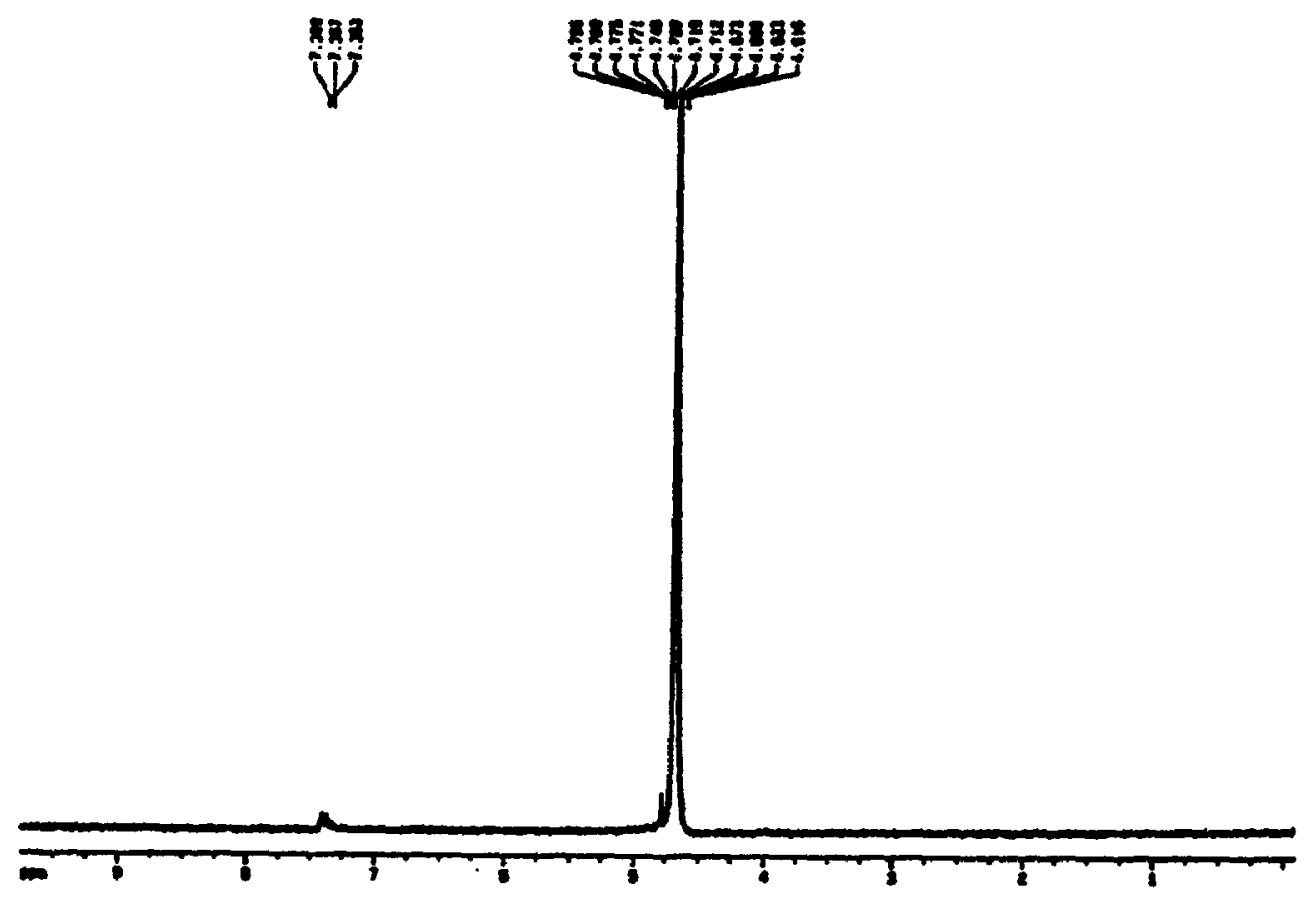

Figure 4.5: The H-NMR spectrum of the solution of chlorobenzene in deuterium oxide before sonication. 


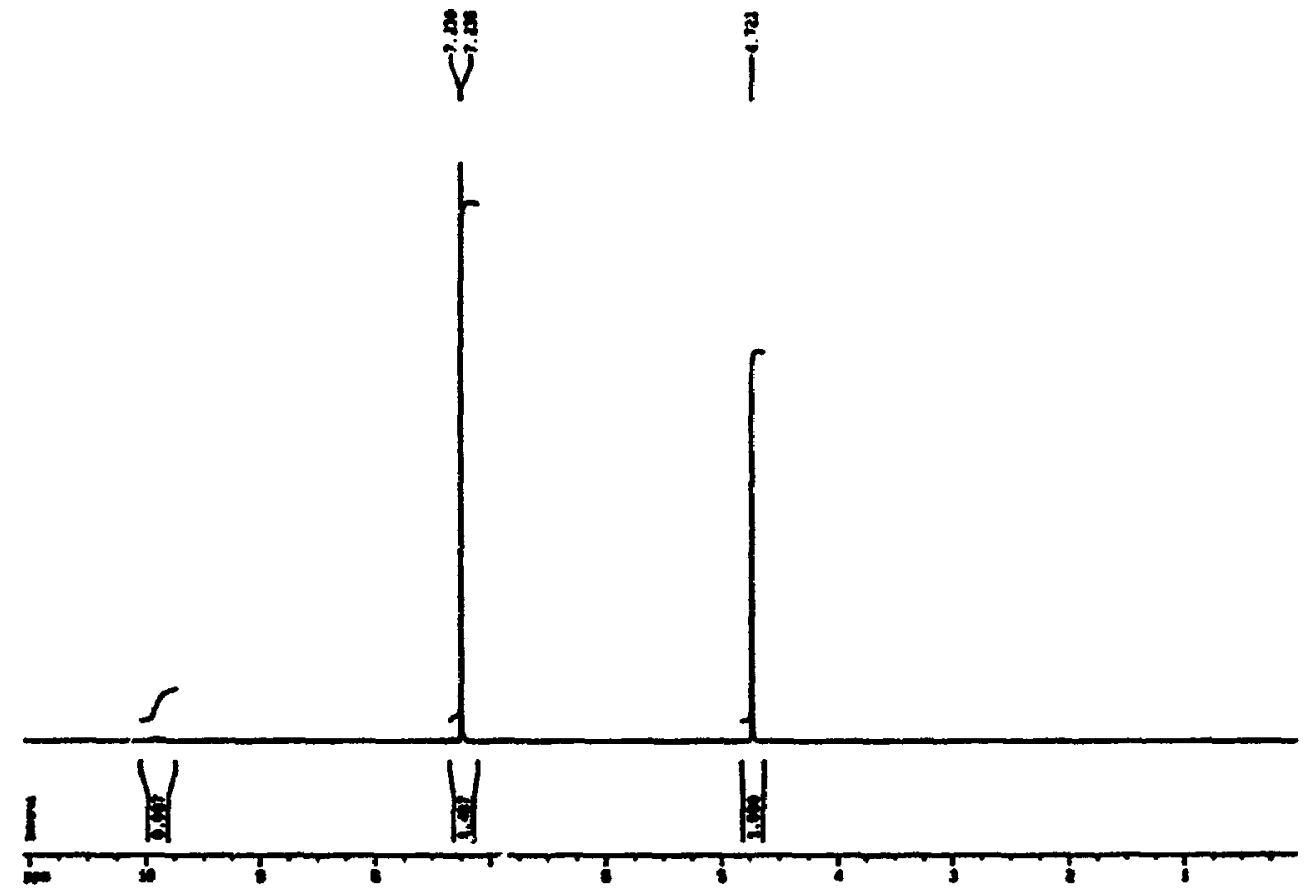

Figure 4.6: The H-NMR spectrum of the solution of chlorobenzene in deuterium oxide after sonication. 


\subsubsection{Frequency effect}

There are a few reports in the literature about the ultrasonic degradation of organic compounds. Some of them describe the effect of frequency on the decomposition rate of organic compounds. J. Berlan et al [1994] recently sfudied the oxidative degradation of phenol in aqueous media using ultrasound. They used a Biosonic GW10 at $541 \mathrm{kHz}$ apparatus, fitted with a submersible 12 $\mathrm{cm}$ horn, and a Sonic \& Material Vibracel 600 at $20 \mathrm{kHz}$ apparatus fitted with an immersible $12 \mathrm{~mm}$ hom. They observed a frequency effect, as the phenol remains almost unchanged at $20 \mathrm{kHz}$ after 2 hours, but is totally degraded after $100 \mathrm{~min}$ at $541 \mathrm{kHz}$. These results are consistent with the previously reported results [Lur'e, 1962; Chen, 1971; Petrier, 1993]. Our results in general show that this difference is not only related to the frequency effect, but that the surface area of sonicator

(12 $\mathrm{cm}$ and $12 \mathrm{~mm}$ horn) is also important and should be considered.

In sono-dissociation of chlorobenzene, comparison of the results at two different frequencies under exactly the same conditions shows that the real effect of frequency on this decomposition is about 1.5 - 2 times greater with 900 $\mathrm{kHz}$ than with $20 \mathrm{kHz}$.

\subsection{Conclusion}

Destruction of aromatic compounds needs extreme conditions, but ultrasound facilitates this degradation under mild conditions. This destruction 
can be more efficient by increasing the surface area of irradiator and using high frequency. 


\section{CHAPTER 5}

SONOCHEMHCAL DISSOCIATION OF

CARBON DISULFIDE 


\subsection{Introduction}

In the literature, the uses of ultrasound in heterogeneous systems are divided into two groups: liquid-liquid and liquid-solid interactions. There is another class of reaction which is homogeneous before, but heterogeneous after sonication. The sonochemical reactions associated with metal carbonyls in an alkane as a solvent illustrate the change from homogeny to heterogeny by ultrasound. Grinstaff et al. [1992] found that the ultrasonic irradiztioni of iron pentacarbonyl $\left(\mathrm{Fe}(\mathrm{CO})_{5}\right)$ under conditions that maximize the cavitational collapse intensity (for example, Ar, low vapour pressures, low ambient temperatures) result in amorphous iron.

This amorphous iron powder is formed from the enormous heating and cooling rates generated during acoustic cavitation. The effective temperature reached during bubble collapse is about $5200 \mathrm{~K}$ with submicrosecond lifetime [Suslick, 1986]; the lifetime of these bubbles are also estimated to be less than one nsec [Barber, 1991]. It is thus expected that heating and cooling rates during cavitational collapse should be in the range of $10^{\circ}-10^{13} \mathrm{~K} \mathrm{~s}^{-1}$. Acoustic cavitation might therefore provide a new method for formation of amorphous material which needs enormous rate of cooling.

This chapter reports the results of a study of the sonochemical decomposition of carbon disulfide. This system is homogeneous before, but heterogeneous after sonication. The variation of the rate of disscciation was studied as a function of ultrasonic frequency and power, hom tip area, 
temperalure, and the presence of gases.

\subsection{Experimental procedure}

The experimental apparatus have been described [Entezari, 1994]. The ultrasonic equipment used for $20 \mathrm{kHz}$ was a Vibra-Cell VC375 ultrasonic processor with horns having tip area of $1.1 \mathrm{~cm}^{2}$ (referred to as "small") and a special hom provided by Vibra-Cell with a tip area of $8.04 \mathrm{~cm}^{2}$ ("X-large"). The $900 \mathrm{kHz}$ apparatus was specially designed and constructed; it used the electrical supply obtained from Meinhardt Ultrasonics in Leipzig, Germany.

In this series of experiments, $50 \mathrm{~mL}$ of carbon disulfide was poured into a Rosette cell for direct sonication with $20 \mathrm{kHz}$ by two different homs. The power was set at position 7, unless otherwise indicated; this delivers $49 \mathrm{~W}$ acoustic power into the solution by both homs at $298 \mathrm{~K}$. The position of both homs was the same with respect to the Rosette cell. Unless otherwise indicated, the runs were done under a nornal atmosphere with no gases bubbled through the solution. In the study of gas effects, $100 \mathrm{~mL}$ of carbon disulfide was sonicated inside a cell specially designed for gas studies.

After sonication, the solid phase (black particles) was separated from liquid phase (yellow solution) by a filter paper. The mass of black particles in a sample run with $100 \mathrm{~mL}$ under normal atmosphere for one hour was about $0.04 \mathrm{~g}$ (small hom). The black particles were collected from several runs. The yellow solution was also evaporated at room temperature and the remaining 
solid phase collected. Both sample were sent for ESM (Electron Scan Microscopy), $x$-ray spectrum and element analysis.

Sonication of sample with a $50 \mathrm{kHz}$ ultrasonic bath (Bransonic 1200) was done under a normal atmosphere for 4 hours. An Erlenmeyer containing 100 $\mathrm{mL}$ of sample was immersed into the ultrasonic bath with water as the coupling fluid.

Sonication with $900 \mathrm{kHz}$ was also for a $100 \mathrm{~mL}$ samples under air, Ar, and He atmosphere. Owing to the interaction of carbon disulfide with RTV on the piezoceramic (Chapter 2), the sample was sonicated indirectly by immersing a container (125 $\mathrm{mL}$ Erlenmeyer) into the cell with water as the coupling fluid.

The rate of dissociation was followed by monitoring the intensity of colour by Uv-Visible at $379 \mathrm{~nm}$ (maximum absorbance, Figure 5.1) vs time using four or five data points. This rate can also be followed by the mass of black particles produced by sonication, but owing to the small amount of precipitate, the intensity of colour was preferred. During the rate determination, the temperature varied sornewhat depending on the acoustic power. At low power, the temperature was constant to within $\pm 3^{\circ} \mathrm{C}$ during a run, while at the highest power it could vary up to $\pm 7^{\circ} \mathrm{C}$ when the temperature of the thermostat was set at zero degrees.

The effect of temperature on the dissociation of carbon disulfide was studied in the range of $-50^{\circ} \mathrm{C}$ to $+10^{\circ} \mathrm{C}$ using a dry ice-acetone bath. In this case the variation of temperature in during a run varied up to $\pm 12^{\circ} \mathrm{C}$. 


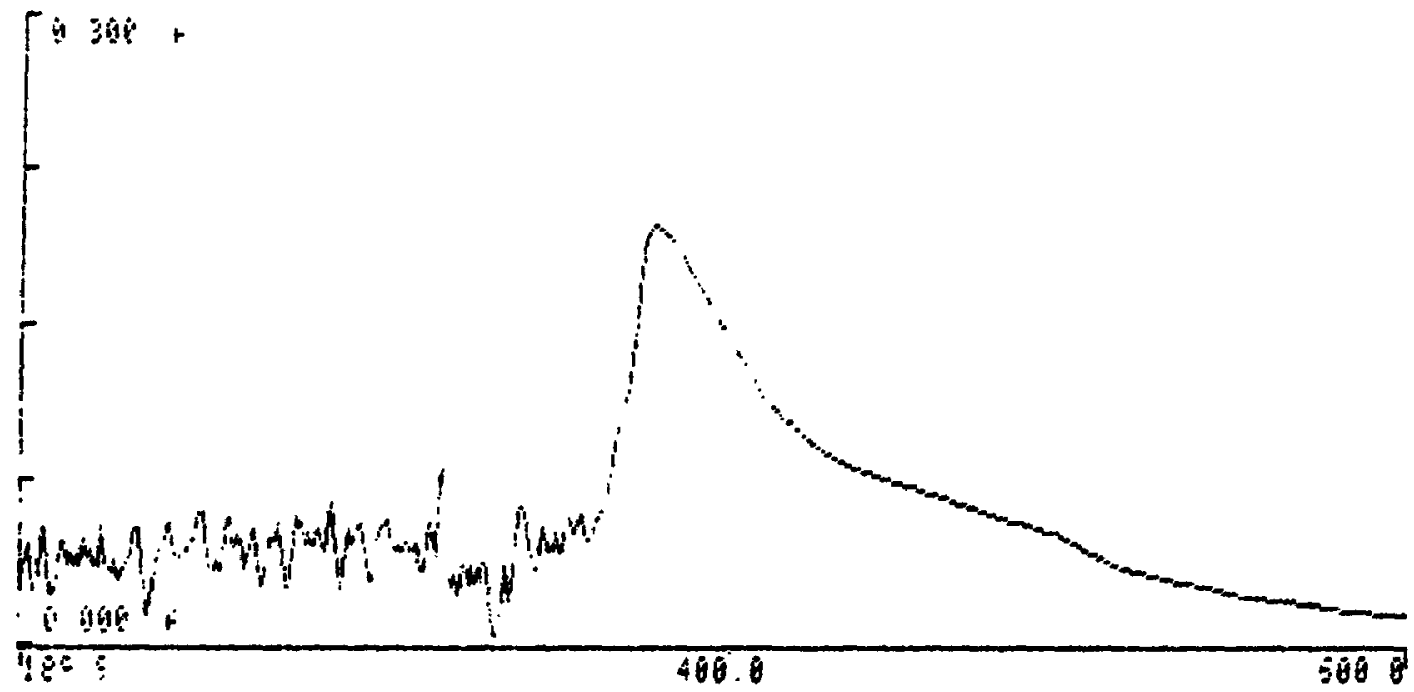

Figure 5.1: The Uv-Visible spectrum of yellow solution produced by sonication of carbon disulfide. 


\subsection{Results}

\subsubsection{Intensity dependence}

The variation of the dissociation rate of carbon disulfide with two different tip sizes at $20 \mathrm{kHz}$ is shown in Figure 5.2. It is evident that the rate of dissociation is larger with the small hom than X-large horn. It means that a higher intensity $(44.5 \mathrm{~W} \mathrm{~cm})$ is more effective than lower intensity $(6.10 \mathrm{~W} \mathrm{~cm})$ under the same power (49 W). This comparison was done under the same condition and the only variable was the size of the tip. The data in Figure 5.2 was obtained with power setting at position $7(49 \mathrm{~W})$, and the temperature of the system was set at zero degrees (ice bath).

Figure 5.3 shows the rate of dissociation with two different tip sizes under different power. This figure again indicates that the rate of dissociation is larger with the small horn at all power setting. In this range of power, the rate of dissociation of carbon disulfide is linear with X-large horn, but is not linear with small one; at the highest intensities, the reaction rate per unit power drops off.

The high intensity with the small hom causes a migration of a large fraction of the visible bubbles out of the solution. Many bubbles can also be seen close to the transducer tip. These must interfere with the introduction of ultrasound into the liquid. This is a possible explanation of the "saturation" of. the sonochemical effect at higher intensities noted in Figure 5.3 . 


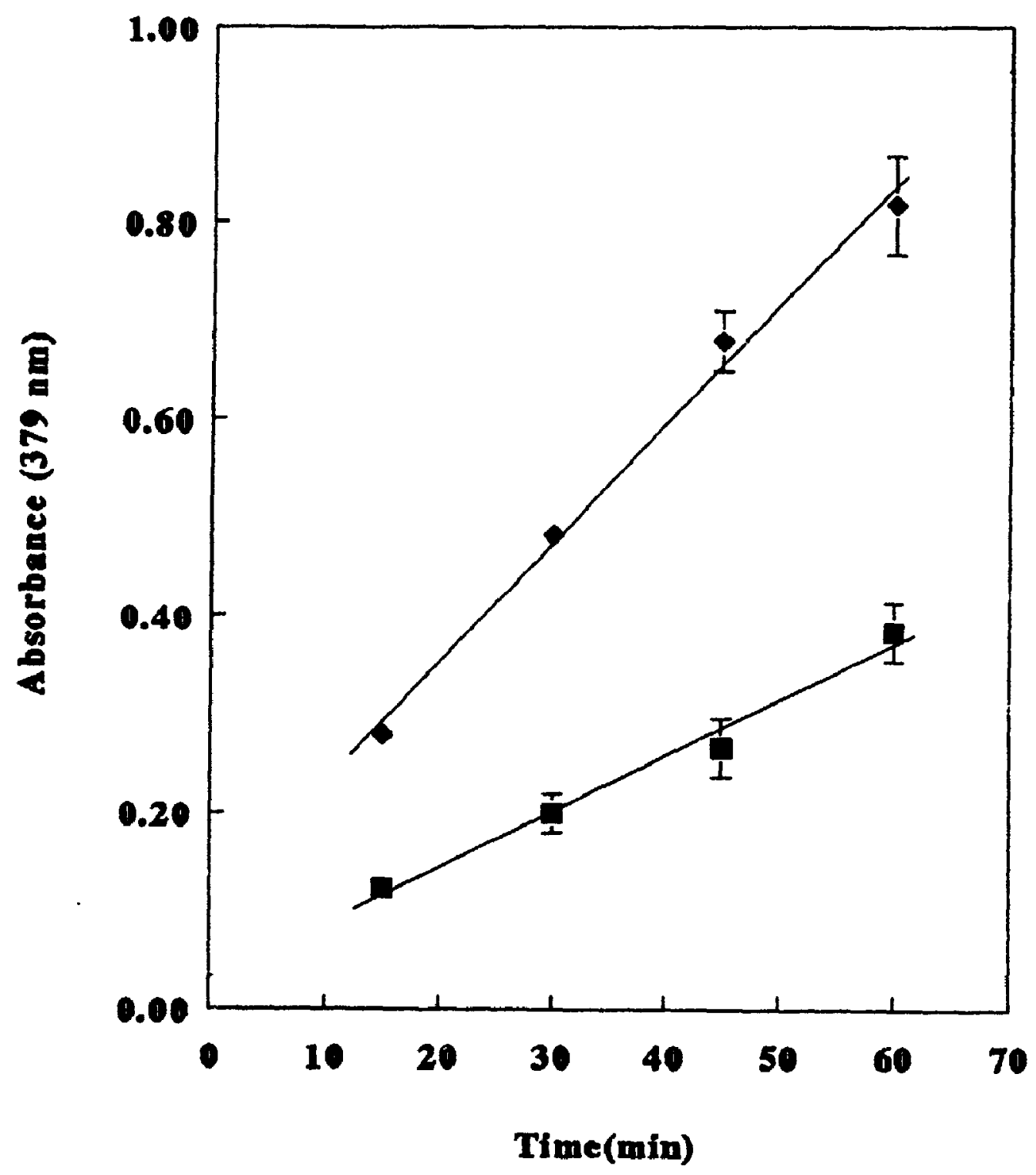

Figure 5.2: Time variation of sono-dissociation of carbon disulfide using $20 \mathrm{kHz}$ irradiation with two different tip sizes. Sonication by small hom $\left(1.10 \mathrm{~cm}^{2}\right)$; sonication by $X$-large hom $\left(8.04 \mathrm{~cm}^{2}\right)$. The temperature was set at $0^{\circ} \mathrm{C}$ by an ice bath; the power was fixed at position 6 ( $42 W$ in case of water at room temperature). Corrections for loss of carbon disulfide during sonication and in fittration has been considered. The error bars show the standard deviation of the average of 3 independent runs. 


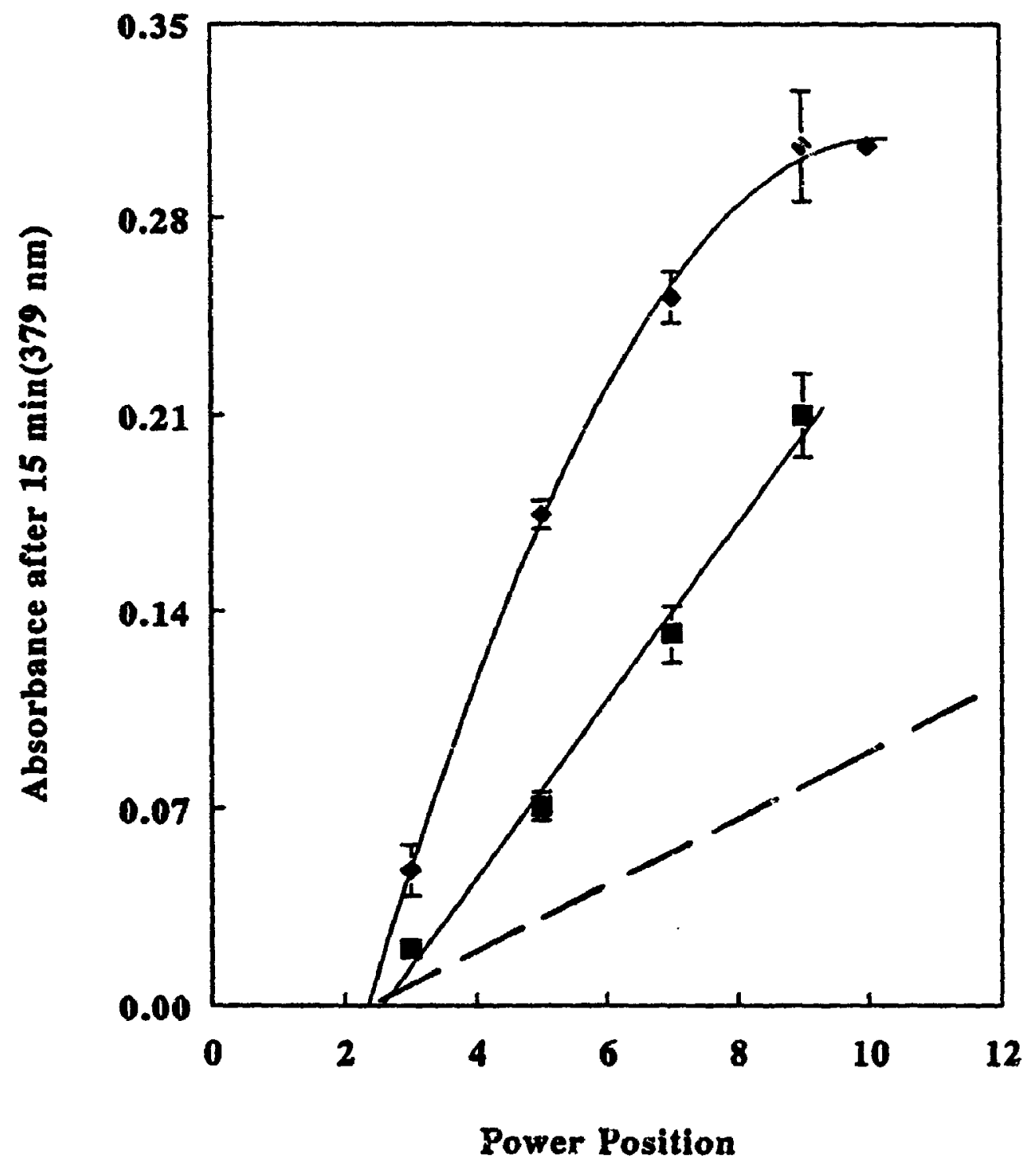

Figure 5.3: Variation of sono-dissociation of carbon disulfide vs power at $0^{\circ} \mathrm{C}$ with two different homs. Sonication by small hom; sonication by $X$-large hom at different power positions of $3,5,7,9,10(21,35,49,64$ and 71 $W$ respectively in case of water at room temperature). The data are the average of 3 runs. An estimated curve - is shown for the case of $20 \mathrm{kHz}$ with tip area the same as $900 \mathrm{kHz}\left(21 \mathrm{~cm}^{2}\right)$. 


\subsubsection{Temperature dependence}

The sonochemical dissociation of carbon disulfide was measured in a range of low temperatures $\left(-50 \approx+10^{\circ} \mathrm{C}\right)$ to prevent excessive evaporation. Fiçile 5.4 shows the rate of dissociation with respect to temperature for the two different tip sizes. There was some loss of carbon disulfide during sonication and filtration for separating the solid phase from the yellow solution, but a correction for this loss of volume was made on Figure 5.4. This figure again shows that in this range of temperature, the rate is greater with the small horn than with the $\mathrm{X}$-large one and also the rate change of dissociation against temperature is greater with the small hom than with the $X$-large one.

\subsubsection{Gas dependence}

The effect of different gases ( $\mathrm{Ar}, \mathrm{H}_{2}, \mathrm{Air}, \mathrm{He}, \mathrm{O}_{2}, \mathrm{CO}_{2}$ ) was studied on the sono-dissociation of carbon disulfide (Table 5.1). Each gas was bubbled through liquid carbon disulfide for $\mathbf{3 0}$ minutes before sonication and also the $\mathbf{3 0}$ minutes of sonication at a lower bubbling rate. These experiments were done unaer the same conditions except the nature of the gas. The noise from the cavitation process was louder, and the filtration for separation of the two phases was longer for helium and hydrogen than for the other gases. These observations showed that the cavitational collapse was more intense with hydrogen and helium than the other gases. 


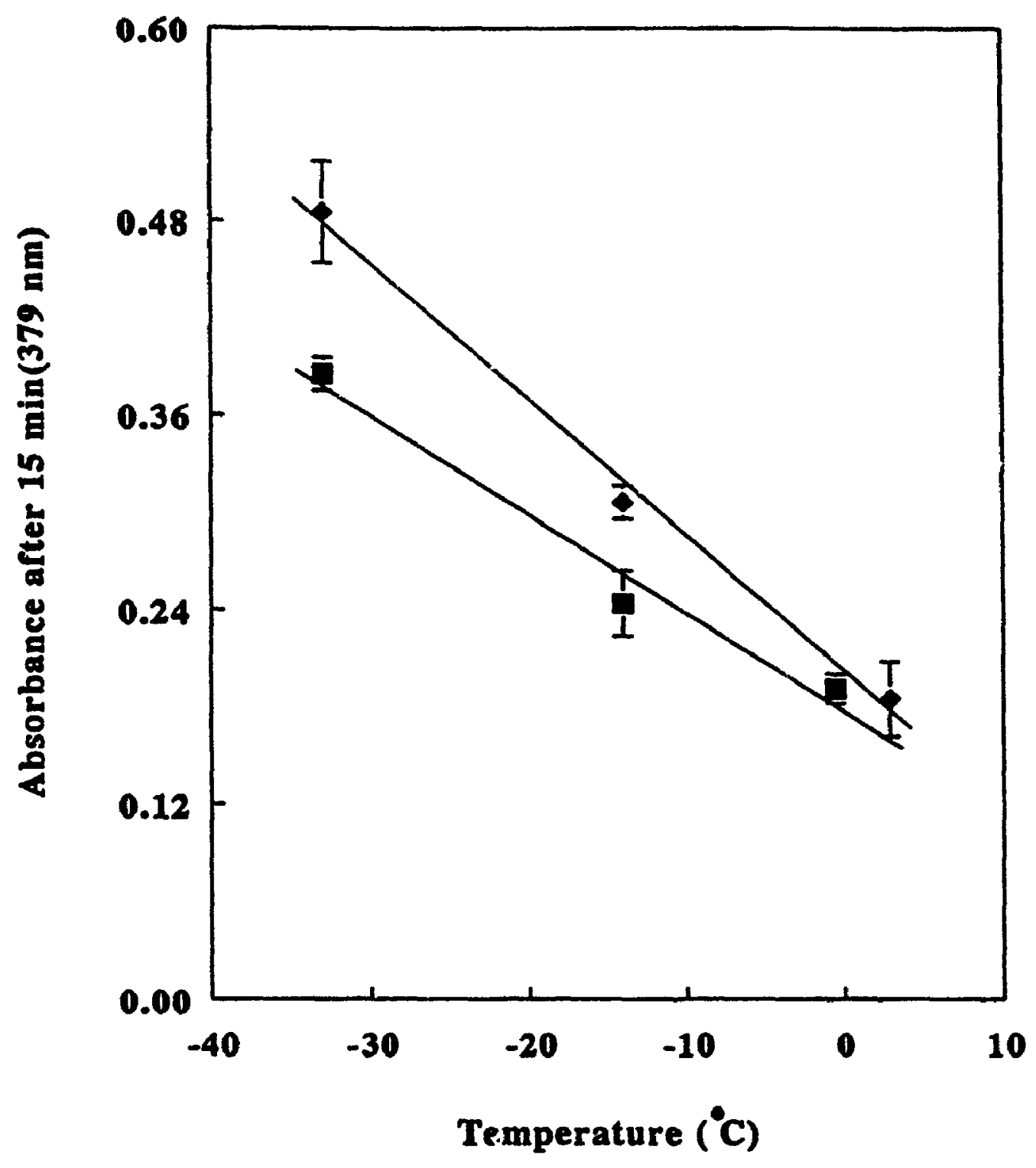

Figure 5.4: Variation with temperature of sono-dissociation of carbon disulfide using $20 \mathrm{kHz}$ irradiation with two different tip sizes. $\quad$ Sonication by small hom; sonication by the $X$-large hom at power position 7 (49 $W$ in the case of water at room temperature). The data are the average of 3 runs. 


\subsection{Discussion}

\subsubsection{Dissociation of carbon disulfide}

The dissociation of carbon disulfide by s snication might be explained by the collapse of the cavity which produces very high temperature (roughly $5000^{\circ} \mathrm{C}$ ), pressure (roughly $500 \mathrm{~atm}$ ), and cooling rates above $10^{\circ} \mathrm{K} / \mathrm{sec}$ [Suslick, 1986]. Another important factor could be low heat conductivity of carbon disulfide vapour (Table 5.1). Under this critical conditions the C-S bond is broken and produce carbon and sulfur. Due to this process, the homogeneous carbon disulfide liquid is converted to the heterogeneous solution with a very fine black particles and a yellowish solution.

\subsubsection{The $x$-ray spectrum}

The $x$-ray spectrum of the fine black particles showed that a signal for sulfur (monoclinic, $\approx 24.5$ Degree), another signal for titanium ( $\approx 40$ Degre $\theta$ ), which belonged to the ultrasonic probe, and a wide signal for amorphous carbon (Figure 5.5). The black sample was analyzed for carbon, and was found to contain $24.74 \%$ carbon, which was in an amorphcus form. There is only $16 \%$ of carbon by mass in carbon disulfide.

The signal for monoclinic sulfur from the black particles could be related to the sulfur dissolved in the carbon disulfide (a yellow solution produced by sonication) which was adsorbed by the carbon. It should be noted that this sample was sent for $x$-ray analysis without washing. 
The $x$-ray spectrum of the evaporated solution (yellow solution) also indicated a presence of much more monoclinic sulfur together with an amorphous phase (Figure 5.5) which might be related to the small black particles passed through the filter paper.

ESM also confirmed the presence of sulfur and carbon in the two phases after sonication.

Another sample of the solid was prepared by sonication of carbon disulfide in a dry ice-acetone bath at $-50^{\circ} \mathrm{C}$. The black particles at this temperature attached to each other more and were roughly separated by decantation. They were put in chloroform and mixed. The black particles stayed in the chloroform phase, which was then placed on a washglass and allowed to evaporate. An x-ray anaiyses of the remained black particles did not show any signal for sulfur (Figure 5.5). The most probably adsorbed sulfur had thus been washed from the black particles by chloroform. This spectrum presented a very large and broad peak for amorphous carbon.

\subsubsection{Effect of intensity}

Figure 5.2 shows the effect of tip size on the dissociation rate with 20 $\mathrm{kHz}$ irradiation. At the same overall power, the rate is greater with the small tip, that is, with the higher intensity. This result is opposite to the results for to the sonication of potassium iodide solution with different horn sizes (Entezari, sub.nitted 1994). Figures 5.3 and 5.4 show this effect to be generally valid. 


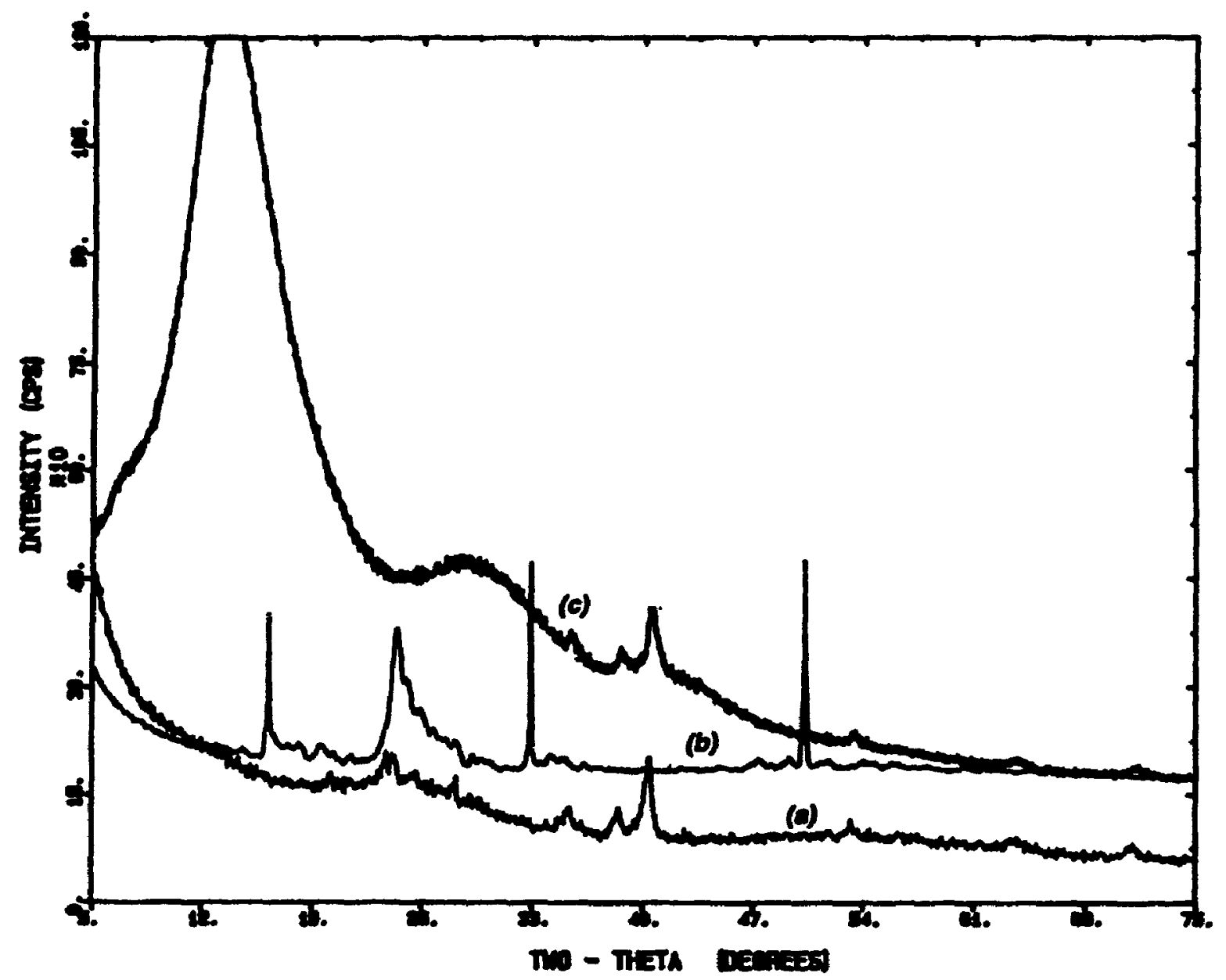

Figure 5.5: X-ray spectrum of the products producec' by sonication of carbon - disulfide. (a) black particles without washing, (b) solid phase produced by ovaporation of yellow solution and (c) black particles washod by chloroform. The sharp peaks in curve (b) are from the special sample holder. 
This different behaviour might be related to the different cavitation process. In the case of carbon disulfide, the dissociation should be most probably happened inside the bubble as a first reaction. In potassium iodide solution, the oxidation process is a secondary reaction which would occur in the liquid, following the dissociation of water inside the bubble.

In gentral, an increase in intensity will provide an increase in the acoustic amplitude. Since the collapse time, the temperature, and the pressure on collapse are dependent on the acoustic amplitude, the bubble collapse will be more violent at higher acoustic amplitudes. This will cause an increase in the sonochemical effects.

According to the Figure 5.3, it is possible to estimate a curve for a hom with tip area the same size as $900 \mathrm{kHz}\left(21 \mathrm{~cm}^{2}\right)$ by assuming a linear relationship between the rate and the tip sizes. The slope of the rate vs power graph for this case is about one fifth of the small hom $\left(1.1 \mathrm{~cm}^{2}\right)$. At a power of $20 \mathrm{~W}$, the rate of reaction is expected to be very small.

Sonication of carbon disulfide with $900 \mathrm{kHz}$ for an hour produced no visually observable change. The GC-MS chromatogram also showed no change before and after sonication. Due to the indirect sonication, the power reached inside the reaction place was about $20 \mathrm{~W}$. Another run with higher intensity $(\approx 60 \mathrm{~W})$ for 15 minutes also produced no noticeable change.

Sonication of carbon disulfide in a $50 \mathrm{kHz}$ ultrasonic bath for four hours also led to the conclusion that there was no apparent change due to sonication. 
This may be related to its very low intensity. The rate of oxidation of potassium iodide in the ultrasonic bath sonicator was very slow; sonication of $50 \mathrm{~mL}$ of potassium iodide for one hour led to the formation of $0.6 \mu \mathrm{mol}$ iodine, about $2 \%$ of the rate of oxidation with the $900 \mathrm{kHz}$ apparatus.

The experiments with the $50 \mathrm{kHz}$ bath are of importance, as sonication in carbon disultide is a common method of separating trapped impurities from filters used to evaluate air quality. Any formation of carbon from the solvent would mean faulty analysis of air particulate level.

\subsubsection{Effect of temperature}

Figure 5.4 shows the effect of temperature on the rate of dissociation of carbon disulfide. In this range of temperature, the rate with the small hom is greater than that with the $X$-large hom. With increasing the temperature the rate of dissociation is decreased for both homs. With an increase in temperature, the vapour pressure inside the bubble is increased, and hence the collapse of the cavity is cushioned, leading to more moderate conditions.

\subsubsection{Effect of gas}

The presence of gas in the bubble has dramatic affects on the cavitational collapse. There are several parameters of gases that can affect sonochemical reactivities. The heat capacity ratio $\gamma\left(=C_{\alpha} / C_{y}\right)$ which affects the final temperature produced by a gas during compression. Monatomic gases 
with highest heai capacity ratio give the highest temperature; polyatomic gases with lower $\gamma$ give lower temperature. Another parameter that affects cavitational collapse is the thermal conductivity of the gas. The gas with the higher thermal conductivity reduces the collapse intensity and lowers the final temperature. According to the hot spot theory, a gas with high $\gamma$ and low heat conductivity has more efficiency on the sonochemical activities. The solubility of the gas in the liquid used is also an important aspect.

The results summarized in table 5.1 show the order of dissociation of carbon disulfide as $\mathrm{He}>\mathrm{H}_{2}>$ Air $>\mathrm{Ar}>\mathrm{O}_{2}>\mathrm{CO}_{2}$. According to the table 1, it seems that the solubility is a predominant factor and determines the approximate order of the dissociation rate. This order was confirmed quantitatively by the intensity of color as well as by the mass of black particle produced by ultrasound. More evidence for this order can be qualitatively obtained based on the intensity of cavitational noise, for example, the intensity of cavitational noise was much harsher under hydrogen and helium than other experienced gases.

Air, $\mathrm{H}_{2}$, and $\mathrm{O}_{2}$ may have a reaction with intermediates species produced by ultrasound, so that for an explanation attention should be given to the $\mathrm{He}$ and Ar results. According to the hot spot theory, the sonochemical activity should be higher under Ar [Grinstaff, 1992] than He due to the lower heat conductivity of Ar than He. Our results showed an opposite behaviour. This situation may be due to consideration of other properties of the gases, such as 
Table 5.1: Variation of sono-dissociation of carbon disulfide by $20 \mathrm{kHz}$ ultrasound with different gases. Heat conductivity (H.C.) is in unit of $\mathrm{CaV}(\mathrm{sec})\left(\mathrm{cm}^{2}\right)\left({ }^{\circ} \mathrm{C} / \mathrm{cm}\right) \times 10^{\circ}$ at $4.4^{\circ} \mathrm{C}, \gamma$ is heat capacity ratio at $25{ }^{\circ} \mathrm{C}$; solubility of gases (S) at 298 ; absorbance (Abs.) of colored solution produced by ultrasound was measured at $379 \mathrm{~nm}$ after 30 minutes of sonication (Average of 3 runs).

\begin{tabular}{|c|c|c|c|c|}
\hline Gas & H. C. & $\gamma$ & $S\left(X_{d} / 10^{-4}\right)$ & Abs. \\
\hline Air & 58.31 & 1.39 & $\ldots$ & $0.248 \pm 0.012$ \\
\hline Ar & 40.09 & 1.67 & 4.9 & $0.199 \pm 0.045$ \\
\hline $\mathrm{H}_{2}$ & 417.39 & 1.40 & 1.6 & $0.297 \pm 0.005$ \\
\hline $\mathrm{He}_{\theta}$ & 343.42 & 1.67 & 1.2 & $0.312 \pm 0.018$ \\
\hline $\mathrm{O}_{2}$ & 59.43 & 1.39 & 4.4 & $0.167 \pm 0.016$ \\
\hline $\mathrm{CO}_{2}$ & 35.62 & 1.29 & 32.8 & 0 \\
\hline $\mathrm{CS}_{2}$ & 16.53 & 1.22 & $\cdots$ & $\ldots$ \\
\hline
\end{tabular}


the solubility; such data are however not available.

\subsection{Conclusion}

The major contribution of this work is to present a new method for formation of amorphous carbon from sonochemical dissociation of carbon disulfide using a $20 \mathrm{kHz}$ apparatus. This dissociation is more efficient under helium and hydrogen gas than air, argon or oxygen. There is however no observable change when sonication is carried out with $900 \mathrm{kHz}$ under $\mathrm{He}, \mathrm{Ar}$ and air, nor with a $50 \mathrm{kHz}$ ultrasonic bath. This study also showed that the effect of tip size on this reaction is the reverse of that found in the oxidation of potassium iodide. 


\section{CHAPTER 6}

SUMMARY AND CONCLUSIONS 


\subsection{Apparatus}

The first major contribution of this study is the design and construction of a new apparatus which produces $900 \mathrm{kHz}$ ultrasound through a flat transducer mounted at the bottom of a reaction vessel holding the solution. The power amplifier for this apparatus was obtained from Meinhardt Ultrasonics in Leipzig, Germany.

In order to improve the reproducibility of the results, we designed and made some devices which facilitated the repetition of experiments under identical conditions. For example, the position of the cell in the acoustic field was adjustable by a holder equipped with a micrometer. The temperature of the solution was controlled by a coiled glass tube inside the solution and circulating water outside the vessel. With a good control on the system, it was possible to have a reproducibility even to about $1 \%$ under some conditions. It is important to have good control on the system to get good reproducibility.

The behaviour of the solutions during sonication at $900 \mathrm{kHz}$ differs markedly from that at $20 \mathrm{kHz}$. There is no cavitation noise at $900 \mathrm{kHz}$ to be heard in the audible range; while at $20 \mathrm{kHz}$, this could be very harsh and irritating to the ears even with ear protection. This is one of the advantages of studying and utilizing sonochemistry at higher frequencies.

It is visually apparent that the cavitation bubbles are much smaller at high frequency $(900 \mathrm{kHz})$ than at low frequency $(20 \mathrm{kHz})$; fewer bubbles also migrated to the top of the solution and if we assume that each cavitation bubble 
is a "mini reactor", we will lose more "mini reactors" with low frequency than with high frequency.

Sonication with $20 \mathrm{kHz}$ is accompanied by contamination of the sonicated solution with small particles produced by an eroded horn. In contrast, direct sonication with the $900 \mathrm{kHz}$ apparatus might have introduced some contamination of the sonicated solution owing to a RTV layer on the piezoceramic transducer. Sonication of carbon disulfide and aqueous solutions of chlorobenzene were done indirectly. In this case, there is no contamination, and about $70 \%$ of the acoustic power still enters the sonication cell.

\subsection{Temperature}

The second major contribution of this study is to note the effect of temperature on the sonochemical reactions which is different at different frequencies. In the case of $20 \mathrm{kHz}$, as the temperature of the solution is increased, the reaction rate generally decreases. The shape of the rate versus temperature relation is dependent on the acoustic power.

By contrast, in the case of $900 \mathrm{kHz}$, the reaction rate versus temperature can show a maximum. The position of this maximum is dependent on the power level. An increase in the power moves this maximum toward a lower temperature. The maximum may even disappear at powers higher than those available in our laboratory. The shape of the curves was explained by the ratio of partial pressures of dissolved gas and the vapour of the liquid. These results 
also clarified some contradictory results in the literature.

\subsection{Power and intensity}

The variation of the rate with acoustic power at $20 \mathrm{kHz}$ is not linear. At higher power, the reaction rate drops off from linearity; a clear cavitation threshold is not evident in sonication of potassium iodide. However, sonication of carbon disulfide shows a clear cavitation threshold at $20 \mathrm{kHz}$. At very high intensities, the application of more power may be counterproductive. There are so many large cavities under the tip that the contact between tip and liquid is poorer, and the acoustic energy is dissipated to a greater extent into heating the hom. However, the variation of the rate with acoustic power at $900 \mathrm{kHz}$ is linear in the range available experimentally, and there is a clear cavitation threshold, at least for potassium iodide solution.

The third major contribution of this work is to study the effect of tip size on the reaction rate with $20 \mathrm{kHz}$ irradiation. This effect is related to the type of reaction. For example, in the sonication of potassiun! iodide solutions and dilute solutions of chlorobenzene, at the same overall power, the rate is greatest with the largest tip, i.s. with the lowest intensity. In contrast, in the case of sonication of carbon disulfide, the effect of tip size is revarsed.

Why with increasing the tip size at constant power (decreasing the intensity) do thie rates of some reactions such as sonication of aqueous poiassium iodide and dilute aqueous solution of chlorobenzene increase and 
the rates of some other reactions such as sonication of carbon disulfide decrease? Giving a general answer to these questions requires the study of more different systems. According to the results, the reactions can be divided into two groups.

First, the reactions which occur in the interior of a collapsing bubble as a first reaction such as sono-dissociation of carbon disulfide. In this case the bubble collapse will be more violent at higher intensities (smaller tip size than larger one at same power). The second group is where a secondary reaction occurs in the liquid such as sonication of aqueous potassium iodide and aqueous dilute solution of chlorobenzene, following the dissociation of water inside the bubble. The iodide anion in aqueous solution can not participate inside the bubble owing to its non-volatility and therefore it must be oxidized outside the bubble.

Neat chlorobenzene itself undergoes sonochemical reactions. In this case, the concentration of solute is very low $(\approx 200 \mathrm{ppm})$ and its vapour pressure is lower than that of water. Very little chlorobenzene will thus be present inside the bubble. Therefore secondary reactions in the aqueous media will likely dominate.

Intensity is a very important factor such that irradiation at two different intensities can give completely different results. 


\subsection{Gas}

The nature of the gas present in the solution does affect the reaction rates. For example, in the case of aqueous potassium iodide solution, with 20 $\mathrm{kHz}$ irradiation, the order of the reaction rate is: argon ) air > degassed, while with $900 \mathrm{kHz}$ it is: air ) degassed ) argon. The order of dissociation of carbon disulfide with $20 \mathrm{kHz}$ under different gases is: $\mathrm{He}>\mathrm{H}_{2}>$ Air $>\mathrm{Ar}>\mathrm{O}_{2}>\mathrm{CO}_{2}$. These differences in behaviour can be explained by the different properties of the gases (e.g. solubility, ratio of heat capacities, thermal conductivity) and the spatial and temporal behaviour of the cavitation bubbles at the two different frequencies.

\subsection{Frequency}

In our initial experiments, we found that with the newly designed $900 \mathrm{kHz}$ apparatus the rate of oxidation of potassium iodide could be as much as 30 times greater than with $20 \mathrm{kHz}$. The conditions for both apparatuses were exactly the same, but there was an intrinsic difference in the surface area of ultrasonic irradiator. The surface area for $900 \mathrm{kHz}$ was $21 \mathrm{~cm}^{2}$ and for $20 \mathrm{kHz}$ only $1.1 \mathrm{~cm}^{2}$. This increase of rate is related to the frequency effect, but also to the surface area. The rate of oxidation with $900 \mathrm{kHz}$ apparatus is estimated to be about 2 times greater than with $20 \mathrm{kHz}$.

In the case of dilute aqueous solution of chlorobenzene, the rate of decomposition with $900 \mathrm{kHz}$ apparatus was much more than with $20 \mathrm{kHz}$. With 
study of the tip size on this reaction, we estimated the rate of decomposition with a tip equal size to $900 \mathrm{kHz}$ apparatus. Comparison of the results showed that the real frequency effect on this dissociation is $\approx 2$ times greater with 900 $\mathrm{kHz}$ than $20 \mathrm{kHz}$. These results are of significance for attempts to eliminate organohalides from water with ultrasound. It is obvious that the use of a higher frequency is more promising.

The fourth major contribution of this work is to present a new method for formation of amorphous carbon from sonochemical dissociation of carbon disulfide using a $20 \mathrm{kHz}$ apparatus. The results of a study of the tip size on this dissociation suggest that a noticeable reaction should occur with the $\mathbf{9 0 0}$ $\mathrm{kHz}$ apparatus. There was tiuwever no observable change when sonication is carried out with $900 \mathrm{kHz}$. This difference must be due solely to the effect of frequency. 


\subsection{Summary}

The major contributions of this study are:

1) The design and construction a new $900 \mathrm{kHz}$ apparatus

2) Finding different behaviours with respect to temperature at two different frequencies

3) Discovery of the effect of tip size on the reactions at $20 \mathrm{kHz}$

4) Discovery that high frequency is more effective for eliminating organohalides (chlorobenzene) from water than low frequency.

5) Development of a new method for formation of amorphous carbon from sonochemical dissociation of carbon disulfide 
peferenences 
Akulichev, V.A. Sov. Phys. Acoust., 13, 149, (1967).

Ando, T.; Sumi, S.; Kawate, T.; Ichihara, J.; Hanafusa, T. J. Chom. Soc., Chom. Commun., 439, (1984).

Apfel, R.E., in Mothods of Exporimental Physics: Ultrasonics (Ed. Edmonds, P.D.) Academic Press, New York, (1981).

Apfel, R.E. J. Acoust. Soc. Am., 48, 1179, (1970).

Apfel, R.E., Utirasonics, 22, 167, (1984).

Barber, B.P.; Putterman, S.J. Nature, 352, 318, (1991).

Benkovskii, V.G.; Golobnichii, P.I.; Olzoev, K.F. Sov. Phys. Acoust., 20, 74, (1974).

Berlan, J; Trabelsi, F; Delmas, H.; Withelm, A.M.; Petrignani, J.F. Ultrasonice Sonochemistry 1, S97, (1994).

Blake, F.G.,Jnr., Tech. Momo. No. 12, (1949).

Bondy, C.; Sollner, K. Trans. Faraday Soc., 32, 556, (1936).

Boudjouk, P.; Han, B.H., J. Catal., 79, 489, (1983).

Boudjouk, P.; Han, B.H. Totrahedron Lett., 22, 3813, (1981).

Brohult, S. Naturo, 140, 805, (1937).

Chatakondu, K.; Green, M.L.H.; Thompson, M.E.; Suslick, K.S. J. Chom. Soc. Chem. Commun., 900, (1987).

Chen, W.; Chang, J.A.; Smith, V. Chemical Engineering Progreas Sympodum Series 67, 18, (1971).

Cheung, M.; Bhatnagar, A.: Jansen, G. Environ. Sel. Tochnol. 25, 1510, (1991).

Crum, L.A. I.E.E.E. Ultrasonice Symposium, 1, 1, (1982a).

Crum, L.A. Appl. Sol. Ros, 38, 1, (1882b).

Crum, L.A. J. Acoust. Soc. Am., 72, 1568, (1982c). 
129

Crum, L.A. Appl. Sci. Res., 38, 101, (1982d).

Cum, G.; Galli, G.; Gallo, R.; Spadaro, A. Ultrasonics, 30, 267, (1992).

Del 'Duca, M.; Jeager, E,; Davis, M.O.; Hovarka, F. J. Acoust. Soc. Am. 30, 301, (1958).

Didenko, Y.T.; Gordeychuk, T.V.; Koretz, V.L., J. Sound and Vibration, 147. 409, (1991).

Didenko, Y.T.; Nastich, D.N.; Pugach, S.P.; Polovinka, Y.A.; Kvochka, V.I. Uitrasonies, 32, 71, (1994).

Diedrich, G.K.; Kruus, P.; Rachlis, L.M. Canadian Journal of Chomistry 50 , 1743, (1972).

Doktycz, S.J.; Suslick, K.S. Sclence, 247, 1067, (1990).

Einhorn, C.; Einhom, J.; Luche, J.L. Symtheds, 11, 787, (1989).

Eller, A.E. J. Acoust. Soc. Am., 57, 1374 (1975).

El 'piner, I.E. Utrasound: Physical, Chomical, and Blological Effocts, Consultants Bureau, New York, (1984).

Entezari, M.H.; Kruus, P Uitrasonics Sonochemistry 1,2, S75, (1994).

Entezari, M.H.; Kruus, P. Uttrasonics Sonochemistry (Submitted, 1994).

Flint, E.B.; Suslick, K.S. Sclence, 253, 1397, (1991). -

Flynn, H.G. Uttraconice, 30, 3, 168, (1992).

Flynn, H.G., in Phyoleal Acourtics Vol IB (Ed Mason, W.P.) Academic Press, New York, (1984).

Fogler, S. Can. J. Chom. Eng., 47, 242, (1969).

Frenkel, Y.I. Zh. Fiz. Khim. 14, 305, (1940).

Fujikawa, S.; Akamatsu, T. J. Fluid. Moch., 97, 481, (1980).

Geers, T.L. J. Acoust. Soc. Am. Dec. (1981). 
Gondrexon, N.; Renaudin, V.; Bernis, A.; Gonthier, Y.; Boldo, P.

Environmental Technology, 14, 587, (1993).

Gould, R.K. J. Acoust. Soc. Am., 56, 1740, (1974).

Grinstaff, M.W.; Cichowlas, A.A.; Choo, S.-B.; Suslick, K.S. Ultrasonics 30, 3, 170, (1992).

Henglein, A.; Gutierrez, M. J. Phys. Chem., 97, 158, (1993).

Henglein, A.; Herburger, D.; Maritza, Gutierrez The Journal of Physlcal Chomistry 96, 3, 1126, (1992).

Henglein, A.; Herburger, D.; Maritza, Gutierrez The Journal of Physical Chomistry 94, 12, 5169, (1990).

Henglien, A.; Fischer, Ch.-H. Ber. Bunsenges. Phys. Chem. 88, 1196, (1984).

Hart, E.J.; Henglien, A. J. Phys. Chem. 89, 4342, (1985).

Fischer, C.-H.; Hart, E.J.; Henglien, A. J. Phys. Chem.90, 2, 222, (1986).

Ibisi, M.; Brown, B. J. Acoust. Soc. Am., 41, 568, (1967).

Inazu, K.; Nagata, Y.; Maeda, Y. Chomistry Lottors 57, (1993).

Kashkoush, I.; Busnaina, A.A. Journal of Particulate Scionce and Tochnology, 10, 1, (1992).

Kashkoush, 1.; Busnaina, A.A. Proc. IES Annual Mooting, pp. 407-413, (April 1990).

Kerfoot, H.B. Environ. Sel. Technol. 21, 1022. (1987).

Kinsler, L.E.; Frey, A.R.; Coppens, A.B.; Sanders, J.V. Fundamentale of Acoustice, John Wiloy \& Sons (1982).

Kornfeld, M.; Suvorov, L. J. Appl. Phy 3., 15, 495, (1944).

Kotronarou, A.; Mills, G.; Hofimann, M.R. J. Phys. Chem. 95, 3630, (1991).

Kruus, P. in Adv. in sonochem., 2, 1, (1991).

Kruus, P.; Lawrie, J.A.G.; O'Neill, M.L., Uitrasonics, 26, 352. (1988). 
131

Kruus, P.; MacDonald, D.; Patraboy, T.J. J. Phys. Chom., 91,3041, (1987).

Kruus, P.; Patraboy, T.J. J. Phys. Chem., 89, 3379, (1985).

Kruus, P; Dupont, L.A.; Patraboy, T.J. Ultrason. Int., 502, (1983).

Kruus, P. Ultrasonics 201,(Soptomber 1983).

Lindley, J.; Lorimer, J.P.; Mason, T.J. Ultrasonics 24, 292, (1986).

Lindstorm, O.; Lamm, O. J. Phys. Colloid Chom, 55, 1139, (1951).

Lippit, B.; Mc 'Cord, J.M.; Fridovich, I. J. Blol. Chem., 247, 4668, (1972).

Lauterbom, W. od. Cavitation and Inhomogenotios in Under Water Acoustice, Springer-Verlag New York, pp 42-46, (1980).

Lauterborn, W.; Bolle, H. J. Fluid Moch., 72, 391, (1975).

Lauterbom, W. Proc. Symp. Finfte-amplitude Wave Effocts in Fluids, Copenhagen, (1973).

Lindstrom, O. J. Acoust. Soc. Am., 27, 654, (1955).

Lippit, B.; McCord, J.M.; Fridovich, I. J. Blol. Chem., 247, 4668, (1972).

Lorimer, P. in Sonochemistry: The uses of uftrasound in chemistry, Mason, T.J.(ed.), The Royal Society of Chemistry, p14, (1990).

Luche, J.-L.; Damanio, J.C., J. Am. Chom. Soc., 103, 7926, (1980).

Lur'e,Y.; Kandzas, P.E.; Mokina, A.A. Russ. J. Phys. Chem. 36, 1422, (1962).

Margulis, M.A. Ultrasonice Sonochomistry, 1, 2, (1994).

Margulis, M.A. Sov. Phys. Acoust., 22, 310, (1991).

Margulis, M.A. Adv. Sonochom., 1, 39, (1990).

Margulis, M.A. Uttresonice, 23, :57, (1985).

Margulis, M.A.; Dmitrieva, A.F. Ruselan J. Phys. Chem., 56, 198, (1982).

Mason, T.J. (Ed) Sonochemistry: The Uses of Ultrasound in Chemistry, 
Royal Society of Chemistry, Cambridge, UK, (1990).

Neppiras, E.A. Physics Roports, 61, 160, (1980a).

Neppiras, E.A. Uitrasonics, 18, 201, (1980b).

Neppiras, E.A.; Noltingk, B.E. Proc. Phys. Soc. B, 64, 1032, (1951).

Nomoto, O.; Okui, S. J. Phys. Soc. Japan, 3, 47, (1948).

Nyborg, W. in Ultrasound: Its Application in Medlcine and Blology. (Fry, F.J., Editor), Part 1, Vol. 2, Elsevier Scientific Publishing Co., Now York, (1971).

Oliis, D.F.; Pelizzetti, E.; Serpone, N. in Photocatalyols- Fundamentals and Applications, (Serpone, N.; Pelizzetti, E.; Editors), Wiley Interscience, Now York, (1989).

Olson, L. J. Sound and Vibration, (1988)

Patraboy, T.J.; Kruus, P. J. Phya. Chern., 89, 3379, (1985).

Petrier, C.; Jeunet, A.; Luche, J.; Reverdy, G. J. Am. Chem. Soc., 114, 3148. (1992).

Pickworth, M.J.W.; Dendy, P.P.; Leighton, T.G.; Waiton, A.J. Phys. Mod. Blol., 33, 1249, (1988).

Plesset, M.S. Trans. ASME., J. Appl. Mech. 71, 277, (1949).

Price G.J.; Lenze, E.J. Uttrasonics, 31, 6, 451, (1993).

Price, G.J. Chomistry \& Industry, 75, 1 February (1993).

Price, G.J. Advances in Sonochemistry, 1, 231, (1990).

Prosperetti, A. Uitrasonics, 22, 69, 115, (1984).

Prudhomme, R.O.; Guilment, Y. J. Chem. Phys., 54, 336, (1957).

Rayleigh, L. Phil. Mag., 34, 94, (1917).

Renaud, P. Bull. Soc. Chim. Fr., Ser. 5, 17, 1044, (1950).

Repic, O.; Vogt, S. Totrahedron Lett., 23, 2729, (1982). 
Richards, W.T.; Loomis A.L. J. Am. Chem. Soc., 49, 3086, (1927).

Riesz, P.; Berdahl, D.; Christman, C.L. Environ. Health Perspect., 64, 233, (1985).

Rooney, J.A., in Uttrasound: Its Chomical, Physical, and Blological Effects (Ed. Suslick, K.S.) VCH publishers, New York, (1988).

Rooney, J.A., in Mothods of Exporimental Physics: Ultrasonics (Ed.Edmonds, P.D.) Academic Press, New York, Vol. 19, (1981).

Rosenberg, L.D. Uitrasonic Nows, 4, 16, (1960).

Rudenko, O.V.; Soluyan, S.I., Theoretical Foundations of Nonlinear Acoustics; Beyer, R.T., Trans.; Consultants Bureau, New York, (1977).

Safar, M.H. J. Acoust. Soc. Am., 43, 1188, (1968).

Saksena, T.K.; Nyborg, W.L. J. Phys. Chem., 53, 1722, (1970).

Schmid, G.Z. Phys. Chom., A186, 113, (1940).

Sehgal, C.; Sutherland, R.G.; Verral, R.E. J. Phys. Chem., 84, 525, (1980).

Serpone, N.; Terzian, R.; Colarusso, P. Research; on Chemical Intermediates 18, 183, (1992).

Sokol 'skaya, A.V.; El 'piner, I.E. Akust. Zhur., 3, 293, (1957).

Strasberg, M. J. Acoust. Soc. Am., 31, 163, (1959).

Suslick, K.S. Science, 247, 1439, (1990).

Suslick, K.S.; Doktycz, S.J.; Flint, E.B. Uitrasonics, 28, 280, (1990).

Suslick, K.S.; Casadonte, D.J.; Doktycz, S.J. J. Chem. Mater., 1, 6, (1989a).

Suslick, K.S.; Doktycz, S.J. J. Am. Chem. Soc., 111, 2342, (1989b).

Suslick, K.S. Scientific American, 260, 80, (1989c).

Suslick, K.S. od. Uitrasound: Its Chomical, Physical and Biological Effects VCH, New York, (1988). 
Suslick, K.S.; Casadonte, D.J. J. Am. Chem. Soc., 109, 3459, (1987).

Suslick, K.S. Modern Synth. Mothods, 4, 1, (1986).

Suslick, K.S.; Hammerton, D.A.; Cline, Jr., R.E. J. Am. Chem. Soc., 108, 5641. (1986).

Suslick, K.S.; Johnson, R.E. J. Am. Chem. Soc., 106, 6856, (1984).

Thonton, T.D.; Savage, P.E. Ind Eng Chem Res 31, 2451, (1992).

Thomycroft, J.; Barnaby, S.W. Inst. Civ. Eng., 122, 51, (1985).

Tomita, Y.; Shima, A. J. Fluid Mech., 169, 535, (1986).

Umemura, S.; Kawabata, K.; Yumita, N.; Nishigaki, R.; Umemura, K. Proceedings of the 14th Annual International Conference of the IEEE Engineering in Medicine and Blology Socioty, 92 CH3207-8, p 354, (1992).

Vasilina, T.V.; Starchevskii, V.L.; Mokryi, E.N. Zh. Flz. Khim., 58, 1926, (1984).

Weissler, A. J. Am. Chem. Soc., 81, 1077, (1959).

Weissler, A. J. Acoust. Soc. Am., 25, 651, (1953).

Weissler, A.; Cooper, H.W.; Snyder, S. J. Am. Chom. Soc., 72, 1769, (1950).

Winterton, R.H.S. J. Phys. D. Appl. Phys., 10, 241, (1977).

Yong, F.R. J. Acoust. Soc. Am., 60, 100, (1976).

Zechmeister, L.; Wallcave, L. J. Am. Chem. Soc. 77, 2953, (1955).

Zechmeister, L.; Magoon, E.F. J. Am. Chem. Soc. 78, 2149, (1956). 


\section{APPENDIX}

ULTRASONIC HYDRATION OF UO 
Note: This chapter was chosen as an appendix due to two reasons. First, there were no significant changes in the reaction with sonication as compared to other mechanical methods. Second, a focussed ultrasonic apparatus was used for sonication and it had an acoustic field different from the others.

\section{A-1 Introduction}

The use of ultrasound in heterogeneous systems is in the literature divided into two groups: liquid-liquid and liquid-solid interactions. In immiscible liquids (liquid-liquid) ultrasound can generate extremely fine emulsions which result in the dramatic increase in the interfacial area between the liquids. This process facilitates the reaction between species dissolved in the different liquids. In solid-liquid interaction, there are two types of reaction. In one reaction, the solid plays the part of catalyst; in another it acts as a reagent and is consumed in the process.

Historically, Renaud [1950] was the first to use ultrasound in heterogeneous liquid-solid reactions. He prepared some organometallic compounds with metals such as $\mathrm{Al}, \mathrm{Li}$, and $\mathrm{Mg}$. Microjet and shockwave are thought to be responsible for localized erosion and also the sonochemical effects on heterogeneous reactions. For example, when liquid-powder slurries are irradiated by ultrasonic waves, the cavities and the s'ock waves which are produced can accelerate solid particles to high velocities. The resultant interparticle collisions are capable of inducing dramatic changes in surface 
morphology, composition, and reactivity. Luche and Damiano [1980] reported a direct formation of alkyl and anyl lithiums by reaction of organic halides with lithium wire. This ultrasonic activation of stoichiometric heterogeneous reactions was carried out with an ordinary ultrasonic cleaner which gave excellent yields (61-95\%). Boudjouk [1981] reported the synthesis of novel cyclic compounds and the production of new reactive intermediates with the reactions of difunctional organosilanes and lithium. This reaction has done with lithium dispersions in tetrahydrofuran with reaction times about 20 minutes and a yield of about $\mathbf{8 5 \%}$.

The synthetic utility of lithium, magnesium, and other reactive metals in heterogeneous synthetic organic reactions is showed by the intense investigation into the activation of these metals by ultrasound. In this kind of synthesis, as a general, ultrasonic irradiation increases reaction rates, increases product yields, and decreases induction periods. Ultrasonic irradiation also allows reactions to proceed at lower temperatures, reducing side reactions and achieving better reaction control.

An increase in the efficiency of heterogeneous reactions with ultrasound can be due to a number of different causes such as: reduction of particle size, thereby increasing the reactive surface area [Lindley, 1986]; intense mixing which improves the mass transport [Repic, 1982]; removal of passivating surface coatings which cleans and activates the surface [Suslick, 1989c]. The main mechanisms responsible for the cleaning process in an ultrasonic field are 
cavitation, acoustic streaming and the formation of a pressure gradient across the particles [Kashkoush, 1990, 1992, Geers, 1991]. The removal of contamination was studied by high speed photography [Rozenburg, 1960]. This study proposed two mechanisms for removal of contamination films. The first one was the partial tearing of a film from the surface by the collapse of the bubble; the second was the penetration of energetic small bubbles into all pores and gaps between the contamination layer from the surface.

\section{A.2 Experimental Procedures}

\section{A.2.1 Types of apparatus}

Two trequencies of ultrasound were used in these experiments, 20 and $850 \mathrm{kHz}$. The $20 \mathrm{kHz}$ ultrasonic wave was produced by a Bransonic Cell Disrupter model 350. The Disrupter was coupled to a Bransonic 102 converter and a titanium horn which transmitted the ultrasound directly to the sample solution. The reaction vessels used were two sizes of bumpy bottom vessels, or a $250 \mathrm{~mL}$ beaker. The temperature was controlled by a circulating water thermostat.

An Ultraschalltechnik apparatus was used for producing $850 \mathrm{kHz}$ ultrasonic waves. The solutions were irradiated indirectly through the concave metal piece at the bottom of the system (see Figure 1). The reaction vessels for this apparatus were the same as for the $20 \mathrm{kHz}$ apparatus, but without the bumpy bottom. 


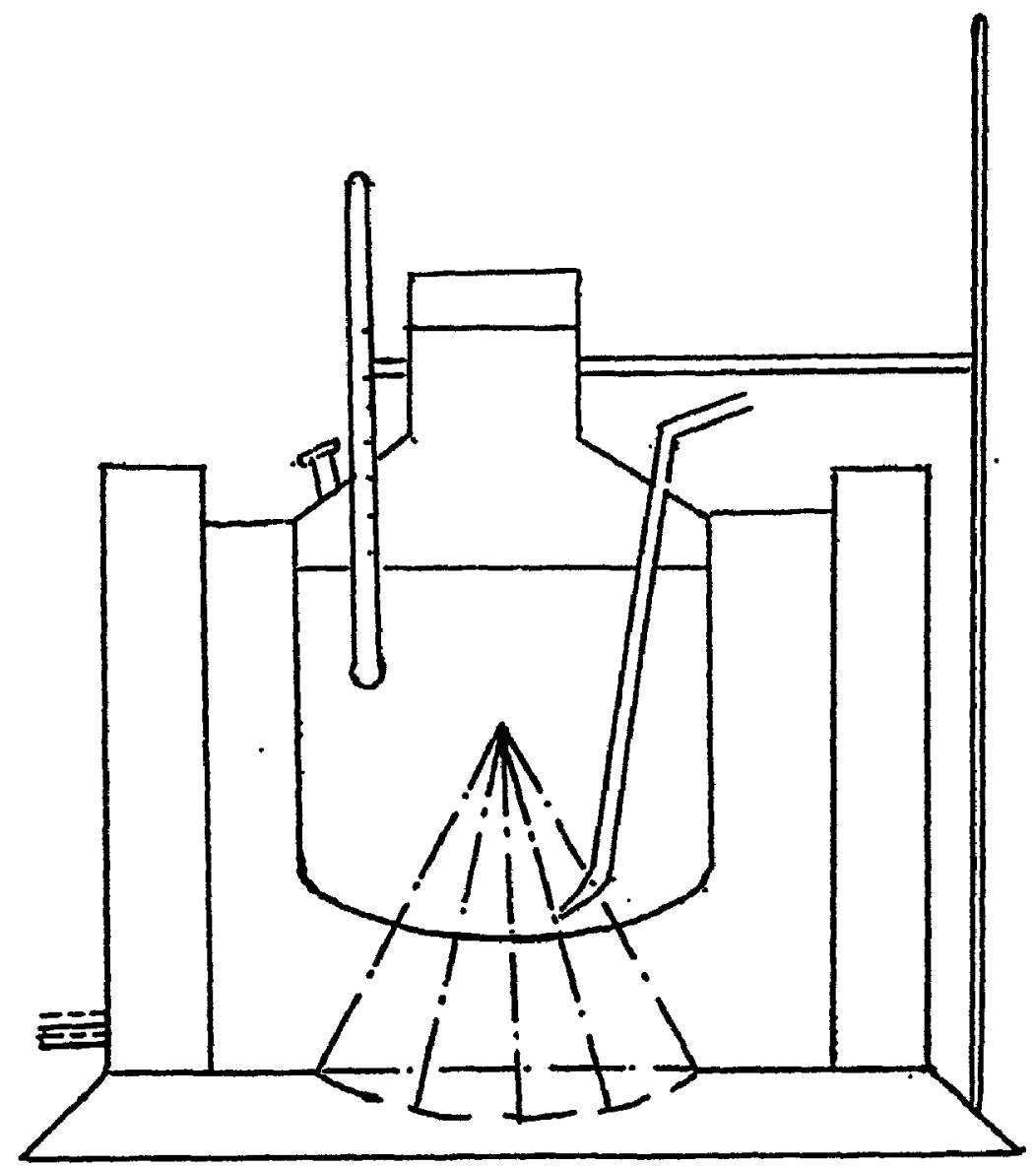

Figure A.1: The $850 \mathrm{kHz}$ apparatus with a concave transducer. 


\section{A.2.2 Intensity calibration}

It is important to periodically check the acoustic power delivered to the liquid. This was easily done in the case of the $20 \mathrm{kHz}$ apparatus by immersing the hom tip in a known amount of water in a Dewar flask and noting the rate of temperature increase on irradiation.

In the case of $850 \mathrm{kHz}$ ultrasound, it is more difficult to obtain a measure of the acoustic power delivered to the solution as there is no direct coupling. The conic shape of the ultrasonic wave produced in this system means that the acoustic power is quite different at different points in the solution. A chemical dosimeter must thus be used for this apparatus.

There are several chemical dosimeters: the formation of hydrogen peroxide followed by the oxidation of lito $l_{3}$ as measured by spectrophotometry, the use of the stable free radical, diphenylpicrylhydrazyl, as a radical trap in non-aqueous sonochemistry, and the decomposition of iron pentacarbonyl.

\section{A.2.3 Hydration of uranium trioxide}

Uranium trioxide $\left(\mathrm{UO}_{3}\right)$ powder from Cameco was sieved by a mechanical shaker. The hydration was carried out by three methods:
a) Sonication at $20 \mathrm{kHz}$ with and without stirring
b) Sonication at $850 \mathrm{kHz}$ with stirring
c) Agitation by stirring without ultrasound 


\section{A.2.4 Experiments at $850 \mathrm{kHz}$}

In a typical experiment, $25.0000 \pm 0.0002 \mathrm{~g}$ of $\mathrm{UO}_{3}$ of a specific size fraction was weighed and put into a $50^{\circ} \mathrm{C}$ oven for one night. One hundred millilitres of distilled water was poured into a vessel designed specifically for $850 \mathrm{kHz}$ ultrasonication (see Figure A.1). The vessel was then immersed in the ultrasound-bath and allowed to reach thermal equilibrium. Uranium trioxide was added into the water and the system was irradiated with ultrasound while agitated by a stirrer for a period of time. The stirrer was used because the ultrasound $(850 \mathrm{kHz})$ could not keep the uranium oxide in suspension.

After ultrasonic irradiation, the suspension was transferred to a $250 \mathrm{~mL}$ beaker and the orange colored solids were separated from the yellow colored ones by decantation. After filtering, both of them were put into the oven at $50^{\circ} \mathrm{C}$ overnight. The weight of each sample was determined after drying in this manner.

\section{A.2.5 Experiments at $20 \mathrm{kHz}$}

The conditions for $20 \mathrm{kHz}$ were the same as $850 \mathrm{kHz}$, but the shape of the vessels were different and also the systems were sonicated in presence and absence of agitation. In the absence of stirring, the streaming could usually keep most of the powder in suspension. The acoustic energy forces the fluid and particles down towards the centre of the bottom of the vessel, where they are deflected upwards along the sides. 
A.2.6 Experiments without ultrasound

Experiments were also done using a beaker $(250 \mathrm{~mL})$ as a reaction vessel. The suspension was mixed with different kinds of stirrers without any ultrasonic irradiation.

It was possible to control the temperature in the $20 \mathrm{kHz}$ experiments to within $2^{\circ} \mathrm{C}$ of the starting temperature (after an initial 5 minute period) and in the $850 \mathrm{kHz}$ experiments to within $2{ }^{\circ} \mathrm{C}$ from the initial time.

\section{A.3 Factors affecting the rate of hydration}

\section{A.3.1 Effect of temperature}

This series of experiments were done by $20 \mathrm{kHz}$ without stirring at 17.6 $W / \mathrm{cm}^{2}$. A sample of $25.0000 \mathrm{gr}$ with mesh size of $-60+80$ was suspended in $135 \mathrm{~mL}$ water inside a bumpy bottom vessel.

Table A.1 shows the rate of hydration at different temperatures. It is clear that with increasing temperature the rate of hydration is increased.

Table A.1: Rate of hydration at different temperatures

\begin{tabular}{|c|c|}
\hline Temp. $/{ }^{\circ} \mathrm{C}$ & $\begin{array}{c}\text { Rate of Hydration' } \\
(\mathrm{g} / \text { min })\end{array}$ \\
\hline 22.8 & 0.011 \\
\hline 31.7 & 0.020 \\
\hline 43.7 & 0.045 \\
\hline 62.0 & 0.077 \\
\hline
\end{tabular}


From the plot of In(rate) versus $1 / T$, an experimental enthalpy of activation can be calculated as $43 \mathrm{~kJ} / \mathrm{mole}$. The plot is not linear, especially at higher temperature. The actual enthalpy of activation for the hydration process is therefore probably somewhat higher than this. Using only the three lower temperature points, the calculated value is $58 \mathrm{~kJ} / \mathrm{mole}$. The non-linearity at higher temperature may be due to the reaction becoming diffusion limited i.e. diffusion of the water through the previously hydrated outer layers of the solid particles.

\section{A.3.2 Effect of shape of cell}

Three different vessels were used under the same conditions (20 kHz, 50 $0^{\circ}, 25 \mathrm{~g},-60+80$ mesh $\cup_{3}, 135 \mathrm{~mL}$ water). Referring to Table A.2, the rate of hydration is significantly affected by the shape of the vessel used. The small bumpy bottomed vessel produced the largest rate of hydration.

Table A.2: Effect of type of vessel on rate of hydration

\begin{tabular}{|c|c|}
\hline Type of vessel & $\begin{array}{c}\text { Rate of Hydration } \\
(\mathrm{g} / \mathrm{min})\end{array}$ \\
\hline Large Bumpy & 0.077 \\
\hline Small Bumpy & 0.134 \\
\hline Roselte Cell & 0.048 \\
\hline
\end{tabular}

It should be noted that these changes of hydration rate are not only 
related to the shape of the vessel, because a few parameters (especially agitation) were not constant. There was little motion of the $\mathrm{UO}_{3}$ particles through the arms of the rosette cell, explaining the low rate in this cell.

\section{A.3.3 Effect of $\mathrm{UO}_{3}$ mesh size}

Figure A.2 shows the relationship between the mass of hydrated product and starting $\mathrm{UO}_{3}$ particle size. The conditions for this series of experiment we:a the same as above. It was expected that the lower size fraction of the $\mathrm{UO}_{3}$ would yield more hydrated material due to its higher specific surface area.

\section{A.3.4 Effect of stirring}

The effect of the presence of a magnetic stirrer on the rate of hydration by $20 \mathrm{kHz}$ ultrasound was investigated. A magnetic stirrer in a plastic bag was placed in the bath beneath the vessel (a $150 \mathrm{~mL}$ beaker). The rate of hydration with stirring only was $0.027 \mathrm{~g} / \mathrm{min}$, while with a combination of stirring and sonication, the rate was higher $(0.067 \mathrm{~g} / \mathrm{min})$.

\section{A.3.5 Effect of power}

With stirring, $125 \mathrm{~mL}$ of water with $25 \mathrm{~g}$ of $\mathrm{UO}_{3}$ was irradiated by $20 \mathrm{kHz}$ ultrasound at different intensities. A $150 \mathrm{~mL}$ beaker was used as a vessel. Table A.3 summarizes the results and shows that increasing the power increases the rate of hydration. 


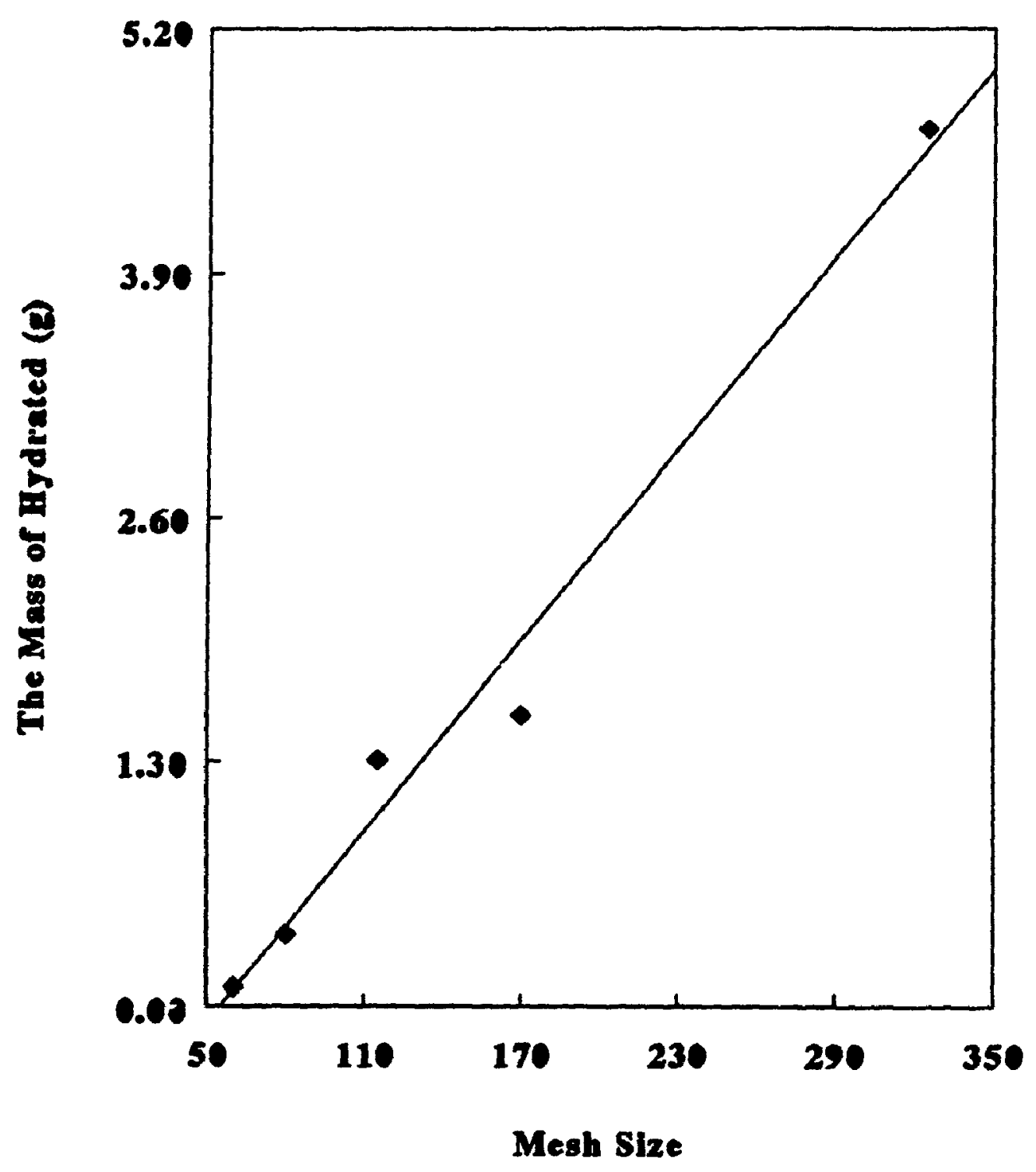

Figure A.2: The effect of particle size on the hydration of $\mathrm{UO}_{3}$. 
Table A.3: Effect of power level on the rate of hydration

\begin{tabular}{|c|c|}
\hline Power $(W)$ & Rate $(g /$ min $)$ \\
\hline 60 & 0.064 \\
\hline 78 & 0.095 \\
\hline 87 & 0.105 \\
\hline
\end{tabular}

\section{A.3.6 Effect of hydrogen gas}

Hydrogen gas was passed through a slurry of $\mathrm{UO}_{3}$ in water during sonication. The product was similar to that obtained without hydrogen gas present, i.e. a yellow solid. There was no evidence of any chemical reduction having taken place. The quantity of hydrated material produced, however, was much lower with the hydrogen gas present, presumably due to the effect of the gas bubbles on transient cavitation.

\section{A.4 Sonication in Organic Solvents}

Two organic solvents were used, propanol and toluene. The reaction conditions used for both of them were the same. After sonication for a period of 60 minutes a small amount of hydrated product was produced in both solvents. The products were completely yellow, whereas in water medium the hydrated product had a greenish tinge.

The reason for having any hydrated product in propanol may be related to the $\mathrm{OH}$ group of the alcohol or the existence of water as an impurity. It 
appeared that the "hydrated" material from sonication in propanol was much finer than that from water, since the former could not be trapped on a filter paper.

The reason for hydration in toluene must have been related to water as an impurity. Separation of the "hydrated" material was easily accomplished, indicating a coarser material.

\section{A.5 Frequency and agltation}

The kinetics of hydration using $20 \mathrm{kHz}$ and $850 \mathrm{kHz}$ ultrasound were measured. The kinetics were also measured without ultrasound, but using a magnetic stirrer (in the $20 \mathrm{kHz}$ experiments) or a propeller-like agitator (in the $850 \mathrm{kHz}$ experiments) for agitation. Figure A.3 shows the amount of hydrated material versus time under the same conditions of temperature, volume and $\mathrm{UO}_{3}$ mesh size, but under different sonication or stirring conditions. It should be noted that a large magnet (almost the diameter of the beaker) was used for stirring in the $20 \mathrm{kHz}$ experiments.

According to Figure A.3, the rate of hydration is greatest using magnetic stirring and no ultrasound. This may be related to the effectiveness of the stirring method at maintaining a good suspension, but also possibly due to changes in particle size during the mixing of the system. In other words, the $\mathrm{UO}_{3}$ prills may be pulverized between the magnet and the beaker walls. However, a direct comparison can not be made in this case, since the 


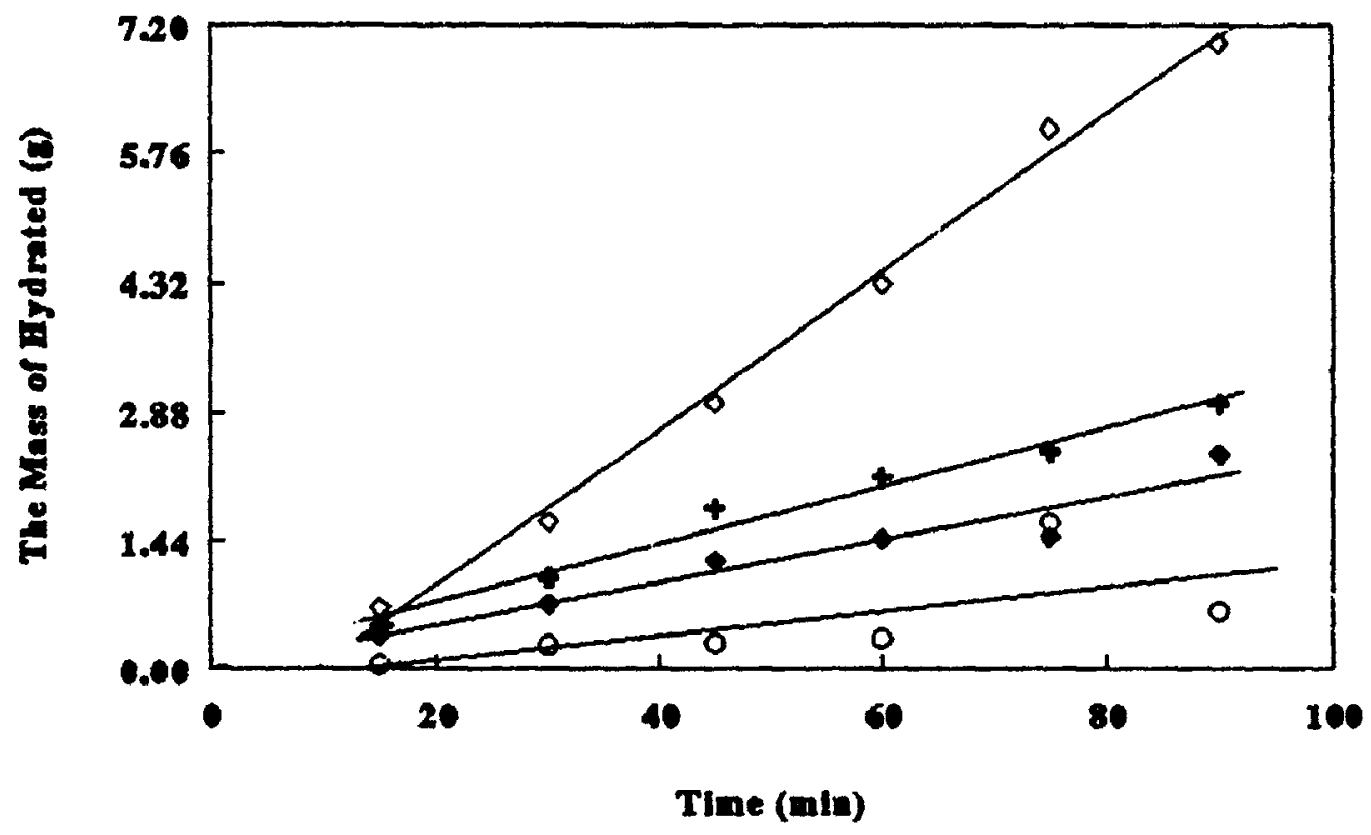

Figure A.3: Effect of ultrasonic frequency and stirring on the hydration of $\mathrm{UO}_{3}$. - Stiming only, $850 \mathrm{kHz} \&$ stirring, - stirring only in $850 \mathrm{kHz}$ cell, $+20 \mathrm{kHz}$ (self-stirring). 
experiments involving stirring without ultrasound were performed in a beaker, whereas those involving ultrasound were performed in the bumpy bottomed vessel.

The rate of hydration measured at $20 \mathrm{kHz}$ is greater than at $850 \mathrm{kHz}$. This may be explained by a greater ultrasonic power or better mixing conditions at $20 \mathrm{kHz}$ compared to $850 \mathrm{kHz}$.

Experiments were performed using a small magnet for agitation. This magnet was just large enough to keep the $\mathrm{UO}_{3}$ in suspension. According to the result, the rate of hydration is greater in the case of ultrasound plus stirring than with only stirring, as expected.

A surprising thing was observed regarding the color of hydrated form of the $\mathrm{UO}_{3}$. In the presence of ultrasound, the color had a slight greenish tinge, whereas without ultrasound, the product was a definite yellow. One possibility was that the greenish color was due to titanium particles from the tip of ultrasonic hom immersed into the suspension. This was checked by SEM/EDS spectrometry. No titanium was observed in any of the samples tested.

Another idea was that the color differerice was related to the amount of water of hydration. However, no difference in weight loss values at $270^{\circ} \mathrm{C}$ between the greenish and yellow samples could be obsinved.

An attempt was made to measure the percent water in samples by measuring the EDS oxygen peak intensity relative to that in $\mathrm{UO}_{3}$. Analysis of several greenish and yellow samples gave the following results: 
Hydrated (yellow)

Hydrated (green)
$20.4 \pm 2.2 \% O$

$22.7 \pm 2.2 \% 0$

Thus, there is a possibility that the application of ultrasound results in a slightly higher amount of hydration, and a material which has a slightly different colour.

\section{A.6 Factors affecting the size distribution of the unhydrated $\mathrm{UO}_{3}$}

\section{A.6.1 Temperature}

The Scanning Electron Microscope was used to measure the particle sizes of the remaining orange material (presumably unhydrated $\mathrm{UO}_{3}$ ) after sonication at different temperatures. Table A.4 presents the results in terms of the average projected particle area i.e. the area of the "shadow" projected by the particle. At least $\mathbf{4 0 0}$ particles were measured in each sample. This analysis was not possible for the hydrated material, since it was impossible to prepare the sample as a one-particle thick layer.

Table A.4: Particle sizes after sonicating at different temperatures

\begin{tabular}{|c|c|c|}
\hline Temperature/ $/{ }^{\circ} \mathrm{C}$ & $\begin{array}{c}\text { No.of Pirticles } \\
\text { Counted }\end{array}$ & Mean Area $/ \mathrm{mm}^{2}$ \\
\hline 62 & 435 & 0.0257 \\
\hline 43 & 480 & 0.0307 \\
\hline 24 & 451 & 0.0252 \\
\hline
\end{tabular}

Note: The starting $\mathrm{UO}_{3}$ mesh size was $-60+80$. 
There is apparently little correlation of the temperature with the resultant particle size of the unhydrated $\mathrm{UO}_{3}$.

\section{A.6.2 Initial particle size}

Several runs were done using $\mathrm{UO}_{3}$ of different mesh size, and the standard run conditions listed earlier. Referring to Table A.5, the effect of sonication on the unhydrated $\mathrm{UO}_{3}$ appears to have a greater effect on the larger size fraction. This may indicate that the ultrasound itself can only comminute the particles to a certain extent. Further comminution may require other forces (e.g. hydrolysis).

Table A.5: Unhydrated particle areas before and after sonication

\begin{tabular}{|c|c|c|}
\hline Mesh Size & $\begin{array}{c}\text { Mean Area/mm } \\
\text { Before Sonication }\end{array}$ & $\begin{array}{c}\text { Mean Area/mm } \\
\text { After Sonication }\end{array}$ \\
\hline$(-170 /+325)$ & 0.0055 & 0.0059 \\
\hline$(-80 /+115)$ & 0.0216 & 0.0224 \\
\hline$(-60 /+80)$ & 0.0761 & 0.0529 \\
\hline
\end{tabular}

\section{A.6.3 Shape of cell}

The mean unhydrated particle sizes obtained from sonication in different vessels are presented in Table A.6. First, the type of vessel used obviously affects the size distribution of the material. The small bumpy bottomed cell caused the greatest amount of comminution. This was not surprising, since the 
material was observed to be in good suspension when using this cell. A somewhat surprising result is that the particle size using ultrasound and stirring was larger than that using stirring alone. Once again, however, this particle size is of the unhydrated material.

Table A.6. Effect of type of cell used on particle size

\begin{tabular}{|c|c|}
\hline Type of Cell & Mean Area/mm2 \\
\hline Rosette & $0.0248(U)$ \\
\hline Small Bumpy & $0.0109(\mathrm{U})$ \\
\hline Beaker $150 \mathrm{~mL}$ & $0.0207(\mathrm{U}+\mathrm{S})$ \\
\hline Beaker $150 \mathrm{~mL}$ & $0.0178(\mathrm{~S})$ \\
\hline
\end{tabular}

Note: $\mathrm{U}=$ ultrasound, $\mathrm{S}=$ stirring

Note: $-60+80$ mesh size $\mathrm{UO}_{3}$ was used

\section{A.6.4 Sonication in organic solvents}

The mean particle areas after sonication of $\mathrm{UO}_{3}$ in toluene and in propanol are presented in Table A.7. Note that the original particle area was $0.0216 \mathrm{~mm}^{2}$, and that sonication in water did not change the particle size of the unhydrated material appreciably (see Table A.5). The organic solvents, especially toluene, had a large effect on the particle size. 
Table A.7: Particle sizes after sonication in organic solvents

\begin{tabular}{|c|c|}
\hline Solvent & Mean Area/mm2 \\
\hline Toluene & 0.0083 \\
\hline Propanol & 0.0113 \\
\hline
\end{tabular}

Note: $-80+115$ mesh size $\mathrm{UO}_{3}$ was used.

\section{A.7 Conclusion}

The effects of ultrasound on the hydration of $\mathrm{UO}_{3}$ are considered by measuring the rate of hydration under different conditions of ultrasonic frequency, ultrasonic power and temperature. Also considered are the type of vessel, the mesh size of the $\mathrm{UO}_{3}$, and the type of agitation used.

In general, use of $20 \mathrm{kHz}$ ultrasound resulted in faster hydration than use of $850 \mathrm{kHz}$. Higher ultrasonic power led to a faster hydration rate. Higher temperature also resulted in faster hydration. An experimental activation enthalpy of $58 \mathrm{~kJ} / \mathrm{mole}$ was calculated. The shape of the sonication vessel was found to be important. Sonication in organic solvents produced very fine material. Addition of hydrogen gas during sonication in water did not produce any lower oxides of uranium. 


\section{VITA}

The author, Mohammad H. Entezari was borm on August 23, 1958 in Birjand, Iran. He attended many public schools and graduated in 1977.

He received a Bachelor of Science in Chemistry from Mashhad University in 1985 and a M. Sc. in Chemistry from Mazandaran University in 1988. He did his research with Dr. F. Milani-nejad studying the de-icing properties of Asphalt.

He came to Ottawa on May 4, 1990. He entered Carleton University and joined tha research group of Professor Peeter Kruus in January 1991. The author has spent the last four years studying the Effect of Frequency on Sonochemical Reactions.

Currently, he has the following:

Entezari, M.H. and Kruus, P. Ultrasonics Sonochemistry 1994, The Effect of Frequency on Sonochemical Reactions I: Oxidation of lodide, 1, 2, S75.

Entezari, M.H. and Kruus, P. Ultrasonice Sonochemistry 1995, The Effect of Frequency on Sonochemical Reactions II: Temperature and Intensity Effects, accepted.

Entezari, M.H.; Kruus, P. and Otson R. J. Am. Chem. Soc., The Effect of Frequency on Sonochemical Reactions III: Dissociation of Carbon Disulfide, submitted.

Entezari, M.H.; Kruus, P. and Otson R. J. Phys. Chem., The Effect of Frequency on Sonochemical Reactions IV: Dissociation of Chlorobenzene in Dilute Aqueous Solution, plan to submit.

Some of this work has presented in:

$76^{\text {th }}$ Canadian Society for Chemistry Conference and Exhibition, Sherbrook, May 30, 1993. 1993.

Suslick's group at University of Illinois at Urbana-Champaign, U.S.A., January 

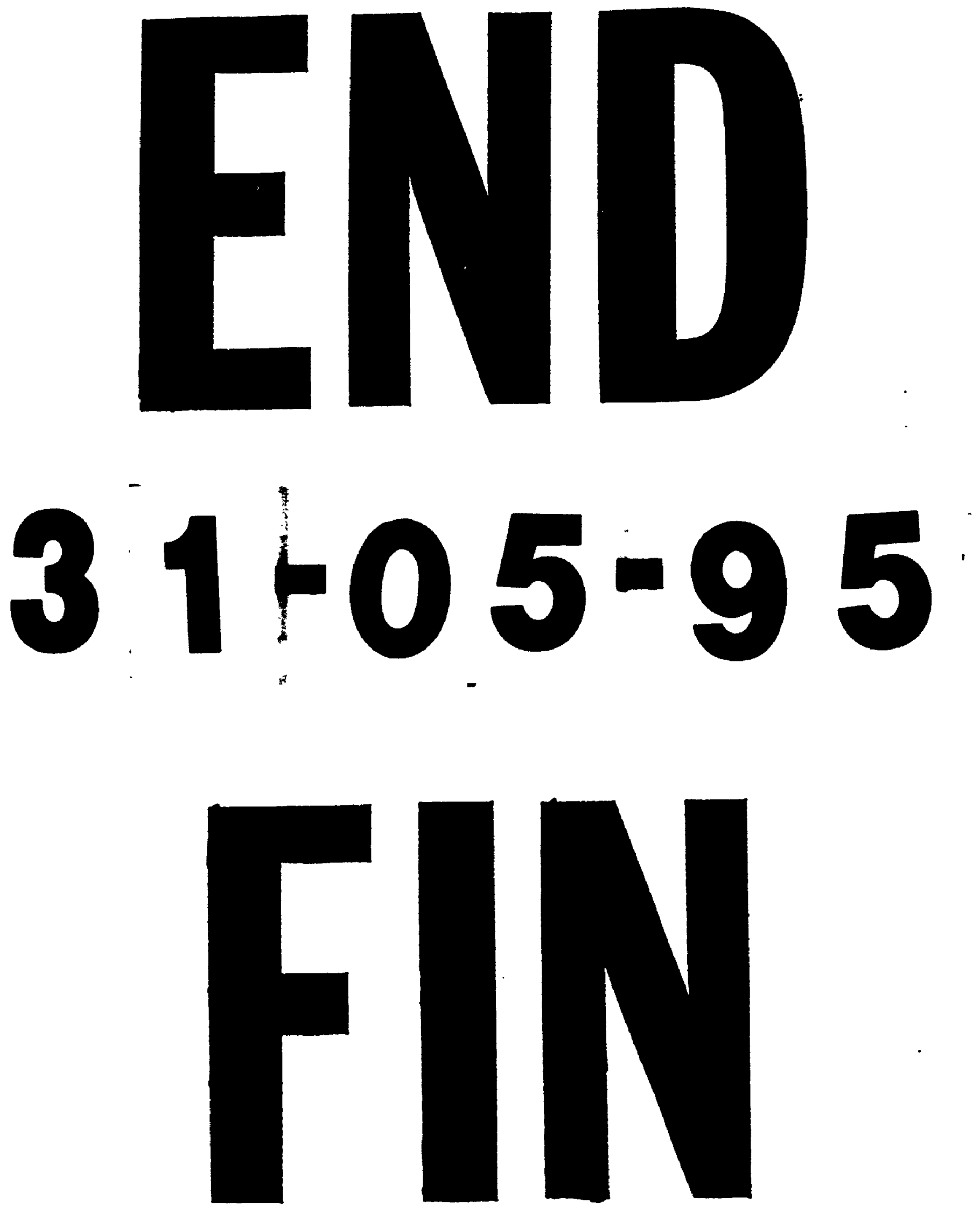